\title{
AN EXPLORATION OF THE COLLABORATIVE PRACTICES WITHIN \\ LEARNING NETWORKS OF NEW ZEALAND SCHOOLS
}

BY

REBBECCA SWEENEY

\begin{abstract}
A Thesis
submitted to the Victoria University of Wellington

in fulfilment of the requirements for the degree of

Master of Education
\end{abstract}

Victoria University of Wellington 


\begin{abstract}
This thesis investigates the practices of participants in three "clusters" of New Zealand schools associated with the Extending High Standards Across Schools (EHSAS) project funded by the Ministry of Education from 2005 to 2009. The investigation addresses four questions: (i) What collaborative practices were used by the participants in the EHSAS clusters? (ii) Do the research participants perceive the collaborative practices that they used as making a difference to student achievement? (iii) What do the participants perceive as the benefits and limitations of collaborative practice? (iv) How consistent are participants' perceptions with research findings in the field?
\end{abstract}

The thesis begins by searching national and international research in order to define effective collaboration. It is argued that across certain relevant studies, the key purposes of collaboration are for teachers and students to learn and improve in order to reach the common goal set by the cluster. Associated practices can be used to build skills and knowledge in teachers, school leaders, and cluster members. Following this, a Grounded Theory approach was used to analyse and interpret data that emerged from the three clusters' milestone reports and interviews with cluster members. The analysis found that the leaders of EHSAS clusters believed that shared leadership across principals is essential to cluster work, and that a hierarchical cluster structure is the best way to transmit knowledge from leaders to teachers. They also believed that if they shared resources, ideas, strengths and expertise with one another they would then have knowledge that would be useful to teachers wanting to change and improve their practices, and raise student achievement. Despite some of their beliefs being consistent with research literature on effective collaboration, according to the literature, many of the EHSAS leaders' practices would not have enabled the learning and improvement that they espoused to be leading. The final chapter of this thesis identifies where EHSAS leaders' beliefs and practices were inconsistent and what this means for future research and the implementation of similar projects aiming to promote collaboration across schools. 


\section{Acknowledgements}

I could not have completed this study without the input and support of many people. I cannot name all of the friends, family, colleagues and students who have contributed in some way to this research, but thanks must go to my employer, the Ministry of Education for providing the majority of the funding of my Master's Degree and associated study leave. Special thanks must go to my first Ministry of Education boss on the EHSAS project, Denise Sainsbury who quietly encouraged me to learn and introduced me to the fields of school improvement and effectiveness, and to collaboration.

It was an honour and a pleasure when I won the chance to work alongside schools through the EHSAS project. I would like to thank all of the cluster leaders and members involved in EHSAS who taught me so much about the professional learning and innovation happening in their schools and who willingly shared their experiences and achievements with me during our conferences and meetings and through their milestone reports. Special thanks must go to the nine participants in this research. Your willingness to give your precious time to me and to share your experiences so openly has enabled a unique insight into the way New Zealand leaders work together towards improving outcomes for students.

Special thanks to my two supervisors from Victoria University of Wellington, Doctor Vivien van Rij and Doctor Judith Loveridge for their support. Viv's high quality critique helped to improve my academic writing. She was critical of my thinking and processes, and had unlimited patience, providing support that improved my sometimes less than coherent written discussion and critique. Judith provided invaluable constructive feedback on Grounded Theory Method and on the quality of the discussion in this research. Both supervisors joined me in a real team approach to questioning and refining my thinking and writing. Our regular meetings were highly motivating for me. I am also grateful to my professional acquaintances at the University of Auckland, Professor Stuart McNaughton and Doctor Rebecca Jesson from the Wolf Fisher Research Centre who generously gave their support and time in teaching me about qualitative data analysis. 
Mentors are important and I found a great one in past Ministry colleague and good friend, Doctor Brian Annan. Brian encouraged me to embark on the Master's degree in 2008, and then helped me to grow and change both personally and professionally through my study. He challenged me, supported me and guided me to take on new learning and apply it to my studies and my work. As well as that, he helped me as a friend through tough times by listening, giving advice, and introducing me to running as a stress buster. I am ever grateful for Brian's guidance and support.

Finally, thanks to my friends, in particular Vienna Muller, Chris and Andy Wells, and Tiffany Beaver, and to my family who have kept me going during these years by listening and keeping me in touch with the real world. I am forever indebted to my late Dad, Trevor, and my Mum, Margaret for telling and showing me in their different ways that I could achieve anything in life. My brothers Darryl, Aaron and Ryan and particularly my sister Kimberlee have shown interest in my studies and have given incredible support to me during the last few years, listening and offering help and advice and loving and caring for me constantly. My nieces Neve, Taylor, Caitlin and Alexi and nephews Dominic and Thom are a constant source of inspiration for me in my chosen field of work, and they simply reinforce my love for all children. Children are, of course, at the centre of it all! 


\section{TABLE OF CONTENTS}

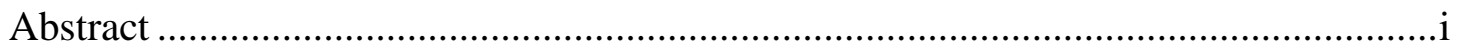

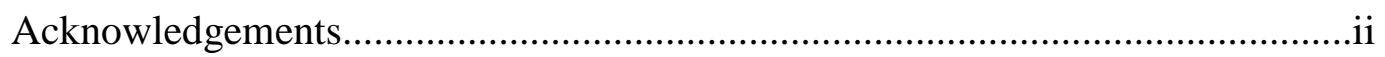

Chapter 1 Introduction............................................................................................................1

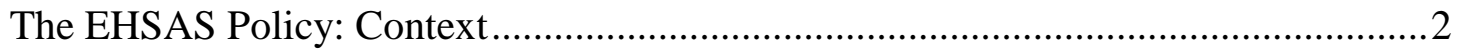

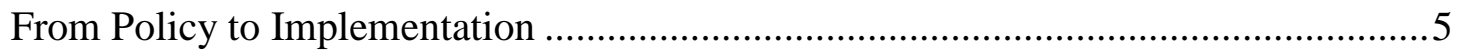

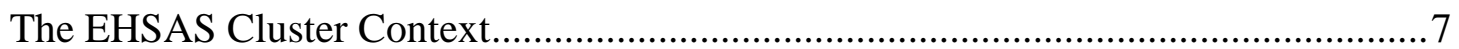

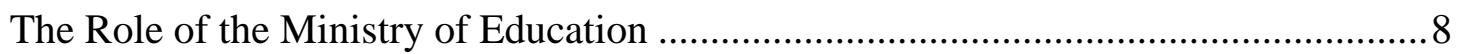

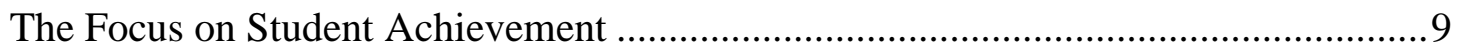

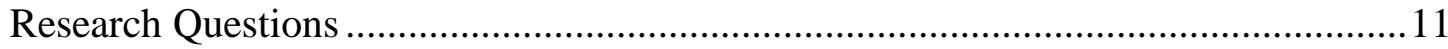

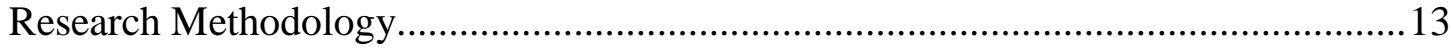

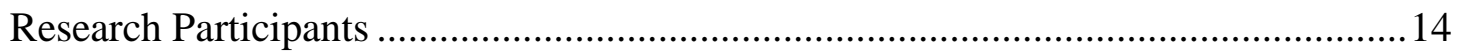

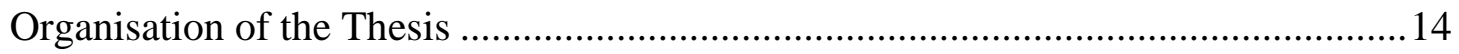

Chapter 2 Literature Review .......................................................................16

Collaboration: Competing Terminology and Definitions .........................................16

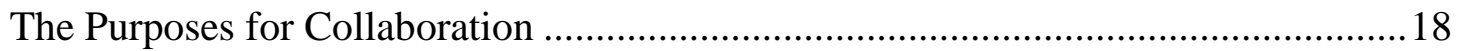

Collaboration for learning and improvement .................................................... 18

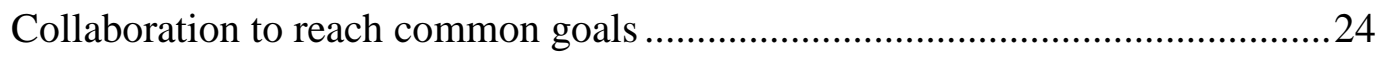

Effective and Ineffective Collaborative Practices....................................................2 27

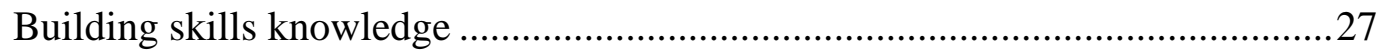

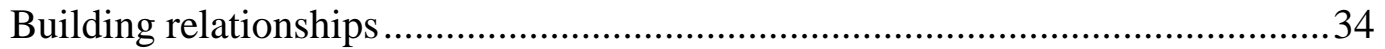

The tension between building skills and knowledge and building relationships in

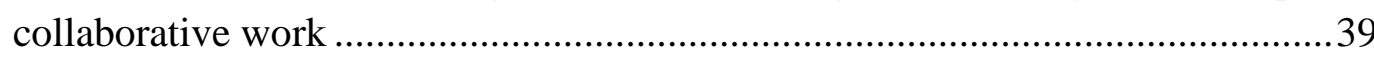

Indicators of effective and ineffective practices in collaborating schools............40

Chapter 3 Methodology .......................................................................................45

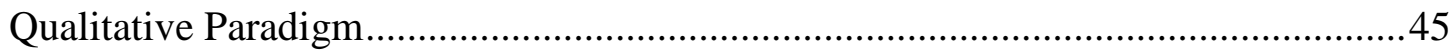

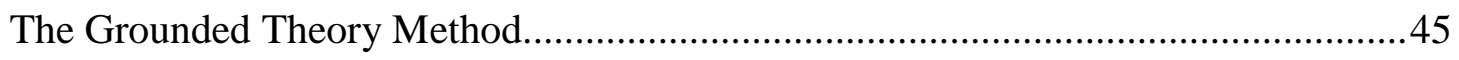

Development of Research Questions for the Discovery of Theory ............................47

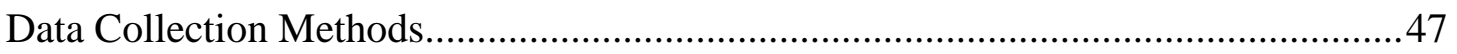

Selection of Cluster Sample and Interview Participants ..........................................51 
Chapter 4 Results .61

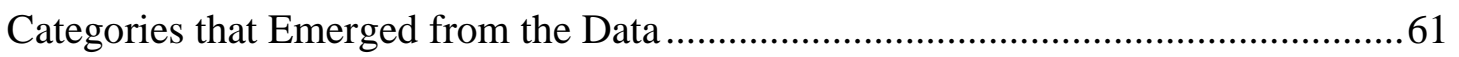

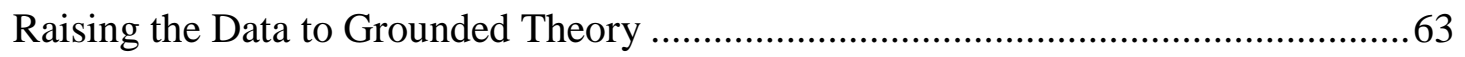

Leadership is essential for EHSAS cluster work ..............................................69

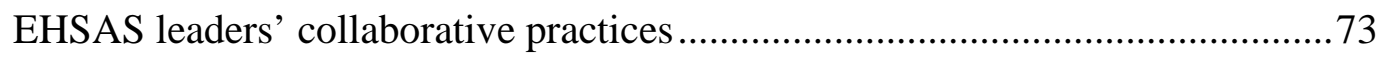

EHSAS leadership style to achieve change in teacher practices .........................76

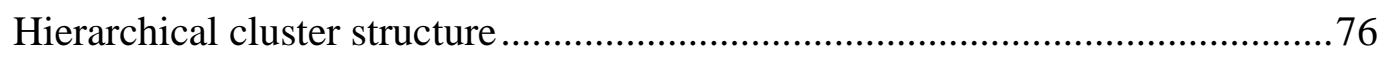

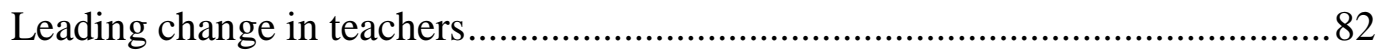

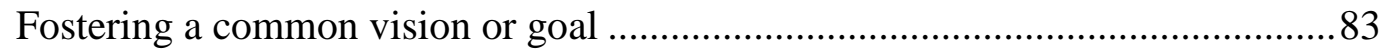

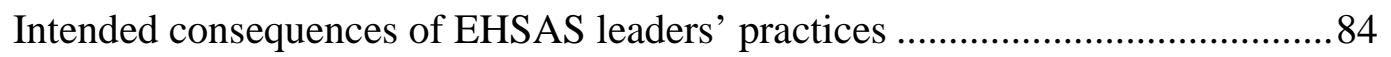

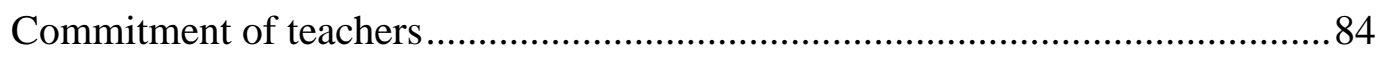

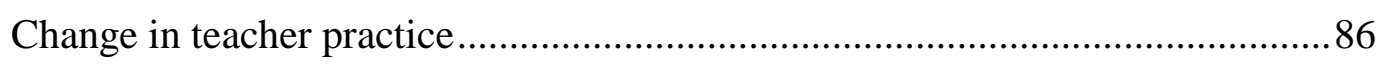

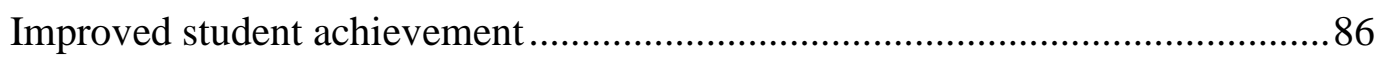

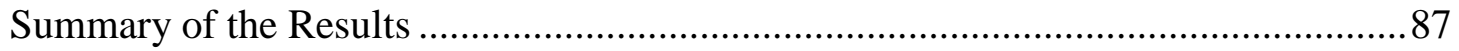

Chapter 5 Discussion and Conclusions ...........................................................88

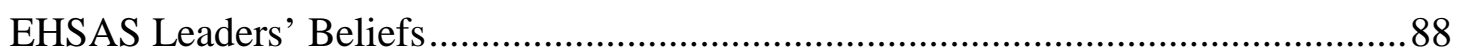

Research Questions: What collaborative practices were used by the participants in the EHSAS clusters? What do the participants perceive as the benefits and limitations of collaborative practice?

Research Question: Do the research participants perceive the collaborative practices that they used as making a difference to student achievement and what did they perceive were the benefits and limitations of those practices? ...............................................99

Leadership style makes a difference to student achievement ...........................93

Hierarchical cluster structures make a difference to student achievement...........94

The commitment of all cluster members makes a difference to student achievement

Keeping the focus on a common vision or goal makes a difference to student achievement

Conclusion .98

Issues and implications 100

Limitations of this study 101 
References

\section{Appendices}

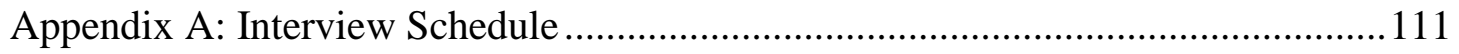

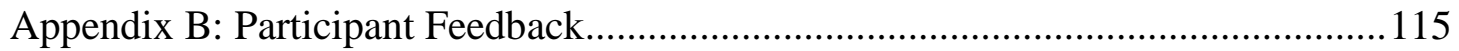

Appendix C: Information sheets and consent forms ..............................................117

Appendix D: Categories that Emerged from Cluster A .............................................119

Appendix E: Categories that Emerged from Cluster B ........................................... 121

Appendix F: Categories that Emerged or Changed after Analysis of Cluster C Data122

\section{List of Figures}

Figure 1: Flow chart model for the process of data analysis using Grounded Theory Method.

Figure 2: The final list of 70 categories that emerged from the data.........................63

Figure 3: Diagrammatic Interpretation of Cluster A Hierarchical Structure ................77

Figure 4: Interpretation of the "Lead Teacher Model" Provided by Cluster B in the Proposal Stage of the EHSAS Application Process ....................................................... 78

Figure 5: Diagrammatic Interpretation of Cluster C Hierarchical Structure.................79

\section{List of Tables}

Table 1: Intended Outcomes for EHSAS Clusters ........................................................

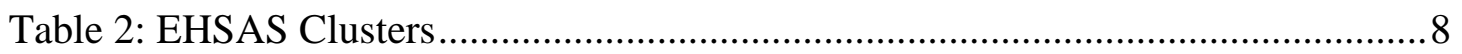

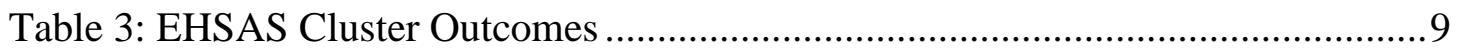

Table 4: A Summary of Effective Practices from the Literature about Collaborating

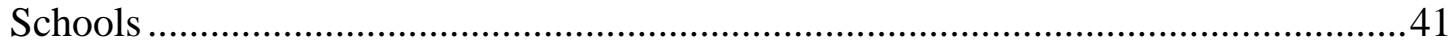

Table 5: A Summary of Ineffective Practices from the Literature about Collaborating Schools

Table 6: Categories with a High Number of Statements where all Nine Participants were Represented .66

Table 7: Categories Representing 11 or 12 Data Sources. .66

Table 8: Results of the Process to Determine the Constructs that were most Represented in all Data 


\section{Chapter 1}

\section{Introduction}

The purpose of this study is to investigate the practices in three clusters of schools associated with the Extending High Standards Across Schools project (hereafter referred to as EHSAS). In response to my requests to those schools for people to participate in my research, each cluster volunteered Lead Teachers or Principals. This research is ultimately about the perspectives cluster leaders.

EHSAS was a project funded by the Ministry of Education for New Zealand schools interested in working together towards common goals. It lasted four years. The EHSAS project was announced in late 2005 and was cancelled in 2009 as part of the National Government's "Budget 2009”. Funding therefore ceased for all 87 clusters from the end of 2009 with around two thirds of the clusters only half way or less through their four year plans.

The EHSAS project was similar to other national and international projects that have been investigated by researchers to determine their effectiveness. For example, following several years involvement in a development and research programme in North America and the United Kingdom, Katz, Earl and Jaafar (2009) found that in schools that worked together as "Networked Learning Communities...together can be better - but it can also make no difference at all or even make things worse" (pp. viiviii). The Ministry of Education provided cluster members with many resources and articles available from the Networked Learning Communities programme ${ }^{1}$ including articles that offer practical guidance for setting up a cluster, and tools to help clusters review their practices in relation to self-review and inquiry. These were sent to cluster leaders by e-mail or were placed on the EHSAS Wikispace (an online environment set up by the Ministry of Education to encourage EHSAS leaders to share ideas, problems and resources with each other).

Within New Zealand, as part of an evaluation of the effectiveness of Schooling Improvement clusters between 2007 and 2010, Timperley and Parr (2010) co-

\footnotetext{
${ }^{1}$ The resources and articles from the Networked Learning Communities programme are available at http://www.nationalcollege.org.uk/index/about-us/national-college-initiatives/previousinitiatives/networked-learning.htm
} 
constructed a series of "position papers on various aspects of schooling improvement" (p. 5) with school leaders, teachers and professional developers. The purpose of this was to share the thinking behind the findings and issues that emerged from their evaluation. These papers were then transformed into a book which included case studies as illustrations of effective school improvement, and tools that schools could use to improve student achievement, either individually or in clusters. The results of the evaluation are highly relevant to the EHSAS context and its focus on raising student achievement.

Annan (2007) conducted an investigation into the seven most effective national and international examples of school improvement. This included two initiatives in New Zealand, one of which was a cluster of schools working together to improve academic achievement for disadvantaged students. Through the critical analysis of the development and implementation practices of the seven initiatives, Annan outlined the key collaborative practices that were common. His analysis of the New Zealand examples in particular are relevant to this study. Like the key studies mentioned above, the schools in Annan's study were grouped in clusters in order to raise achievement.

This study will compare the collaborative practices described by EHSAS participants and those described in the literature in order to establish how effective the participants' collaborative practices were. The resulting information may add to national and international findings about the successes and pitfalls of collaboration for school improvement and effectiveness.

\section{The EHSAS Policy: Context}

A paper addressed to the Minister of Education in March 2005 entitled "Extending High Standards in Schools: Policy Framework" (Ministry of Education, 2005a) referred to school effectiveness and school improvement. The paper attempted to link the EHSAS project to existing Ministry policy developments, such as "Schools Planning and Reporting”, "Schooling Improvement Policies”, and "The Schooling Strategy” (pp. 45). According to the paper, the initiative would encourage schools to work together to engage in continuous improvement and to share their good practices. In emphasising the importance of consistency between the EHSAS project and existing Ministry policy 
developments, the paper provided advice that the project should be positioned "alongside Schooling Improvement programmes" while encouraging effective schools in the EHSAS project to "be creative in developing cutting edge, evidence-based practice" (p. 5). The paper gave no information about what was considered effective about the existing foundations or how the EHSAS project should be positioned alongside them.

The original principles and objectives of the EHSAS project were outlined in several papers to the Minister of Education and New Zealand Cabinet, and clear links were made between collaboration and student achievement. The intended outcomes of the EHSAS project were taken from these papers and consolidated into a table by Multi Serve Education Trust who completed an analysis of the papers (see Table 1). This study will focus on the first and third outcomes in Table 1, and will attempt to identify the participants' perceptions about whether the sharing of best practice, increased collaboration, strengthened professional learning communities and improved student outcomes.

Table 1

Intended Outcomes for EHSAS Clusters

\begin{tabular}{|l|l|}
\hline For Schools & Indicator of Success \\
\hline Outcome & $\begin{array}{l}\text { Schools, through boards of trustees and principals, } \\
\text { should be able to show evidence of improved student } \\
\text { achievement - particularly in critical areas and across } \\
\text { sharing best practice } \\
\text { broad student groups. }\end{array}$ \\
\hline $\begin{array}{l}\text { Improving teacher } \\
\text { quality }\end{array}$ & $\begin{array}{l}\text { Schools, particularly through principals, should be able } \\
\text { to provide information to demonstrate: } \\
\text { (i) teaching practice is informed by evidence-based } \\
\text { decision-making } \\
\text { (ii) teachers, principals and boards are collecting, } \\
\text { collating, analysing, discussing and using quality } \\
\text { information to inform changes to teaching and learning } \\
\text { in classrooms, across syndicates/departments, school- } \\
\text { wide and between schools } \\
\text { (iii) professional development budgets are allocated to } \\
\text { support the desired changes in teaching and learning. }\end{array}$ \\
\hline $\begin{array}{l}\text { Strengthened } \\
\text { professional learning } \\
\text { communities and }\end{array}$ & $\begin{array}{l}\text { Schools' project applications and project reporting } \\
\text { should include evidence of current and intended } \\
\text { collaboration at varying levels - within schools, within }\end{array}$ \\
\hline
\end{tabular}




\begin{tabular}{|l|l|}
\hline $\begin{array}{l}\text { increased } \\
\text { collaboration }\end{array}$ & $\begin{array}{l}\text { partnerships of schools, and outside of formal } \\
\text { partnerships with other interested groups in the } \\
\text { education sector such as other schools, other providers, } \\
\text { research institutes and the Ministry. }\end{array}$ \\
\hline $\begin{array}{l}\text { A developing } \\
\text { knowledge base of } \\
\text { models of } \\
\text { effectiveness and } \\
\text { examples of practices } \\
\text { and processes that can } \\
\text { be used to enhance } \\
\text { school performance }\end{array}$ & $\begin{array}{l}\text { Schools applying to participate in EHSAS will be } \\
\text { expected to agree to projects and the outcomes of } \\
\text { projects which will contribute to a knowledge base for } \\
\text { the rest of the system - to increase understanding by } \\
\text { teachers, principals, students, school communities and } \\
\text { the Ministry about what works to improve student } \\
\text { achievement. }\end{array}$ \\
\hline
\end{tabular}

Note. From "Extending High Standards in Schools Business Plan" by Multi Serve Education Trust Limited, 2005, p. 13

The March 2005 paper to the Minister of Education discussed collaboration across participating schools as being most effective when using the model of a "lead school" (Ministry of Education, 2005a, p. 5) in which a nominated school would manage the partnership and share its more successful strategies and practices with the other "partner schools" (Ministry of Education, 2005a, p. 6). The intent behind the lead school model was to ensure the spreading of school effectiveness to other less effective schools in the system and to place responsibility for managing the partnership on the lead school.

A paper addressed to the Minister of Education in May 2005 entitled "Revised Submission: Extending High Standards in Schools Operational Policy" stated that the EHSAS project would provide researchers and policy makers "with an opportunity to work alongside practitioners to further investigate and report on the best means for supporting improved outcomes for the schooling sector" (Ministry of Education, 2005b, p. 2). The paper provided an initial framework for this to happen through a small project team with a project manager who would implement a "strong support structure" (Ministry of Education, 2005b, p. 3) for participating clusters that would ensure first that the cluster learning was shared with the entire school sector, and second that clusters would be provided with tools and evidence to support their collaboration. It was also intended that the cluster learning would feed into a research and evaluation component for the initiative and a scoping process was to take place for this before the launch of the project in February 2006. 
The March 2005 paper to the Minister of Education referred to "international evidence about system transformation" (Ministry of Education, 2005a, p. 4). The paper briefly noted some similar projects operating in the United Kingdom and Australia that had been designed to promote innovation and the transfer of knowledge between schools. ${ }^{2}$ Relevant research by David Hargreaves, and Timperley's “work on professional learning communities" (p. 4) were referred to briefly in the paper, and the lessons learned from Ministry funded Schooling Improvement clusters and Information, Communications Technology Professional Development (ICT PD) clusters were mentioned but not described in any detail. ${ }^{3}$ The practices associated with an "Assessment for Learning" approach, and the "AToL research project" (p. 13) were emphasised as having made significant improvements in student achievement levels.

A Ministry of Education paper entitled "Cabinet Policy Committee: Minute of Decision: Extending High Standards in Schools" (Ministry of Education, 2004) discussed a "Funding Model" for the EHSAS project. It was intended that additional funding would be provided to clusters as an "incentive for high performance". The paper stated that the funding should be "equivalent to approximately ten per cent of...existing per-pupil funding component and base funding component entitlement", and that schools would "not be constrained regarding the use of this additional funding" (pp. 6-7). ${ }^{4}$

\footnotetext{
${ }^{2}$ These initiatives were the Leading Edge Partnership Programme in the United Kingdom and the Leading Schools Fund in Australia.

${ }^{3}$ The paper references Hargreaves as follows: Working Laterally: how innovation networks make an education epidemic. Innovation Unit. DfES. 2004, but does not provide reference to Timperley's work. ${ }^{4}$ Base funding and per pupil funding are components of a school's operational funding. Operational funding is "money a board of trustees receives from the government to implement the goals of a school's charter and for the running of the school" Further information about per-pupil funding and base funding can be found at: http://www.minedu.govt.nz/NZEducation/EducationPolicies/Schools/SchoolOperations/Resourcing/Reso urcingHandbook/Chapter1/OperationalGrantComponents.aspx\#base
} 


\section{From Policy to Implementation}

The EHSAS project was implemented through an annual application process where the Ministry of Education invited schools to apply to join the project. Initially, there were three phases to the application process. The "Operational Policy" paper (Ministry of Education, 2005b) described these phases, as summarised below:

1. Identification: Schools nominate themselves, or are nominated by other schools or stakeholders and are preliminarily assessed for eligibility to move to the second phase of the process. Assessment criteria required the Ministry to assess each school's "professional capability, strategic direction" and governance and management capability, "including financial management" (p. 5). Evidence of these criteria could be gained from Education Review Office reports, Ministry of Education staff with knowledge of the school and data held by the Ministry of Education.

2. Schools that passed stage one assessment were then invited to complete an "expression of interest" as one school or as a group of schools, but in both cases, they were required to have a plan for collaboration across nominated schools. The expression of interest involved "a balance between using data and narrative to identify a group of schools that demonstrated high performance across a range of indicators" (p. 6). These indicators included evidence that schools were using student information to plan teaching and learning programmes, and that they could show improvement in student outcomes. They also had to provide evidence that each school was committed to collaborating with other schools. The expression of interest also had to provide a brief outline of the group's plan, should they be approved.

3. Shortlisted schools were then invited to submit a detailed "proposal" which included the intended outcomes for their four year project, how their project would extend school performance and how that could be shared across the system, how they would collaborate with other schools, and how the funding would be used. 
Cluster files show that from 2006 the application process was refined from three stages down to two stages. These were:

1. Submission of an expression of interest by interested clusters of schools (no individual schools could apply).

2. Shortlisted schools invited to submit a detailed proposal Cluster files contain evidence that personal support was provided to shortlisted clusters by the Ministry of Education during the writing of proposals through e-mail correspondence and telephone calls to discuss and critique the plans and the evidence.

At the same time, funding levels were reduced for the second round of applications. While policy guidelines indicated that funding should be "equivalent to approximately ten per cent of...existing per-pupil funding component and base funding component entitlement" (Ministry of Education, 2004, p. 7), internal meeting minutes show that the implementation team positioned the EHSAS project alongside Schooling Improvement programmes, as recommended by the "Policy Framework" paper (Ministry of Education, 2005a). Funding provision was revised to less than ten per cent of the above mentioned funding components, based on what was known to achieve positive shifts in student achievement in Schooling Improvement programmes, while allowing a little more funding for schools to "be creative in developing cutting edge, evidence-based practice" (Ministry of Education, 2005a, p. 5).

\section{The EHSAS Cluster Context}

By February 2008 there were 87 EHSAS clusters across New Zealand. Each cluster of schools designed its own four year project through an application process. If applications were approved, cluster representatives then negotiated with the Ministry to agree on an additional operational funding amount. The funding was paid to one school representing each of the 87 clusters in six-monthly advances.

EHSAS clusters started their four-year projects at different times. There were three application rounds that resulted in the clusters being phased in over three years. Each 
round started at the beginning of each year from 2006 to 2008 (see Table 2). The 87 clusters were made up of 537 schools and ranged in size from two schools to 15 schools.

Table 2

EHSAS Clusters

\begin{tabular}{|c|l|l|l|}
\hline $\begin{array}{l}\text { Application } \\
\text { Round }\end{array}$ & Start date & $\begin{array}{l}\text { Number of } \\
\text { clusters }\end{array}$ & $\begin{array}{l}\text { Number of schools } \\
\text { involved }\end{array}$ \\
\hline One & April 2006 & 28 & 193 \\
\hline Two & April 2007 & 28 & 171 \\
\hline Three & February 2008 & 31 & 173 \\
\hline
\end{tabular}

\section{The Role of the Ministry of Education}

In 2006, the Ministry of Education employed a Project Manager for the EHSAS project. At the same time I was employed by the Ministry of Education to assist the Project Manager to implement the EHSAS project. My title was Operational Policy Adviser. As a team, the Project Manager and I provided support to schools involved from the application process, to project planning, design and implementation. We also monitored the work of the clusters through visits, phone calls, e-mails and the critique of milestone reports. Prior to accepting applications, I travelled around New Zealand with the Project Manager to promote the EHSAS project and answer questions from members of the sector who attended these public meetings. During the application process I was a key point of contact for the applicants and I liaised with them by e-mail and telephone to answer questions and assist with completing forms. I then worked closely with the Project Manager and a panel of professionals from within and outside the Ministry of Education to assess each application and then advise clusters of the outcome. The professionals from outside the Ministry of Education were school principals nominated by representatives of teacher unions and principals' associations.

In 2006 the Project Manager role was filled by a primary school Principal who was seconded into the Ministry of Education for 12 months. In 2007 the Project Manager role was taken up by a secondary school Principal who remained in the position until 
the EHSAS project ended. In 2008 a third position was created in the team and a Senior Adviser was employed to assist with monitoring the growing number of clusters entering into the project.

In 2008 the Ministry of Education contracted Martin Jenkins and Associates Limited to scope and define an evaluation plan in order to assess the feasibility of any future evaluation of the EHSAS project. The resulting "Evaluability Assessment" indicated that Ministry monitoring of the clusters was light, reflecting a "high trust model" (Ogier and Sankar, 2008, p. 8). Monitoring by the Ministry of Education included annual visits to every cluster. Notes were made on a cluster file after the visit. I attended almost all monitoring visits with at least one other colleague from the Ministry of Education EHSAS team. My role was to ask questions related to the information that we had on file about the cluster projects and take written notes of the cluster members' responses.

\section{The Focus on Student Achievement}

Some EHSAS clusters had stated project outcomes that related only indirectly to improving student achievement through intermediary outcomes. For instance, some intended outcomes stated a desire to improve student engagement, teacher practice, or the use of "Key Competencies" as outlined in The New Zealand Curriculum (Ministry of Education, 2007, p. 12). Other EHSAS clusters had project outcomes that directly related to improving student achievement. For instance, some outcomes stated a desire to improve students' reading and writing.

While every cluster had to include at least one high performing school (a "lead" school that had demonstrated success in improving learning outcomes for all students), EHSAS cluster projects were diverse. All projects shared the same broad purpose to link to EHSAS policy outcomes, but each cluster had the flexibility to choose a focus and desired outcomes according to the preferences of the schools involved. For example, Table 3 shows the stated outcomes from two different clusters: 
Table 3

EHSAS Cluster Outcomes

\begin{tabular}{|l|l|}
\hline $\begin{array}{l}\text { Cluster name \& number/ type of } \\
\text { schools involved }\end{array}$ & Stated Outcomes from Proposal document \\
\hline $\begin{array}{l}\text { Sentral Region Special } \\
\text { The Normal Schools }\end{array}$ & $\begin{array}{l}\text { This was a cluster of five Special Schools. The } \\
\text { aim of the Cluster is to develop an expanded } \\
\text { Level One curriculum framework with an } \\
\text { emphasis on numeracy. This framework will } \\
\text { enhance Level One and link with current } \\
\text { assessment tools. }\end{array}$ \\
\hline $\begin{array}{l}\text { This was a cluster of 15 Normal Schools. The } \\
\text { aim of the cluster is that all students will have a } \\
\text { deeper understanding of each key competency } \\
\text { and how the key competency relates to their } \\
\text { achievement and daily lives. } \\
\text { The schools involved will investigate the impact } \\
\text { of their approaches to the implementation of the } \\
\text { key competencies on student learning. (They } \\
\text { will explore various methods of planning for, } \\
\text { and teaching the key competencies across } \\
\text { curriculum areas at a variety of levels in order } \\
\text { to discover examples of practice that have } \\
\text { effective outcomes for students.) } \\
\text { Teachers will examine their practices in the } \\
\text { teaching of key competencies through the } \\
\text { curriculum content and context. }\end{array}$ \\
\hline $\begin{array}{l}\text { and } \\
\text { and }\end{array}$
\end{tabular}

Note. From Ministry of Education. (2011, January 12). Round 1 Clusters [Document]. Retrieved from http://www.minedu.govt.nz/goto/extending

The Evaluability Assessment by Martin Jenkins and Associates Limited described how the EHSAS initiative operated at that time. The report noted some key points about how the initiative had been implemented and how it had evolved over time:

The practice shared has not always been 'proven' or tested within the lead school. The practice may be innovative but yet to be evidenced as 'good' through the EHSAS project. This challenges the founding principles of EHSAS as an initiative that extends high standards across schools.

Clusters appear to have assumed a role as developers of practice...This signals a shift in the role of clusters from sharing existing knowledge to collectively creating knowledge. 
Initially EHSAS was structured around a lead school sharing their experiences with a cluster of schools. That is, knowledge is transferred from one school to many schools. However, in reality, the Ministry has formed the view that no one school is an 'expert,' and that all schools in the cluster have a range of expertise/experience that can be shared. [Lead schools] no longer have the role of leading other schools. (Ogier and Sankar, 2008, p. 9)

The Evaluability Assessment report also noted the following in relation to the focus on student achievement:

Whilst the intention of EHSAS is to fund practice that has a demonstrable impact on student outcomes, the link between the practice being implemented in EHSAS and student outcomes is not always explicit...Student data has been used as a 'general indicator of health', rather than evidence of effectiveness of practice. This means that there is not enough evidence to show that the practice being shared...has an impact on student achievement. Therefore the link between good practice and student outcomes is weak. (Ogier and Sankar, 2008, p. 12)

My interest in the effectiveness or otherwise of the collaborative practices used by EHSAS clusters is driven by my previous role as a monitoring and support person for the EHSAS clusters. I held this role while clusters were implementing their four year plans to ensure that they were reaching their intended outcomes. In supporting the clusters I located relevant research and resources about collaboration that clusters could access through a "Virtual Learning Network" that I created as a way to connect the EHSAS cluster members with one another in an online forum. ${ }^{5}$ I also took the lead role in organising face to face meetings with cluster members in the four regions (centred at Auckland, Hamilton, Wellington and Christchurch) and annual conferences in Wellington for representatives from all clusters to attend. This involved arranging appropriate keynote speakers and workshops based on the needs of the clusters attending.

\footnotetext{
${ }^{5}$ More information can be found about Virtual Learning Networks at http://www.vln.school.nz
} 


\section{Research Questions}

Throughout my involvement in the EHSAS project, I became curious about the effectiveness of the collaborative practices each cluster was using and was interested in knowing how and why each cluster chose to work together. As the Ministry of Education was not closely monitoring the cluster activities, it was difficult to find out about these things and I therefore decided to develop research questions in relation to them.

My overall research question is:

What collaborative practices were used by the participants in the EHSAS clusters?

Sub-questions are:

a. Do the research participants perceive the collaborative practices that they used as making a difference to student achievement?

b. What do the participants perceive as the benefits and limitations of collaborative practice?

c. How consistent are participants' perceptions with research findings in the field?

In keeping with my interest in the effectiveness of EHSAS clusters, and to ensure that the scope of this study is manageable, my research focuses specifically on the first and third anticipated outcomes in Table 1: "Improved student outcomes, through sharing best practice" and "Strengthened professional learning communities and increased collaboration". An initial consideration of the 87 EHSAS projects' monitoring and reporting information, and project outcomes held on files at the Ministry of Education indicated that a focus on the two selected areas would provide a rich source of data for analysis. Cluster milestone reports on student outcomes, also held by the Ministry of Education, provided a further source of data. However, it was not possible to collect, collate and compare data about student outcomes across the clusters in the time available, due to the varied project foci and the different assessment practices and tools used among clusters. 
I therefore investigated the perceptions of those involved in the EHSAS project and any evidence they had as to whether or not their collaborative practices made a difference to student outcomes. Because I was not asking for further data that could have been seen by cluster members as additional monitoring for accountability purposes, I avoided conflict of interest between my role as a monitoring and support person, and my role as a researcher. It was particularly important to be sensitive to any perceptions about additional monitoring through this research as it began after the unexpected cancellation of the EHSAS project in the National Government's "Budget 2009" announcements.

\section{Research Methodology}

The research questions focus on the reports and perceptions of people who were participating in the EHSAS clusters. Therefore a qualitative paradigm underpins the data collection and analysis in this study, allowing an overall understanding of the social behaviours being investigated. Quantitative evidence would not have provided the understanding of perceptions about social behaviour that I was looking for. Furthermore, the evidence available within EHSAS clusters on the actual effects of collaborative practice on student achievement could not have been measured. There were also issues with the reliability and validity of the achievement data collected within the clusters because of the lack of baseline data or a comparison cohort of students within clusters, and the lack of consistent and comparable data available across clusters. Moreover, cause and effect relationships between collaborative practices and student achievement were too difficult to measure quantitatively in the time that I had due to the complex nature and varied settings and structures of each cluster.

Grounded Theory is the chosen methodology for this study as it can be used to investigate qualitative evidence. It does not test a hypothesis but instead allows the researcher to discover what theory accounts for the situation being researched. The main aim of Grounded Theory method is to understand the research situation. It is well suited to investigating experiences through the use of interviews and document analysis as Suddaby (2006) suggests in pointing out the key differences between Grounded Theory and Phenomenological approaches: 
Although grounded theory retains some sympathy for phenomenological assumptions and techniques, researchers using grounded theory are less focused on subjective experiences of individual actors per se and are instead more attentive to how such subjective experiences can be abstracted into theoretical statements about causal relations between actors. (Suddaby, 2006, p. 635)

The Grounded Theory that emerges from the data will be outlined in Chapter 4: Results and refined in Chapter 5: Discussion and Conclusions which will also consider implications for future collaborative work in New Zealand schools. This chapter will also take account of key research and literature on collaborative practices in educational settings and build these into the final Grounded Theory.

Grounded Theory method emphasises the qualitative information found, rather than the specific methods that are used to find it. Data analysis occurs throughout the data collection process in an iterative way that allows the theory to emerge gradually. The data analysed in this study came from interview transcripts, cluster milestone reports and monitoring notes by the Ministry of Education. The full process used for data collection and analysis is outlined in Chapter 3: Methodology.

\section{Research Participants}

The participants in this research project come from three EHSAS clusters. They include two teachers from each cluster who have been more fully involved in the project, plus one key leader in each learning community (usually a principal or a facilitator) who has been involved from the design stage of the project. Thus, there is a total of nine research participants. The selection process used to choose the clusters themselves are described in more detail in Chapter Three.

\section{Organisation of the Thesis}

This thesis is organised into five parts. The next chapter locates the EHSAS project in national and international contexts by providing a review of the literature about collaboration within and between schools. It outlines the purpose of collaboration in 
educational settings and then differentiates between effective and ineffective collaborative practices.

Chapter 3: Methodology provides an overview of Grounded Theory methodology used to explore the research questions and Chapter 4: Results provides the results of my analysis of the data, ending with a Grounded Theory that represents the experiences and perceptions of the EHSAS cluster members who participated in the research.

Chapter 5: Discussion and Conclusions refines and discusses the Grounded Theory that emerged from the data. It compares the perceptions and experiences of the research participants with relevant literature in order to develop an understanding of the links between these. Finally, the implications of such links are discussed, recommendations for further research are made, and propositions of an ideal model for future cluster work are stated. 


\section{Chapter 2}

\section{Literature Review}

In order to investigate collaborative practice in clusters, it is necessary to review previous key research and literature about collaboration between adults in educational settings. This can then be taken into account when discussing the implications of the Grounded Theory in Chapter 5: Discussion and Conclusions. This chapter draws from relevant theories and research in national and international educational settings in order to provide an overview of how collaboration is currently defined and practiced, whether effectively or ineffectively. Two purposes for collaboration are commonly referred to in the literature. The first purpose is for school, teacher and student learning and improvement and the second is to reach common goals. These purposes are discussed in this chapter, and then effective collaborative practices are distinguished from those that are ineffective with a particular focus on improving outcomes for students.

\section{Collaboration: Competing Terminology and Definitions}

The literature about collaboration in educational settings does not offer one clear description of what it constitutes. De Lima (2001), discusses the lack of clear description and the disparities between researchers when they use terms like “collaboration”, “collegiality" and "co-operation" (p. 99). In highlighting the disparities between researchers, De Lima describes how some researchers believe that cooperation is a "key component of the concept of collaboration" (p. 99), while others believe that "collaboration is more than mere cooperation" or is completely distinct from cooperation (p. 99). De Lima refers to Little's (1987) argument that collegiality is collaboration that is "basically occasional, meaningless, and lacking in rigour" (pp. 9899). Hall and Wallace (1993) see collegiality as a collaboration between equals while Hargreaves (1995) states that collegiality is "far from being a synonym of collaboration" (p. 32). Hynds (2007) has also discussed "competing definitions" (p. 11) used for collaborative work. She has noticed a "confusing array of terms" (p. 12) used for collaboration and has noted that some descriptions focus on collaboration as a concept "with different interacting dimensions or levels" (p. 11), while other 
descriptions emphasise the need to consider the influences of social context, such as existing relationships and cultures in a group.

Different terminology, definitions and descriptions of collaboration not only occur between researchers, but also within single pieces of research. For example, Wohlstetter, Malloy, Chau and Polhemus (2003) use the words "networks" "clusters" and "collaboratives" synonymously in one article to describe schools learning from and supporting one another through sharing "ideas, experiences and strategies" to achieve outcomes (p. 402). Like De Lima (2001), Toole and Seashore Louis (2002) believe that varying terminology is confusing. They provide the following illustration of this and identify the terms commonly used and their sources:

Adding to the confusion, researchers use a variety of terms to describe how to organize schools for teacher learning: collegiality (Barth, 1990; Little, 1982, 1990; Sergiovanni, 1994) collaboration (Nias et al., 1989; Rosenholtz, 1991; Zellermayer, 1997), professional community (Louis \& Kruse, 1995; McLaughlin $\&$ Talbert, 2001), discourse communities (Putnam \& Borko, 2000), teacher networks (Lieberman, 2000), professional learning community (Hall \& Hord, 2001); democratic communities (Kahne, 1994), and schools that learn (Leithwood, 2000; Senge, Cambron-McCabe, Lucas, Smith, Dutton, \& Kleiner, 2000). (p. 247)

Overall, therefore the lack of clarity about what collaboration actually is appears to be largely due to competing terminology and descriptions. However, it may be possible to gain some clarity through focussing first on the purposes of collaborative practices, and second on what is and is not effective about the practices used when groups of schools work together. There is some commonality across the many definitions in the literature which builds a picture of effective and ineffective collaboration in educational settings. An understanding of these common themes and a focus on purposes and practices, allows for sense to be made of the competing ideas. Before describing practices, it is first important to gain an understanding of the broad purposes for collaboration in education settings. Effective and ineffective practices can then be clearly linked to those purposes which are relevant to this study. 


\section{The Purposes for Collaboration}

Two broad purposes for effective collaboration are referred to across the literature that was reviewed. They are first, for teachers and students to learn and improve (Annan, 2007; Katz, Earl and Jaafar, 2009; Timperley and Parr, 2010; and Timperley, Wilson, Barrar and Fung, 2007), and second for those working together to reach a common goal (Head, 2003; Katz et al.; Timperley, McNaughton, Lai, Hohepa, Parr and Dingle, 2009; and Wenger, 1998). These purposes are interconnected in that an effective collaborative group does not only have common goals, but also makes changes to current processes and practices related to teaching and learning in order to improve. Making changes to processes and practice for improvement will not be as effective without the group working towards a common goal. The literature that supports these ideas is outlined in more detail below under the two broad purposes.

\section{Collaboration for learning and improvement.}

Collaborative practice for the purpose of learning and improvement at the school, teacher and student level is highlighted by several of the studies reviewed. Katz et al. (2009) researched the way professional learning communities work in educational contexts to find out what should be emphasised in order for these groups to be successful and productive. They focussed on 1,500 English schools (132 networks) taking part in a programme called "Networked Learning Communities" (NLCs programme) (p. 4). The findings presented the key features of effective learning communities and how they worked in practice.

Katz et al. (2009) devised a "theory of action" (p. 20) based on the most effective professional learning communities in the NLCs programme (those that improved student outcomes). The theory of action included several key practices that enabled teacher learning, and change in teacher practice. According to Katz et al. the most effective learning communities demonstrated that when changes occur in thinking and practice after teacher learning takes place adult practices improve and lead to improvement in "student learning, engagement, and success" (2009, p. 20). 
The overall emphasis in the data that Katz et al. (2009) collected about school practices and shifts in student achievement therefore supports collaborative practice that enables focused professional learning and thus improved student outcomes. EHSAS clusters were required through their contracts with the Ministry of Education to meet similar goals: to improve teacher quality and student outcomes during their four year projects. Although it was difficult for EHSAS cluster members to link their collaborative practices to raised student achievement, Katz et al. based their theory of action on evidence that when networked schools worked together, there was an impact on student learning. They noted in an earlier article related to the same research that associations found between networks and student outcomes suggested a "connection between the participation in a network and improvements in pupil attainment" (Earl, Katz, Elgie, Jaafar and Foster, 2006, p. 8). Therefore, the linking of collaborative practices to student outcomes is a useful way to assess the impact of collaborative projects between schools.

Annan's (2007) investigation into the seven most successful national and international examples of school improvement referred to two initiatives in New Zealand, one of which was a Schooling Improvement cluster working together to improve academic achievement for disadvantaged students. ${ }^{6}$ Through critical analysis of the development and implementation practices of the seven initiatives and their effectiveness, Annan developed a theory about how they accelerated learning and improved student achievement. Like Katz et al. (2009), Annan also focussed on schools that were collaborating to improve teacher quality and student outcomes.

The New Zealand Schooling Improvement cluster in Annan's (2007) study demonstrated non-hierarchical learning connections between the participants. Annan termed these "horizontal learning connections" (p. 164). In this case researchers, government officials, professional development providers and national policy makers developed knowledge with, rather than for school practitioners as part of a community of practice. "Lead practitioners" (p. 164) developed these learning connections with other practitioners in the cluster schools and "made sure that the knowledge and

\footnotetext{
${ }^{6}$ The seven most successful initiatives were selected from the available literature about schooling improvement at the time of Annan's study. Annan used a criteria for effectiveness that allowed him to locate evidence of gains in student achievement in each initiative and then rate each initiative as having either "strong", "promising" or "insufficient" evidence of effectiveness (Annan, 2007, p. 57).
} 
practices agreed to...were adopted and used back in the individual schools" (Annan, 2007, pp. 164-165).

The other six national and international initiatives demonstrated strong "vertical learning dimensions" (Annan, p. 140) which means that mandates were driven by national policies and independent researchers more than they were driven by horizontal learning connections. While all seven initiatives were effective, it may be that the findings related to the New Zealand cluster are more relevant to the EHSAS context. The revision of New Zealand's Education Act in 1989 devolved the responsibility for governance and management of schools from a central Department of Education to schools with Boards of Trustees. Since this education reform in New Zealand, schools have had far fewer external accountabilities placed upon them by a bureaucracy when compared with schools in other countries. It will also be important to consider whether or not both vertical and horizontal learning connections occurred in EHSAS clusters in order to establish the degree to which the EHSAS project was effective.

While Annan's (2007) study is broader in scope than this study (he investigated collaboration across researchers, government officials, professional providers and school practitioners), his major findings do refer to the practices and approaches used by effective school practitioners in raising student achievement. Learning and improvement were the key purposes in all of the initiatives, and all partners in the work developed knowledge with each other. Annan's analysis provided a different view to that of Katz et al. (2009), in that the practices he considered were at both the development and implementation phases of the cluster projects. Annan was therefore able to clarify the roles involved in planning and implementing effective practices. For example, what parties agreed to do in their schools and what they actually did could potentially be two different things if checks were not in place to ensure that knowledge and practices were actually used in schools.

With the same focus on the improvement of teacher practice and student outcomes, Timperley and Parr (2010) worked alongside their University of Auckland and Ministry of Education colleagues over the years to support and investigate schools involved in “development projects that were designed to improve students' learning and achievement" (p. 5). They then led a Ministry of Education funded research and 
development project that began in 2007. The project was "designed to build evaluative capability in schooling improvement across clusters of schools in New Zealand" (p. 5). Timperley, McNaughton, Lai, Hohepa, Parr and Dingle (2010) explain that "evaluative capability" is "the capability to evaluate the effectiveness of particular activities in an ongoing way" (p. 31) and that it requires schools to use evidence during teaching and learning so that practitioners and leaders in schools can engage in inquiry and knowledge building cycles. Unlike Annan (2007), who selected only the effective examples of New Zealand Schooling Improvement clusters, the Timperley and Parr team worked with all New Zealand schools that took part in the Schooling Improvement clusters.

The effective practices identified through their research allowed Timperley et al. (2010) to emphasise the importance of self review practices in schools and clusters. They built on Annan's (2007) work which kept the focus on practices within the spaces of development and implementation. They regarded as particularly important the part of the inquiry process that requires a group to check on the impact that their changed practices are having. In this they contrasted to Katz et al. (2009) who emphasised the importance of the entire inquiry cycle. All three studies provide valuable information on the key collaborative practices that are necessary for learning and improvement in schools. The timing of each study allowed each to build on what had gone before, with Timperley et al. (2010) honing in on an area of particular weakness in schools. That is, evaluative capability and checking for the impact that chosen practices have had on teacher practice and student achievement.

Like Annan (2007), Du Four (2007) discussed implementation issues in building professional learning communities in schools and explained that the main purpose of such communities should be to have a positive impact on the learning of the students and adults involved. He stated that a school that is involved in the change process of becoming a professional learning community must have staff that "focus on learning rather than teaching, [on working] collaboratively on matters related to learning" (p. 5), and on aiming for continual improvement. While far more explicit, Du Four placed the same emphasis as Annan on learning rather than teaching. Du Four's critical examination of teaching and learning within the learning community context adds to Annan's findings. Both are relevant to EHSAS practices which were definitely focused 
on the learning of students and adults involved. However, it is not so clear as to whether or not they were explicitly engaged in a change process to become a professional learning community.

In conducting their "realist synthesis" of international and national evidence on how to "promote teacher learning in ways that impact on outcomes" for students (p. xxiii), Timperley, Wilson, Barrar and Fung (2007) identified how and why participants in different teacher professional learning and development programmes achieved positive outcomes for students. To do this, they identified studies that had both successful and less successful outcomes and compared these by identifying and analysing characteristics that were associated with successful outcomes. Through their analyses, Timperley et al. (2007) found that professional communities that provided "opportunities for teachers to plan and negotiate the meaning of new knowledge and skills" (p. 175) resulted in positive change in student outcomes. Further analysis by Timperley et al. of how such opportunities occurred revealed that the members of the professional communities had to have an "unrelenting preoccupation with teachinglearning or teacher-learner connections" (2007, p. 175). By this, they meant that changes in teacher practice must always be "referenced to their impact on students" (2007, p. 175). Effective professional communities were found to promote learning for both teachers and students (2007, pp. 202-203).

Other smaller or less recent studies also refer to learning and improvement as key purposes of collaboration. In her study of school-university partnerships, Hudson-Ross (2001) discusses the need for contexts where group members can confront limits to their own knowledge, learn from common difficulties, challenge their beliefs and build on their existing knowledge. Firestone and Pennell (1997) concluded from their case studies of teacher networks that "capacity-building networks contribute more directly to teacher learning, motivation, and empowerment than do policy-supporting networks" (p. 263). Wenger (1998) developed a "social theory of learning" (p. 3) based on many years of experience and anthropological research on different "communities of practice" in California. His description of communities of practice places learning at the centre through claims that communities of practice are the "privileged locus" (p. 214) for the acquisition and creation of knowledge. In his exploration of research and theory about collaboration, Head (2003) discusses "effective collaboration for learners and 
professionals in communities of support, practice and learning" (p. 47). He argues that effective collaboration is for several purposes, including the purpose of supporting the learning of all students. Thus all these earlier studies have commonalities with the key studies I have previously considered. The practices attached to their findings are discussed later in this chapter in the section entitled "Effective and Ineffective Collaborative Practices".

Another less recent study by Little (2002) focused on collaboration for learning and improvement and questioned how to measure the ways in which professional communities supply resources for teacher learning. Little suggests a framework that exposes and then focuses on the improvement of teacher practice and that finally establishes norms for effective professional interactions involving the "describing and analyzing [of] the learning resources of selected activities in everyday collaborative work among teachers" (Little, p. 936). Using her proposed framework to trace evidence, Little believes that teacher learning will become apparent. It is interesting that Little's focus is solely on collaboration for the purpose of teacher learning and improvement, when others (as noted in this chapter) discuss collaboration for the learning and improvement of students, leaders, and other adults, as well as teachers. This may be because Little has assumed the link from teacher improvement to improved student achievement is obvious. Perhaps Little prioritised a focus on teacher learning and improvement because at the time of her study in 2002, other researchers such as Hattie (2003) were discovering and presenting significant patterns in educational research indicating that outside the student's own abilities, including the expectations and encouragement that come from a student's home, it is the classroom teacher that has the most impact on improving student achievement.

The literature on collaboration for learning and improvement implies that to be effective, the collaborative practices must result in change across school and teacher practices. Katz et al. (2009) note that such change could result in "student learning, engagement and success" (p. 20) if members of learning communities remained focussed on change in thinking and practices. However, Little (2002) warns that teachers in communities of practice cannot "simply equate change with improvement" (p. 935) and therefore, evidence of improvement towards the group's goal should be gathered to inform next steps. Little's stance is aligned with inquiry based practices 
outlined earlier in this chapter and supported by Katz et al. In locating the collaborative practices of EHSAS cluster members, it will be important to look change in school, leader, and teacher practices whilst checking for evidence of improvement.

\section{Collaboration to reach common goals.}

Several studies show that reaching a common goal is a key purpose for collaboration in any setting, and that when combined with the purpose of learning and improvement, a common goal will be reached if a group is involved in solving issues of mutual concern.

Katz et al. (2009) found that a successful network of schools had a "common needsbased focus" (p. 34) which gave schools a reason to work together. School networks that had a common goal had to ensure that the goal was "right for each school, understood by all members, and shared amongst the schools" (p. 34). This characteristic in the NLCs programmes consistently resulted in a positive impact on classroom teacher practice and in turn, student achievement. When considering the practices associated with all of the purposes for collaboration outlined in this review and comparing them to EHSAS cluster members' experiences, I will discuss the effectiveness of the EHSAS clusters' practices and to reveal potential implications.

Wenger (1998) also discusses common goals as a purpose for collaboration. In his description of communities of practice he uses the term "joint enterprise" (p. 77). Unlike Katz et al. (2009), he does not emphasise joint enterprise as being needs-based. Instead he suggests that a community of practice is kept together if its members have a common goal that is negotiated and agreed between them, that is defined by them, that is a stated goal and that it "creates among participants relations of mutual accountability" (p. 78). Mutually accountable relationships are visible when participants value certain practices, when they discuss what matters and what does not, act according to spoken or unspoken rules or standards, and when they continually check each other to ensure that these rules and standards are not violated. Wenger's position is supported by Timperley et al. (2009) who point out that joint responsibility enables a "collective belief that the community can achieve its desire outcomes" (p. 23). However, Timperley et al. (2009) support inquiry approaches which are needs based. 
The lack of clarity in the literature about what collaboration means makes it difficult for schools to collaborate effectively. For example, the collaborative practices evident in EHSAS clusters may vary depending on the literature that cluster members chose to engage with and then how they decided to implement their projects. It will be interesting to compare EHSAS leaders' reported practices to Wenger's identified practices to see whether or not they set goals that were needs based. As noted in Chapter 1: Introduction, the Ministry of Education provided EHSAS clusters with some literature and resources about effective collaboration through regular newsletter and online communication (the EHSAS Wikispace). Cluster's also attended workshops and conferences once a year where Dr Brian Annan delivered his own theories of effective collaboration which support the needs based theories of Timperley et al. (2009). Annan emphasised the importance of cluster's engaging in a deeper analysis of need when determining goals but he also provided the clusters with Wenger's "Community of Practice" theories and research through the same workshops and conferences because he believed the two sets of theories were compatible.

While Katz et al. (2009) and Wenger (1998) provide differing information on the practices required to negotiate a common goal across a cluster, Annan's (2007) viewpoint brings the two sets of information together. Annan discusses the necessity for school leaders first to identify the problem within their own schools and then to "find a group of local schools to work with who [have] a common interest in solving a particular part of the overall achievement problem" (p. 185). This view is similar to the needs-based goal setting proposed by Katz et al. Annan goes on to discuss the collaborative practices that the group of school practitioners must use in order to be effective at raising student achievement. Rather than focussing on locating and maintaining a common goal, a cluster of schools according to Annan should come together for a needs-based reason. Annan supports practices that allow cluster members to "critique and challenge[...] each others' professional decisions and actions" (p. 187). In this case, the goal can change over time to focus on changing needs. Both types of goal setting are relevant to this study as the EHSAS project included schools that came together to address a common need, as well as those that came together in order to negotiate a project plan and common goals. 
Timperley et al. (2009) note that in addition to members of professional learning communities working together towards a common goal, they should each have the goal of trying to advance the others' learning. However, in emphasising the leader's role in setting and maintaining the focus in a professional community, Robinson, Hohepa and Lloyd (2009) add that student outcomes will not improve unless the focus is on "improving student success" (p. 42). They state that the "collegial discussion of the relationship between what is taught and what is learned" (p. 42) will further ensure this focus. Both studies are based on evidence of what works to improve student outcomes, so it is likely that members of a professional learning community must have two specific goals; one to enhance each others' learning and one to improve student success in the same learning area.

Hudson-Ross (2001) found that effective collaboration requires group members to agree on a clear focus and thus a common goal. It is that agreement that is necessary for the clarity of focus and eventual achievement of the goal. Head (2003) supports the need for group consent but found that some collaborative groups with a common purpose were ineffective: "In reality they behave as individuals and only carry out the roles expected of them" (p. 53). Head believes that in order to move beyond this perspective, individuals need to "gain a clear sense of purpose in the group and their role in it" (p. 53). In that way, Head explains that the individuals can have the opportunity to understand the mutual benefits of working together.

So far, this literature review has discovered that several researchers and theorists agree that an effective collaborative group is one that has a clear purpose of learning and improving to reach a common goal. It is agreed across the literature that learning and improvement often requires change in existing practices in schools. To enable such change, strategies should be adopted that include the consideration of cluster structures, and inquiry and self review frameworks that expose current practices and their problems. Ensuring that goals are needs-based and agreed upon across a cluster is equally important. However, there are effective and ineffective practices associated with collaboration for learning and improvement to reach common goals. These are discussed in the next section. 


\section{Effective and Ineffective Collaborative Practices}

According to research literature, there are particular practices that are required if a collaborative group of schools is to succeed in raising student achievement. In this section I outline those practices, as well as ineffective practices that will hinder a group's progress towards learning and improving to reach a common goal. The practices fall into two broad categories. These are first, building skills and knowledge and second, building relationships. I consider each of these separately and the remainder of this section describes the key practices that are aligned to the broad purposes for effective collaboration, and the necessary tension between the practices used to build skills and knowledge, and to build relationships. Finally in this section I summarise in table form specific indicators of effective and ineffective practices in collaborating schools.

\section{Building skills and knowledge.}

Katz et al. (2009) discuss several practices that make collaborative groups effective, developing their argument into a "theory of action" (p. 19). Other researchers also refer to these practices. They involve inquiry, leadership, and capacity building so that learning and improvement can occur for teachers and students. Katz et al. define inquiry as the "use of...reflection to think about where you are, where you are going, and how you will get there" (p. 13). They go on to discuss effective collaboration as involving "interpretation and evaluation of practice" (p. 13) which are themselves part of the inquiry process and involve the questioning of current practices, reflecting on them and then seeking alternative solutions where the evidence suggests that there is a need to do so. If inquiry is demonstrated, members of a collaborative group will work together "in order to investigate practices and ideas through posing more questions" (Katz et al., 2009, p. 14) and in the process will build a better understanding of a particular issue.

A detailed description of inquiry is provided in Practitioner Research for Educators: A Guide to Improving Classrooms and Schools by Robinson and Lai (2006). They discuss ways in which inquiry, or "the critical examination of practice" can be strengthened through the use of Problem Based Methodology. Robinson's Problem 
Based Methodology acknowledges the contextual issues of collaboration and provides solutions to working with disagreements over practices and problems, encouraging inquiry into these problems to find solutions. According to Robinson and Lai, the use of Problem Based Methodology allows issues of context to be addressed, ideas to be challenged and the effectiveness of the collaborative work to be checked. These practices seem to be important indicators for establishing whether or not there were inquiry based practices in EHSAS clusters. If such practices did exist, then the cluster leaders could be seen as having the knowledge and capability to establish systems and processes that address issues related to collaborating across schools.

Issues of capability are addressed by Timperley and Parr (2010) who expand on inquiry based practices by explaining that evidence-informed inquiry for improving student outcomes involves teachers who are "adaptive experts who retrieve, organise and apply professional knowledge when old problems persist or new problems arise" (p. 14). Inquiry-based practices are referred to by Timperley and Parr in this instance as “evaluative capability" (p. 14), which includes the following activities linked to a cycle of inquiry:

- Establishing which outcomes are sufficiently valued by those involved to justify the focus and effort;

- Identifying the information needed to work out how to judge progress towards these outcomes;

- Developing a shared understanding of the conditions that might be limiting student learning and achievement;

- Making an informed selection and take courses of action that address these conditions;

- Checking progress (both rate and level) towards the valued outcomes and make appropriate adjustments to relevant activities;

- Ensuring that all those who need to know can answer their questions with timely and accessible information;

- Embedding these evaluative activities as a socialised practice for all participants within the schooling improvement community. (2010, p. 15) 
Timperley et al. (2010) explain that evaluative capability requires the identification of desired outcomes for students, and "the type of information needed to work out how to make judgements about attainment and progress" (p. 31). To demonstrate this, leaders and practitioners in schools must also "develop a shared understanding of the conditions that may be limiting professional and student learning...engaging in further cycles of inquiry" (p. 31). Timperley et al. (2010) developed specific indicators related to evaluative capability that assist school leaders and teachers to locate their level of competence when engaging in inquiry. While the indicators can be used within one school to determine the ability of its teachers and leaders, they are essentially measures of the effective practice of schools working together to learn and improve. Timperley, McNaughton, Lai, Hohepa, Parr and Dingle (2009) produced a position paper that provided the basis for these indicators by describing the "optimal condition for learning" (p. 22) in professional learning communities and the need for strong content and interpersonal interactions.

Timperley and Parr (2010) point out a weakness of such inquiry-based practices in that the underlying concepts and thinking may not be understood by those trying to engage in the practices. To address that weakness, they emphasise the use of evidence in building evaluative capability in teachers and school leaders is fundamental. This means that the collaborative group must continually check that group members are assessing their ability to engage in inquiry using evidence. To this end, Timperley et al. (2010) developed a rubric with specific criteria indicating several levels of evaluative capability. This "continuum of development" (p. 38) for school leaders and teachers can be used to measure evaluative capability in order that proficiency improves over time. This is a useful tool that could be applied to EHSAS clusters to check if inquiry based practices were used.

Little (2002) argues that before you can build the capacity of teachers, you must apply a framework that exposes their practices within the community of practice through observation to "reveal how teachers differ on matter of practice" (p. 935). Little's argument therefore considers the type of evidence most valid and reliable. Little's claim that the best type of evidence is that which allows the practice to be observed is ideal, but where this is not possible, teacher self-assessment using other types of evidence such as students' work samples may be the next best approach. Little warns 
against making the assumption that teacher change leads to improvement in student outcomes. She thus agrees with other researchers that inquiring into the evidence of effectiveness is paramount.

Firestone and Pennell (1997) found that teacher networks resulted in a greater focus on building teacher capacity because there was no debate among the teachers over state policies and more focus on teachers' learning needs. While the EHSAS clusters were operating in a "high trust" project (as discussed on page 8 in the Introduction chapter) and were therefore unlikely to be debating state policies, they did have a focus on building teacher capacity in their projects. The practices that Firestone and Pennell associate with capacity-building networks will be relevant to this study. Those practices include the need to ensure that a "mix of learning experiences" $(1997$, p. 238$)$ is created for teachers that involves both a knowledge delivery approach as well as a coconstructing approach to knowledge-building for teachers. As Firestone and Pennel state: "Knowledge delivery may help teachers develop procedural knowledge, but knowledge construction is more likely to effectively promote teachers' conceptual knowledge" (1997, p. 241).

In addition to Timperley and Parr's (2010) findings about the building of evaluative capability through engagement in inquiry-based practices, there are other practices that build knowledge and skills in teachers that are participating in professional communities (Timperley et al., 2007). By analysing the practices across several core studies that impacted positively on student achievement, Timperley et al. (2007) found that teachers were involved in negotiating the meaning of new knowledge through using data that indicated their progress towards desired goals. That data "comprised [indicators of] desired teaching practices, indicators of relationships with students and achievement outcomes" (p. 175). However, there also had to be a leader present who could challenge teachers about the meaning that they placed on the data. Where teachers did not reference their practices against outcomes for students, there was little improvement either for them or for their students because they had no reason to challenge or change their current practices. However, Hudson-Ross (2000) attributes a lack of improvement in collaborative groups to the presence of a climate that may be too "positive" where members do not challenge each other and therefore further entrench ineffective practices that make them feel good (p. 443). It can be argued that in addition to the 
presence of a leader, both use of data and relationships have an impact on the effectiveness of a collaborative group. Hudson-Ross' identification of practices that build relationships is further discussed in the next section. The practices identified across the studies outlined in this section support an inquiry based approach where teachers use evidence to understand their own learning needs and those of their students.

When new practices were introduced across a collaborative group, Timperley et al. (2007) found that "professional learning communities did not always promote professional learning...teachers can reject new practices and support one another to maintain the status quo." (p. 151). Coburn (2001) illustrates the same point by explaining her findings on why teachers may do this. When both researchers' findings are considered together, it seems that teachers did not have a shared understanding of why they might take on any new practices. They therefore remained opposed to new practices for philosophical reasons, or because they could not see how they could change their current approaches to accommodate them. This illustrates how important it is to have a shared understanding of what the collaborative group is doing and why, and ensure that all group members agree to the goal and the approaches for reaching it.

As discussed earlier, several researchers believe effective leadership is seen as an important aspect of a collaborative group if its members are to learn and improve. Good leaders demonstrate practices that build skills and grow knowledge in others.

According to Katz et al. (2009) collaborative practices that enable leadership to develop include the encouragement and motivation by "formal leaders" (p. 14) (for example, principals) of others in the group. Leaders must also share their leadership role with others and provide support so that capacity is built allowing the group's goals to be reached. Katz et al. believe that leadership should be distributed so that members of a collaborative group who are not formal leaders can share their expertise and lead particular parts of the project. When capacity is being built in all members of the group, they are examining their existing beliefs and challenging "what they do against new ideas, new knowledge, new skills, and even new dispositions" (p. 15). While leadership must be encouraged in others, the formal leaders must also continue to set and monitor the agenda. Katz et al. explain that this means leaders ensure that the group correctly identifies and maintains the goal until it is accomplished, thereby guaranteeing that there are not too many goals at any one time. 
Annan's (2007) findings about the effectiveness of "horizontal learning connections" (p. 164) (or non-hierarchical connections) support the position of Katz et al. (2009). Nonhierarchical leaders had a similar role in monitoring progress towards accomplishing the group's goals. This involved ensuring that knowledge and practices were adopted and used. Annan found that learning communities demonstrated the following effective collaborative practices:

They nurtured collegial learning and accountability among practitioners and other groups involved in the initiatives. By collegial I mean that they learnt from one another and held each other to account without a power relationship giving one group the upper hand. They had time to try things out and come around to agreeing on the practices that they would commit to. (Annan, 2007, p. 165)

This indicates a need not only for clear leadership in ensuring that goals are met, as agreed by Annan (2007) and Katz et al. (2009), but also for a type of collegial leadership that focuses "directly on knowledge and learning" leaving other necessary leadership tasks such as "administration and line management responsibilities" (Annan, 2007, p. 164) to hierarchical teams or leaders. Robinson et al. (2009) discuss a type of leadership in learning communities that appears to be a blend of both hierarchical and non-hierarchical practices. According to Robinson et al. the achievement of common goals in learning communities is enabled when leaders have expectations that teachers will help one another to do so (p. 124). This implies that the leaders had been demonstrating hierarchical practices to place expectations on their staff, while enabling collegial relationships to develop. Teachers thus had "the help of colleagues who understood what they were up against and who cared about succeeding" (p. 124). Fullan and Hargreaves (1992) also support the notion that leaders must enable collegial relationships between teachers. They emphasise the fact that teachers should be empowered by leaders to frame, understand and solve problems collaboratively (p. 69).

However, Fullan and Hargreaves (1992) also warn against the type of school leader that manipulates a school culture and its teachers to conform to his or her own vision. They believe that this type of leadership suggests a kind of hierarchy that is not useful and 
that can create "an ownership of the school which is personal rather than collective, imposed rather than earned and hierarchical rather than democratic" (1992, p. 119). Fullan and Hargreaves have found that this type of leadership can minimise learning for leaders and can force teachers to conform to a vision that may not match their own and that may even be flawed. Therefore, they believe that in a collaborative culture leaders must be "willing to share control, show vulnerability, and look for ways to involve the reticent or the opposed" (1992, p. 121). According to Fullan and Hargreaves, this sharing of leadership does not mean that leaders use collaboration "to steer one's own personal views" (1992, p. 122). Rather, it requires a leader to be an "interactive professional [who] learns as well as leads through collaboration" (1992, p. 122). While Fullan and Hargreaves (1992) discuss collaboration at the school level, I suggest that it may be equally applicable at the cluster level because the same or similar structures are present on a larger scale.

Head's (2003) work on collaboration focuses mainly on student learning, but also addresses the need for "the roles of managers and teachers [to] shift from positions of authority to participants and learners in a culture of investigation, experiment and mutual sense-making" (p. 58). Ultimately, Head believes that collaboration should benefit all participants and allow new knowledge and understanding to be created. To overcome the problems of collaboration, Head proposes that all collaborative groups must operate as communities of support, of practice and of learners. He explains that collaboration can be problematic due to the complex "repertoire of skills" (p. 49) needed by participants if they are to collaborate effectively. The three community types that Head emphasises encourage the social aspects of learning.

According to these findings, it is likely that a complimentary blend of both types of leadership (hierarchical and non-hierarchical) would result in effective collaborative practice in EHSAS clusters. Hierarchical and non-hierarchical practices both have their strengths and weaknesses and these must be understood if leaders are to enable effective collaboration between themselves and their teachers. 


\section{Building relationships.}

According to the literature, relationships are important in collaborative work (Bryk, 2003; Katz et al.; Timperley et al., 2009; Timperley and Parr, 2010; West-Burnham and Otero, 2004; and Annan, 2007). Developing trust is the precursor to group members fostering a shared understanding about why they are working together, and then agreeing to do so. Only then can they establish good relationships in order to reach a common goal.

The literature on collaboration commonly notes that many of the effective practices discussed earlier in this chapter are not possible without the presence of trust and respect between those working together. For example, after ten years of research which examined relationships between teacher, principals and students in more than 400 Chicago schools, Bryk (2003) confirmed that "relational trust" is central to effective education communities involved in reform. Bryk explains that relational trust is made up of the actions taken by community members to reduce the sense of vulnerability that is present between partners who are dependent on one another to achieve desired outcomes. These actions include "respectful exchanges" between group members, "even when people disagree" (p. 41); "personal regard" between group members which shows the "willingness of participants to extend themselves beyond the formal requirements of a job definition" (p. 42); actions which demonstrate competence of all group members to produce the desired outcomes and that show personal integrity and a "commitment to the education and welfare of children" (p. 42). Such practices enable “collective decision making with broad teacher buy-in" (p. 43). Where relational trust is present the perceived risk of change is reduced, allowing teachers to feel more comfortable about taking part in reform.

Similarly, Katz et al. (2009) take the position that building trust opens a "gateway" (p. 41) to effective collaboration. They also believe that if it is to contribute to improvement, this trust must be the professional type, and not the personal type: "Network members need to trust one another to help them do their professional best, not to be the guardians of their closely held family secrets" (p. 41). To begin developing this trust, Katz et al. note that "commonalities, rather than differences, lie at the root" (p. 41) of successful relationships, and that working together on a common goal enables 
trust to be built along the way. Therefore, relationships grow out of collaborative activity. A balanced professional focus on relationships as well as outcomes that are related to teaching and learning is important, rather than having a "preoccupation with relationships" themselves (p. 41). While the authors do not discuss what a good balance might look like, it may be that the type of balance required depends on the people in the cluster and what they are working on together. It will be important to consider relationships in EHSAS clusters, and to check for the connections between these and teaching and learning outcomes in their activities. Insights may be gained from participants about whether or not they thought that the balance between the two was appropriate.

Timperley et al. (2009) found through their research on New Zealand-based clusters of schools that having role clarity about accountability is "essential to high trust", and that trusting relationships must be "accompanied by task-focused challenges that disrupt current routines and practices, and result in doing something different" (p. 2) in order to get improvement. One particular cluster member involved in this research summarised the relationship between trust and challenge, showing that "high trust" and "high challenge" together can help a cluster to continue making progress in order to "achieve the aim of improving student outcomes" (pp. 8-9)

Like Bryk (2003) and Katz et al. (2009), Timperley et al. (2009) do not emphasise personal trust as being important. Instead they discuss the ways in which professional behaviours impact on the development of trust, focusing on how trust must contribute to the goals of the community. This study takes the position that building professional trust is important, and personal trust will not allow a group to meet their goals. Bryk also favoured "personal regard", however this was about having a personal style in a professional sense, that encouraged openness between group members and a willingness to "reach out to parents, teachers, and students" (p. 42). Bryk's definition of personal regard is about making personal connections in a professional world.

A preoccupation with relationships can be detrimental to a learning community. Katz et al. (2009) highlighted their experiences of learning communities that ended up in "activity traps" which "focus on the doing but not on the outcomes" (p. 41) due to a preoccupation with relationships which did not progress into deeper professionalism 
and effective collaboration. Keeping a focus on the group's goals assisted learning communities to avoid activity traps. Similarly, in analysing the practices attached to many different studies of professional communities, Timperley et al. (2007) found that certain qualities existed in professional communities of schools that successfully promoted student learning. Of these qualities, participants' "mutual trust and respect" (p. 203) was important. However, they also found that "trust, respect, and support may be characteristics of the community...that remove the focus from teaching quality, and/or justify continuing with practice that is less effective than that being promoted by the professional development" (p. 203). Therefore, it is essential when looking for evidence of trust among EHSAS cluster members that I consider whether the cluster also experienced positive change towards reaching their goals. The necessity for personal regard within professional relationships must also be considered when looking for EHSAS participants' perceptions of the most effective balance between relationships and teaching and learning.

Across the literature reviewed there is a common agreement that once trust is built between members of a group they can then develop relationships that are important for effective collaboration. These are relationships that are critical, challenging, and change focused, and that foster role clarity and a shared understanding about why the group members are working together.

A key reason that schools collaborate is to share expertise. However, Timperley et al. (2007) argue that while sharing expertise is important in educational settings, this is not sufficient in itself for raising student achievement. Their view is that if schools are to share expertise effectively, collaborating partners must engage in "challenging dialogue" (p. 203). This is dialogue in which educators address problematic beliefs. If it is challenging, participants will notice that the dialogue contributes to learning opportunities for teachers and ultimately, improved student outcomes.

Like the studies analysed by Timperley et al. (2007), Annan's (2007) research stated that challenge and critique are practices that go hand in hand when it comes to schools working together to reach common goals. Annan describes a specific type of practice called "learning talk" that is useful for people to engage in when solving student achievement problems. Learning talk involves teachers analysing the impact of their 
practices, evaluating the outcomes of that analysis and discussing the changes required to improve. Annan defines this using the terms "analytical talk, critical talk and challenging talk" (p. 187). The critique and challenge components of these practices involve teachers locating evidence of student learning and attributing it to their beliefs and practices and then discussing, challenging and changing their current practices. In particular, Annan emphasises learning talk as a "tool for improving inquiry skills and knowledge across a group of schools" (p. 187) and as essential for enabling the attainment of common goals.

Furthermore, Timperley et al. (2007) emphasise the role of external expertise, which can assist in creating more challenging dialogue across a group. They found that "all studies of professional communities that did not lead to improved outcomes for students lacked external input. In these studies, challenges to assumptions held by community members typically did not happen" (p. 203). External expertise could involve input from an expert leader "prepared to challenge the meanings that teachers attributed to the data, along with their assumptions about teaching practices, relationships, and/or achievement". According to Timperley et al. this ensured that progress was being made towards goals (2007, pp. 154, 175).

Katz et al. (2009) also support the presence of an external person to critique and challenge within a collaborative group. They believe that such a "critical friend" (p. 90) can ensure that a learning community addresses problematic beliefs in order to facilitate change to reach goals. These critical friends should be able to "facilitate reflection on issues, ask questions, probe for justification and evidence to support perceptions, and help reformulate interpretations" (pp. 90-91). However Katz et al. also warn that preexisting relationships between the critical friend and members of the learning community can have an impact on the effectiveness of their role. For example, if the critical friend is in a position of power, learning community members may find it difficult to open up their practices to scrutiny. The authors suggest that one way around this issue is to raise it openly with the group and work towards an equal relationship based on trust. Therefore, while Timperley et al. (2007) suggest that an expert leader could take on this role, it is important to acknowledge and address the issues that Katz et al. have raised about the power that any leader may hold so that they are able to take on the critique and challenge role effectively. 
Bryk (2003) notes that principals can play a key role in assisting school staff to work towards an equal relationship based on trust. He states that "principals establish both respect and personal regard when they acknowledge the vulnerabilities of others, actively listen to their concerns, and eschew arbitrary actions" (p. 44). When principals also make it clear that they are seeking to advance a compelling school vision, they become more effective at sustaining relational trust because they are showing "consistency between words and actions" (p. 44). Bryk found that in difficult situations, the principal had to establish personal regard by reshaping the composition of the school staff, bringing strong experts onto the staff who were able to uphold the school vision and help build relational trust. Therefore, while the presence of a critical friend or external expertise is one effective way to support critique and challenge in a collaborative group, I suggest that Bryk purports a more sustainable solution. He is suggesting that building strong leadership capability to foster such strengths within a school staff is effective in advancing school reform.

As building trust is the precursor to group members fostering a shared understanding, relationships that foster trust are important. Fullan and Hargreaves (1992) discuss the problem of collaboration and point out that some types of collaboration are best avoided because they have limited positive impact on teachers and students. One type of ineffective collaboration is termed "Balkanization" (p. 71) which involves teachers attaching their loyalties to "particular groups of their colleagues" (p. 72). These attachments form cliques that allow teachers to "segment themselves in ways that are detrimental to whole school development" (p. 72). They can lead to "poor continuity in monitoring student progress and inconsistent expectations for [student] performance and behaviour" (p. 72). Fullan and Hargreaves found that some school leaders were able to stop Balkanization by deliberately fostering the development of relationships between different teachers. This could occur through providing opportunities for different classrooms to work together across both students and teachers to create "more understanding among teachers who normally remain relatively isolated from one another" (p. 73). Anything to bring about a closer liaison between teachers who do not normally work together can allow new relationships and understandings that break up old cliques. 
De Lima (2001) is highly critical of teacher communities unless the teachers use conflict as a catalyst for school change and improvement. School change in this case relates to a focus on improved student learning as the key outcome. He believes that most conceptions of teacher community are too focused on the "community" aspect that values collegiality and friendship ties rather than challenge and conflict (p. 102). De Lima's argument is that with "cognitive conflict" (p. 116) teacher collaboration can enable school change. This conflict, according to De Lima, is "a necessary prerequisite to commitment. In school communities without conflict, commitment turns easily into compliance" (p. 117). While De Lima does not value such relationships between teachers, other researchers emphasise the importance of them. However, there are some instances where De Lima is in agreement with others, such as Timperley, et al. (2010) who value "high trust" as well as "high challenge" (pp. 40-45) if capability is to be built. De Lima's negative view on collaboration in educational settings highlights examples of ineffective practice that can be used to discuss the effectiveness or otherwise of EHSAS cluster members' experiences.

\section{The tension between building skills and knowledge and building relationships in collaborative work.}

The literature strongly suggests that the presence of trust and respect enables effective collaboration, but conversely that some effective collaborative practices enable trusting and respectful relationships. As trust grows between cluster members, the sharing of challenges, expertise and ideas may also increase. Robinson and Lai (2006) emphasise the inevitability of "disagreements over practices and problems...in healthy learning communities" and that therefore there is always going to be tension between building skills and knowledge, and creating trust in a group (p. 199). They note that there is a tension between developing trust, and maintaining a level of debate that leads to knowledge growth:

Since disagreements over practices and problems are inevitable in healthy learning communities, there needs to be a way for practitioners to ensure their disagreements do not damage the trust needed to establish and sustain a learning community. (2006, p. 199) 
Robinson and Lai (2006) suggest that the tension can be dealt with in two ways. First, conceptualising disagreements as "theory competition" helps to depersonalise disagreements. This involves checking the accuracy and effectiveness of all competing theories in a group using the same agreed evaluation criteria, thereby enabling the group to test all ideas and theories before deciding together on what steps to take next. Second, tension can be dealt with by having "learning conversations" that enable the recognition of differences. These require group members to use strict rules during discussions in order to explore differences and to find common ground (2006, p. 199). These two practices ensure that barriers to growing knowledge as a group are overcome and respect is fostered. Hudson-Ross (2001) point out that respect is about heightening the "standards and expectations group members hold for one another and for new mentors they invite in.” (p. 443). Again, these practices link back to developing a culture of inquiry so that a critical examination of practice can take place.

Fullan and Hargreaves (1992) warn that some collaborative cultures in and across schools remain at a "comfortable" level where participants avoid the necessary tension discussed above. If teachers do not have opportunities to observe one another's work and to "inquire into and advise one another about their practice" (p. 74), the more difficult and necessary questions about their work and how to improve are not asked. Fullan and Hargreaves describe this less effective, comfortable collaboration as staying at an unchallenging level and as involving practices such as "advice-giving, tricktrading and material-sharing" (p. 75). Fullan and Hargreaves point out that to avoid a lack of positive tension between building relationships and skills and knowledge, it is important to value the fact that collaboration is not always easy. They found that "searching discussions and joint work which might expose disagreements" (p. 76) will push collaborative groups past "cosy relationships" towards "more challenging processes of inquiry" (p. 76).

\section{Indicators of effective and ineffective practices in collaborating schools.}

This review of the literature has considered collaboration for the purposes of learning and improvement to reach a common goal. The role of school leaders in enabling teacher change is an important consideration when collaborating for these purposes, as is the presence of inquiry-based practices. Tables 4 and 5 below provide lists that 
summarise the practices discussed throughout this chapter that can contribute to both effective and ineffective collaboration. This provides a succinct reference point for readers and can also guide later discussion of practices that emerge from data collection and analysis in this study.

Table 4

A Summary of Effective Practices from the Literature about Collaborating Schools

\section{Effective Collaboration to Build Skills and Knowledge Involves...}

Focussed teacher learning.

Horizontal learning connections (the development of knowledge with school practitioners rather than for them).

Checking to ensure that agreed knowledge and practices are actually used in schools.

Using evidence during teaching and learning by engaging in inquiry and knowledge building cycles.

Staff focussed on learning rather than teaching.

Opportunities provided for teachers to plan and negotiate the meaning of new knowledge and skills.

Having an unrelenting preoccupation with teaching-learning or teacher-learner connections (teacher practice is referenced to impact on students).

Contexts where group members can confront limits to their own knowledge, learn from common difficulties and challenge their beliefs.

Capacity-building networks.

Use of a framework that exposes and then focuses on improvement of teacher practice and establishes norms for professional interactions.

Members of learning communities remain focussed on positive change in thinking and practices.

Schools having a common needs-based focus.

Having a joint enterprise that is negotiated and agreed between members, that is defined by them, that is a stated goal and that enables mutual accountability for outcomes.

Valuing as important certain practices, discussing what matters and what does not. Showing any action or practice that makes it clear that the group follows spoken or unspoken rules or standards. 
Continually checking each other to ensure that rules and standards are not violated.

A collective belief that the community can achieve its desire outcomes.

Leaders who first identify the problem within their own schools and then find a group of local schools to work with who have a common interest in solving a particular part of the overall achievement problem.

Every member having the goal of trying to advance others' learning.

A leader who sets and maintains the focus on "improving student success".

Group members have a clear sense of purpose in the group and their roles in it.

Allowing issues of context to be addressed, ideas to be challenged and the effectiveness of the collaborative work to be checked (problem analysis).

Strong content being learnt and discussed which is useful to improve student outcomes.

Strong interpersonal interactions allowing community members to learn from each other.

No debate among the teachers over state policies and more focus on teachers' learning needs.

A "mix of learning experiences" (p. 238) is created for teachers that involves both a knowledge delivery approach as well as a co-constructing approach to knowledgebuilding for teachers.

Teachers are involved in negotiating the meaning of new knowledge through using data that indicates their progress towards desired goals.

A leader who can challenge teachers about the way they interpret data.

A shared understanding of what the collaborative group is doing and why.

The encouragement and motivation of others by "formal leaders" in the group. These leaders must also share their leadership role with others and provide support so that capacity is built in others in the group in areas that will allow the group's goals to be reached.

Formal leaders who hold the role of setting and monitoring the agenda.

Teachers have time to try things out and come around to agreeing on the practices that they will commit to.

Leaders who are willing to show vulnerability, and look for ways to involve the reticent or the opposed.

Managers and teachers who are participants and learners in a culture of investigation, 
experiment and mutual sense-making.

\section{Effective Collaboration to Build Relationships Involves...}

Building relational trust (respectful exchanges) between group members, even when people disagree.

Achieving personal regard between group members which shows the willingness of participants to extend themselves beyond the formal requirements of a job definition.

Trust based on professional ties, not personal ones.

A balanced professional focus on relationships as well as outcomes that are related to teaching and learning.

All members have clarity about their roles in accountability for cluster outcomes.

Task-focused challenges that disrupt current routines and practices, and result in doing something different.

Sharing expertise with challenging dialogue - challenge and critique or learning talk.

The presence of an external person to support critique and challenge within the collaborative group

Principals that establish both respect and personal regard among group members.

Leaders deliberately fostering the development of relationships between different teachers.

Teachers using conflict as a catalyst for positive change and improvement.

Fostering the presence of tension between building trust, and maintaining a level of debate that leads to knowledge growth.

Learning conversations that require group members to use strict rules during discussions in order to explore differences and to find common ground.

All group members valuing the fact that collaboration is not always easy.

Table 5

A Summary of Ineffective Practices from the Literature about Collaborating Schools

\section{Collaboration that does not Build Skills and Knowledge Involves...}

Failing to ensure that the underlying concepts and thinking in inquiry based practices are understood by those trying to engage in those practices.

Making the assumption that teacher change leads to improvement in student outcomes without checking for evidence.

Using teacher self-assessments as the only indicator of successful change in teacher 
practice.

Teachers not referencing their practices against outcomes for students.

The presence of a climate that may be too "positive" where members do not challenge each other.

No shared understanding among teachers about why they might take on any new practices.

A school leader that manipulates a school culture and its teachers to conform to his or her own vision.

No opportunities for teachers to observe one another's work and to inquire into and advise one another about their practice.

Staying at an unchallenging level. For example, using practices such as advice-giving, trick-trading and material-sharing.

\section{Collaboration that does not Build Relationships involves...}

Trust of the professional type, not the personal type.

Having a preoccupation with relationships.

Sharing expertise without challenging dialogue.

Having a critical friend with pre-existing relationships in the group or who is also in a position of power.

Teachers attaching their loyalties to cliques that allow them to segment themselves in ways that are detrimental to whole school development.

Valuing collegiality and friendship over challenge and conflict. 


\section{Chapter 3}

\section{Methodology}

In investigating EHSAS clusters, I aimed to develop an understanding of the collaborative practices from the perspectives of the adult participants. This chapter explains the methods used to collect and analyse data, and to generate a substantive Grounded Theory within the research context. First, the qualitative paradigm used to guide the methodology is described. Second the method of building a Grounded Theory is explained. Third, the research questions are provided and discussed. Fourth, data collection methods are outlined. Fifth, the data analysis using the Grounded Theory method is described and explained. Finally, the chapter discusses how the data has been presented in this thesis. Ethical considerations are discussed in terms of the need to mitigate personal bias as it related to my role as a civil servant, and someone who was involved in monitoring the implementation of the EHSAS project.

\section{Qualitative Paradigm}

This study investigated perspectives on the social practice of collaboration, hence a qualitative rather than quantitative paradigm was appropriate. A qualitative paradigm allows for inductive and deductive inquiry, which are both seen as "necessary to the investigation of meaning" (Northcutt and McCoy, 2004, p. 16). Therefore an emphasis is placed on the meaning that participants make of their social behaviours and on processes rather than actual outcomes. Induction allows information to emerge from the data and the movement from detail in the data to a more conceptual level. Deduction allows the researcher then to look to the research literature for information that supports the emergent theory.

\section{The Grounded Theory Method}

To develop an understanding of collaborative practice across schools in the New Zealand context, Grounded Theory method was chosen. This method allows the researcher to discover a substantive theory "based on actual data gathered through qualitative research" (Corbin and Holt, 2005, p. 49) and guides the analysis of interview 
and document data. Grounded Theory method is not a theory in itself. Theory is discovered from the data, as was intended by the founders of the method, Barney Glaser and Anselm Strauss (1967). The Grounded Theory method does not test a hypothesis. Instead it sets out to find what theory accounts for the research situation as it is. In this respect it is like action research: the aim is to understand the research situation. Given that I could not observe the collaborative practice first-hand, this particular method is appropriate for investigating the research questions in this study. Rather than relying on my own previous knowledge about collaborative practice or preconceived ideas about the clusters, I needed to rely on the reported experiences of the participants in my study.

In using Grounded Theory method the researcher avoids preconceived ideas as these may negatively influence the interpretation of data. Instead, the researcher asserts that for a truer picture of what actually is the case, the theory should evolve from the data itself. While Glaser and Strauss' (1967) original "pure” Grounded Theory method required the researcher to avoid engagement with literature, research or other prior knowledge on the research topic, later versions of the method recognise that often researchers have already engaged with their research topic before undertaking data collection. A researcher will often choose an area to investigate due to prior interest, or work related engagement in that area. In addition, universities often require a thesis student to conduct a literature review of the area to be researched during the proposal submission stage. For these reasons, this study follows later versions of the Grounded Theory method that allow for deductive processes such as engagement with literature to occur. Current Grounded Theorists recognise and understand that contextual issues can impact on inductive inquiry. For example, Dey (1999) points out that a researcher can be familiar with many different theories before developing a theory from his/her current research. The key to ensuring that the Grounded Theory method of analysis is truly underpinning the emerging theory is in "refusing to privilege any one theoretical perspective in advance of the ideas generated by the evidence itself" (pp. 3-4). Relevant literature can then be integrated into the Grounded Theory once there is confidence that the theory has emerged from the data. Therefore, material from the literature must earn its way into the theory, just like any other theoretical construct. 


\section{Development of Research Questions for the Discovery of Theory}

The research questions and guiding interview questions were developed following an initial review of the literature on collaborative practices within and across schools. A key point made by Glaser and Strauss (1967) is that categories "must not be forced on the data, they should emerge instead in the ongoing process of data analysis" (p. 43). Engaging with the literature allowed me to develop an understanding of collaborative practices, and the varying definitions of it that the participants were likely to have. In adhering to the Grounded Theory method (discussed in more detail in the next section) I ensured that the research questions were not a means of categorising emerging concepts in the data gathered.

The research questions were explored through interviews and document analysis. As the EHSAS project was no longer in place when I began this research, I was unable to observe collaborative practice and had to rely on gathering data through interviewing participants and examining milestone reports. Other research on collaborative practices in schools uses observations or surveys, together with interviews (Firestone and Pennel (1997); Katz et al. (2009); Little (2002); Rutherford and Jackson (2006); and HudsonRoss (2001)). In gaining insights from participants through interviews, and documents written by them, I was able to keep the focus firmly on their experiences and perceptions in relation to EHSAS project outcomes 1 and 3.

\section{Data Collection Methods}

The following data was collected to assist with my research:

1. EHSAS policy documents held by the Ministry of Education.

2. EHSAS cluster files held by the Ministry of Education:

- Final "expression of interest" and "proposal" applications and attachments.

- All annual milestone reports and attachments/appendices.

- All milestone report feedback from the Ministry of Education (and any cluster responses including emails, letters and revised reports). 
- All internal Ministry of Education monitoring documents (including project tracking "overview" spreadsheets, monitoring notes, minutes from cluster visits/meetings and e-mails following meetings with clusters).

3. Interview data from nine participants (three per cluster)

4. Participant feedback on data analysis and emerging concepts/theory

The constructionist version of Grounded Theory method used in this study values both the research participants' and the researcher's interpretations of the social situation under investigation. Therefore it is important to recognise participant involvement in building the Grounded Theory after the data collection process. Charmaz (2005) believes that "to develop a grounded theory for the $21^{\text {st }}$ century that advances social justice inquiry, we must build upon its constructionist elements rather than objectivist leanings" (p. 508). The constructionist version of the Grounded Theory method encourages the social construction of findings and the questioning and altering of findings. To ensure that this occurs, Corbin and Holt (2005, p. 52) suggest gaining participant feedback on interpretations of data related to their involvement in the research. Gaining such feedback enables co-construction of the final theory and modifications to the analyses as required.

Hammersley and Atkinson (1995) also support co-construction in research projects and describe this process as "respondent validation":

The value of respondent validation lies in the fact that the participants involved in the events documented in the data may have access to additional knowledge of the context - of other relevant events, of temporal framework, of others' ulterior motives for example - that is not available to the [researcher]. In addition, they have access to their own experience of events, which may be of considerable importance. Such additional evidence may materially alter the plausibility of different possible interpretations of the data (p. 228)

Reliability and validity is also enhanced by the transparency of the data analysis process. The coding and sorting process that guides data analysis in this study (as described in this chapter) provides a specific procedure for building a Grounded Theory 
in a structured way. This process is recorded through memos written by myself during data analysis and every level of categorisation of the data can be recorded and retraced in the tailored software programme entitled "NVivo8". This software contains several sorting functions allowing a researcher to identify possible causal relationships between categories in a consistent way. The data analysis process was applied to interview transcripts, milestone reports written by each cluster, monitoring notes made by the Ministry of Education about each cluster, and participant feedback on the initial results of data analysis. The use of NVivo8 allowed the individual statements that emerged from all of these data sources to be considered together or separately in order first to build the Grounded Theory and second, to consider whether or not every source of data contributed to that theory.

Semi-structured interviews were conducted face-to-face with the use of a voice recorder. I used the same standardised open-ended approach for all participants. The questions and their sequence were known to participants in advance. According to Cohen, Manion and Morrison (2007) this allows for some flexibility in how interviewees respond because there are no response categories given. The use of some structure with consistent wording and sequencing of questions in the interviews ensures that responses can be fairly reliably compared. I drew on the guide provided by Patton (2002) for the sequencing and wording of questions so that they were "open-ended, neutral, singular and clear" (p. 353).

I also followed guidelines from Charmaz (2005) on the use of open-ended questions in Grounded Theory research. Charmaz advises that devising a few, broad, open-ended questions allows the researcher then to use additional focus questions and to invite detailed discussion of any topic that may emerge during the interview (p. 26). Because this method of interviewing is open-ended, yet directed I was able to use prepared prompts and was also able to deviate from the interview script where necessary to gain a better understanding of what participants were telling me. Gillham (2000, p. 46) highlights the fact that prompts can ensure a degree of standardisation, which is critical when analysing data later. One key point that I took from Charmaz's advice is that "questions must explore the interviewer's topic and fit the participant's experience" (2005, p. 29). I ensured that I developed open-ended questions under each of my 
research questions and linked these to questioning participants about their experiences (see the interview schedule in Appendix A).

The interview questions were designed to draw out the participants' understandings about collaborative practice. Charmaz points out that a constructivist approach to interviewing "would emphasise eliciting the participants' definitions of terms, situations and events and try to tap his or her assumptions, implicit meanings, and tacit rules." (2005, p. 32). My research questions also had a focus on participants' perceptions and definitions, so it made sense to ensure that the interview questions followed this theme.

As a new researcher who had never conducted interviews before, I felt it was necessary to trial the questions as I developed them. Gillham (2000) supports this approach in his discussion of semi-structured interviews, emphasising the fact that trialling questions helps the researcher to get the questions right. It also assists a new researcher to get a feel for the interviewing process and "alerts you to the range of factors that give an interview flavour and direction" (p. 54). I was able to trial questions on a Principal who had been part of an EHSAS cluster that was not selected for my research. His feedback on the questions in terms of how stimulating and appropriate they were was invaluable. From that trial, I re-wrote, re-ordered and removed questions that made the interview seem repetitive or uninteresting to the interviewee. According to Gillham: "Questions that are significantly different in character are likely to be more motivating for the interviewee" (p. 54). The trial process also allowed me to listen to my own interviewing style and critique it. I discovered that my obvious nervousness intruded on my ability to make the participant feel at ease and I left out critical aspects of the interview process, such as building a rapport, establishing a context at the beginning of the interview, and ending the interview with an opportunity for the participant to ask questions or clarify thoughts. These are all points recommended by Gillham (p. 37), which I had forgotten about in the "heat of the moment", so I wrote further notes about those important things on the question sheet to guide me during the interview. In turn this reduced any nervousness felt by the participant or myself.

Prior to all interviews, I ensured that participants had a clear idea of why they were being asked to take part in the study and what the purpose of the interview was. They were also given an idea about the likely length of the interview and I met each 
participant in a location suitable to them. Almost all participants chose to have me visit them in their schools during non-teaching periods or after school. I ensured that I explained my research project again at the interview and asked participants if they had any questions. I then checked that I had permission to record the interview and discussed confidentiality with each participant. According to Gillham, taking care of this type of detail is important in establishing a good interview process (2000, p. 38).

While I listened carefully and tape-recorded all of the interviews, I also made a few notes during the interview, so that I could recall what was said and use that information in later questions. I found that this did not seem to interrupt the flow of the interview and the participants appeared to be comfortable with my approach. In two interviews (with principals) we were interrupted by daily business that needed urgent attention, but again, there was no issue with this in terms of impact on the flow of the interview.

The length of interviews ranged from 25 minutes to 80 minutes, with the majority being around 40 minutes in length. The variation in length appears to be due to the person being interviewed, rather than interviewer's style. Some participants articulated their experiences and knowledge through storytelling and lengthy descriptions, while others were more succinct, and used terminology to describe their experiences.

\section{Selection of Cluster Sample and Interview Participants}

In an attempt to reduce as many variables as possible, I decided initially to select EHSAS clusters with similar characteristics. Considerations included clusters that:

- had similar funding (per pupil);

- had the same number and type of schools involved; and

- came into EHSAS in the first or second cohort and therefore had been in the project long enough to have provided at least two milestone reports.

In order to ensure transparency of selection, I established an advisory group for my research project that consisted of two Ministry of Education staff members who had been in some way involved with the project. They were:

- a long standing member of the Steering Group for EHSAS, who had been on the group since its inception in 2005; and 
- a Chief Adviser who had run workshops and seminars for EHSAS learning communities since the first year of implementation in 2006.

The role of the advisory group was to provide me with feedback on my draft research proposal, and then to assist me in developing the criteria (above) for selecting the sample. In early 2010 the group approved the final sample selection and other criteria for selecting interview participants. Transparency of selection was ensured by the group through their independent selection of the sample using the criteria we had developed together. Their independent selections matched my own, showing that the criteria left no room for doubt as to which clusters were most appropriate for the sample.

In selecting the clusters, I started out with a list of all EHSAS clusters from the first two cohorts. I eliminated the third cohort of clusters from the selection process because they had only been operating as clusters in EHSAS for a short period of time and would not have produced the same amount of data for analysis when compared with the first two cohorts. Finally, the advisory group and I agreed on the four clusters that emerged from the list as being reasonably similar and the advisory group agreed to the final selection.

I made contact with representatives from each of the four clusters to request their involvement in my research. One declined, one never responded to e-mails or telephone calls, and the other two accepted my invitation. I discussed this with my supervisor and we agreed I should return to the shortlisted clusters to select one more suitable cluster with whom to work. I went back to our original shortlist in order to find the next closest match.

In the original selection I had selected four clusters that had between four and six schools involved and that were all primary (including area) schools. ${ }^{7}$ In addition to this, two clusters had to be from the first cohort and two from the second cohort. There were only two suitable clusters remaining on the shortlist and the advisory group was asked to select the new one from these two and then get back to me with their choice and reasoning. Both group members chose the same cluster due to its similarity to the

\footnotetext{
${ }^{7}$ Area schools (also known as "composite" schools) are schools that cover a larger geographical area and include students from Year 0 up to Year 13.
} 
others in terms of school types in the cluster. I then approached the representative of that cluster and she agreed to take part in the research.

Three participants from each cluster were invited to take part in tape recorded interviews. I invited two teachers from each cluster who were more fully involved in the EHSAS project. I also wished to conduct a recorded interview with one key leader involved in each project, such as a Principal, facilitator or project manager, all of whom were more fully involved since the design stage of the project. Each cluster was able to volunteer the participants that I asked for.

\section{The Process of Data Analysis: My Role as a Constructivist Grounded Theorist}

With the ultimate goal of building a substantive Grounded Theory, I did not test a hypothesis or pre-existing theory from the literature as such but rather, considered the theoretical underpinnings and implications of any categories that arose from the data (Bryant and Charmaz (Eds.), 2007). In doing this I used the guidance of many different Grounded Theorists (as noted later in this chapter).

Developing a substantive Grounded Theory involves an iterative process where a researcher looks for broad concepts that emerge from categories of data. As Bryant and Charmaz state, this is never "wholly inductive" because during analysis the researcher uses his/her own prior knowledge to analyse the data and define categories towards a theory. A fine balance is required between a researcher using prior knowledge to categorise the data, and as much as possible allowing the data to speak for itself, so that unexpected concepts and ideas can emerge.

Figure 1 provides a model of the process that I used to analyse the data collected from the interviews, milestone reports and other documents. Overall, Charmaz (2005) recommends that a "constructivist grounded theorist" should ensure that an emphasis is placed on the qualitative information found, rather than on the specific methods that are used to find it. Put in Charmaz's terms, my analyses were “interpretive renderings of a reality, not objective reportings of it" (p. 509). 


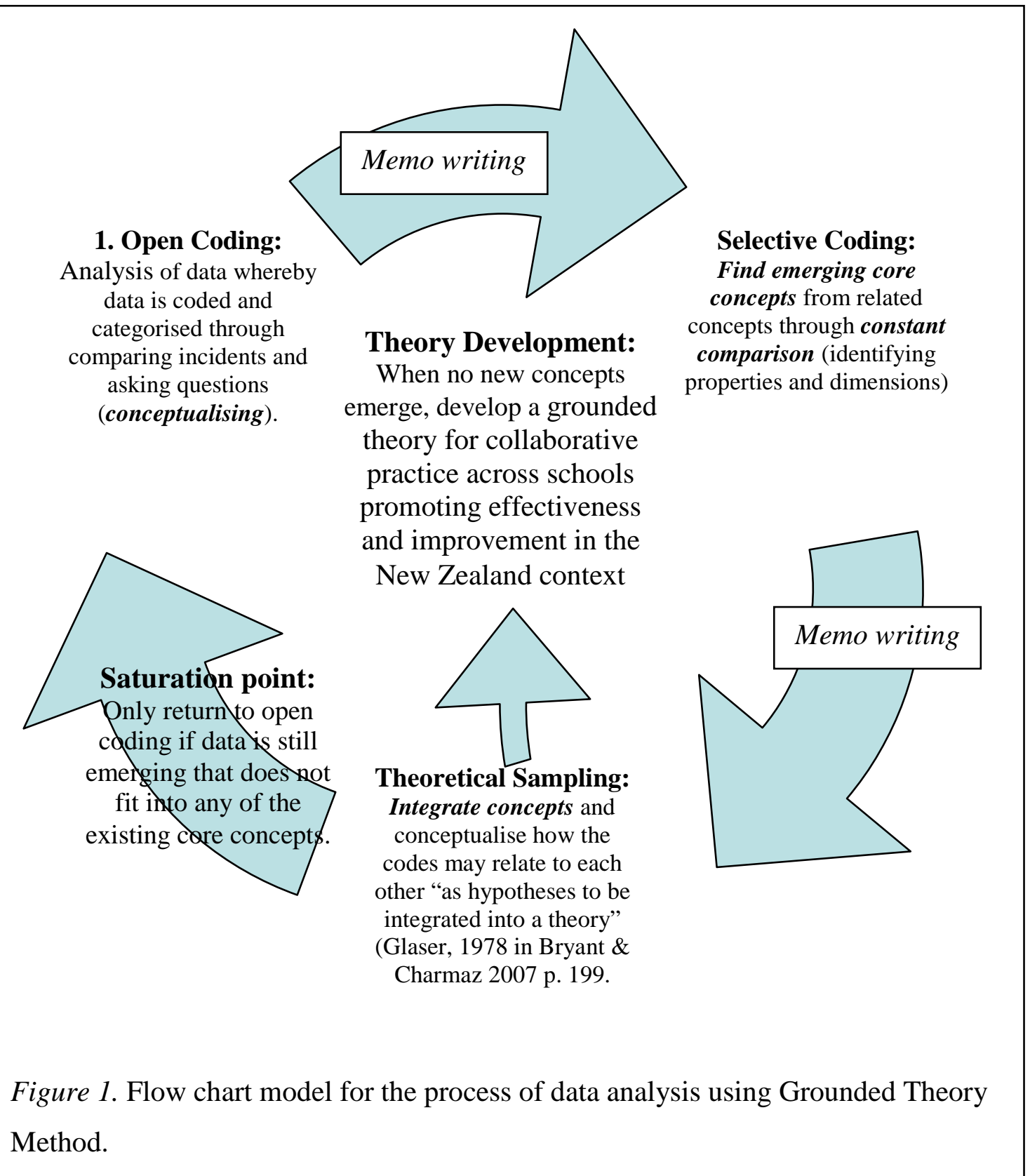

Open Coding.

As demonstrated in Figure 1 above, the Open Coding process involves examining data in order to categorise the experiences of collaborative practices reported by participants and to look for similarities and differences in their perceptions (Corbin and Holt, 2005, p. 50). Such a process can be done manually, or by using software such as NVivo8. Using this software assists the researcher in dealing with large amounts of data, so that he/she can move quickly to further analysis and categorisation of individual statements in the data. 
Traditionally, according to Dey (2007), “A well-defined category will have attributes that are jointly sufficient and singly necessary to identify the category. Only members of the category will possess all these attributes, and all the members of the category will possess each one of them" (p. 169). However, Dey points out that many researchers have discovered the need for flexibility in categorising data, ensuring that context is acknowledged, allowing for coherence of categories through using approximation to assign data to a category. I have followed this less traditional way of categorising data.

As individual statements are selected during Open Coding, their properties and dimensions are identified and they are grouped together into categories. Corbin and Holt (2005) term these "distinct events/incidents in the data" (p. 50) and explain that they are the emerging different practices that can be pooled under the heading of a particular category.

When grouping the data into categories, the Grounded Theory researcher does not describe the data but instead conceptualises it by explaining a pattern of behaviour (or issue or concern) in the social setting being researched. Holton (2007) advises that while "initial attempts at coding may be descriptive" the researcher must raise an analysis to a conceptual level as early as possible. Any descriptions that emerge can serve as "indicators" for a category (p. 270). To help with conceptualising each individual statement, I used a series of questions offered by Holton:

What is this data a study of?, What category does this incident indicate?, What is actually happening in the data?, What is the main concern being faced by the participants?, and What accounts for the continual resolving of this concern? (2007, p. 275)

All data from the EHSAS interviews and documents were entered into NVivo8. This allowed the fast identification of individual statements about collaborative practice in the data which were selected and stored. Each statement was then considered and compared with others and grouped together into broader "categories". 


\section{Selective Coding and Theoretical Sampling.}

The Selective Coding process can occur throughout the initial Open Coding phase. When the researcher begins to integrate categories and conceptualise how individual statements may relate to each other, a combination of Selective Coding and Theoretical Sampling is used. Those processes involve constant comparison of the categories and the identification of the themes that are most represented in all of the data.

Constant Comparison involves contrasting individual statements in the data to develop categories, then comparing more statements to fit into the developed categories. Finally the developed categories are put side by side in order to identify links and integrate them into hypotheses that become theory. The integration is called Theoretical Coding (Holton, 2007, p. 278).

In describing Theoretical Coding, and the transformation of the categories and their properties and dimensions into a theory, Corbin and Holt (2005) advise that one must find out what is going on in the research in a larger sense. The process simultaneously integrates categories and identifies the themes that are most represented in all of the data. At this point, if further data analysis occurs, each new set of data should fit into the categories already identified. If it does not, then "saturation point" will not have been reached and the researcher would need to return to earlier conceptualising phases (Corbin and Holt, p. 51). In returning to earlier phases of the analysis, the researcher samples "new settings which might illuminate through further comparison the properties and relationships of emerging categories" (Dey, 2007, p. 186).

It may be that saturation point is never reached in a study. Glaser and Strauss claim that "the published word is not the final one, but only a pause in the never-ending process of generating theory" (1967, p. 40). As Corbin and Holt (2005) have noted, the end result of research with a Grounded Theory approach is to develop a theory, not to list themes or describe phenomenon. 


\section{Data presentation and theory development.}

Seven themes emerged from the initial analysis of the data. I used these themes to organise the results in Chapter 4. In Chapter 5, I discuss the findings, comparing them to other research literature and making observations about their implications.

The results in Chapter 4 of this thesis included a process whereby feedback was sought from the nine research participants, to whom I sent an early draft of the written results, requesting their feedback (see Appendix B). However, I only received feedback from two participants, each from a different cluster and each of whom indicated that he/she had no further comment to make.

\section{Memo writing.}

Corbin and Holt (2005) emphasise "memo writing" as a way of assisting the Grounded Theorist to build theory from evidence. Memos are written records of the researcher's thoughts, interpretations and directions and enable the researcher to keep track of evolving concepts and complex ideas during data analysis and the building of the Grounded Theory. Memos help to ensure that the researcher is reflecting on the need to be open minded, despite his or her own preconceived ideas (Corbin and Holt, p. 51). Stern (2007) also supports memo writing, stating that "once categories have been developed, clustered, and expanded, the analyst needs to sort [the memos] according to categories and properties...Sorting helps the analyst integrate the theory" (p. 52).

In writing memos, I used guidance from Lempert (2007) who asks questions such as: "What is this an example of? When does it happen? Where is it happening? With whom? How? Under what conditions does it seem to occur? With what consequences?" (p. 249). I then created categories and further analysed their characteristics and the relationships between them. This type of analysis often raised further questions in my memos and those questions sometimes became the basis of more categories to be explored. Lempert has claimed, "As the analysis develops, the content of memos improves in depth and quality of conceptualization, and ultimately of integration" (Lempert, p. 249). 
The memo writing process was not always neat and tidy and often did not show complete coherence of thought in the early stages. Lempert supports this style by stating:

Reflecting the social lives that they interpret and the interactional social positions of the researcher and his/her respondents, memos, especially early ones, are often messy and incomplete... a memo need only be the account of a researcher talking to him/herself. (2007, pp. 248-249)

In the later stages of analysis and theory development, I began to integrate the ideas and themes from all of my memos. As Lempert (2007) points out, and as was the case for me:

The reviews often result in a shift in focus, or a reconfiguration of my analysis, or integrations of what were formerly disparate pieces of analysis, and/or a reconstitution of my argument. I integrate these changes in additional memos that become the basis for publishable work. (2007, p. 254)

Lempert (2007) is of the view that "inexperienced researchers might also force a too early analytical framework on the data". To avoid this it was necessary for me to "embrace the uncertainty and to have extensive data to analyze" (p. 249). I had to remind myself constantly that, as Lempert puts it: "Not every memo is going to be relevant to the final narrative. Some may be totally irrelevant. And all memos are partial and provisional" (p. 251).

\section{Ethical Considerations}

As previously noted, an integral part of my research involved interviewing participants and asking them to assist me with the validity of my analyses through participant feedback. Therefore, I asked selected cluster members to participate in the research and then gained their informed consent. Information sheets and consent forms were signed by all participants (see Appendix C). 
Conducting interviews may not have been ethically appropriate if issues of power and control connected to my role as a Ministry official existed in my relationship with participants. EHSAS cluster members may have felt pressured into providing certain information, or to answering questions that ensured that their projects were not compromised by what could be seen as "extra monitoring" by myself as a civil-servant. I can never be entirely certain that those issues and my continued employment by the Ministry of Education did not have an influence over the information provided by the cluster members through both interview and documents, and I have acknowledged this as a possible limitation to this study. I made it clear to participants that the research was being conducted by myself as an independent student at Victoria University of Wellington, and that I no longer worked in the EHSAS team at the Ministry of Education.

As I have explained in Chapter 1: Introduction, the National Government's "Budget 2009" confirmed that the EHSAS project was to be discontinued from the end of 2009. Final funding payments were approved and made to the clusters on 1 July 2009. In addition to this, since I no longer worked directly in the EHSAS project while conducting this research, I did not have a monitoring role with the clusters. This further mitigated against any concerns that participants may have had during this research about extra monitoring or a reduction of project funding for the schools involved in EHSAS.

The process for requesting information from the Ministry of Education for my research involved writing a letter to the Group Manager of Curriculum, Teaching and Learning Implementation, requesting access to nominated files for the initial selection process under the Official Information Act. A separate request for copies of all monitoring and reporting documents related to the final selection of clusters was also made, and the Group Manager of Schooling Policy provided further background policy documents in response to a request under the Official Information Act. All EHSAS cluster documents from the application process through to milestone reports and monitoring notes are accessible to the public. There was no requirement to seek permission from the Ministry of Education to use the data that was obtained through Official Information Act requests. However, it was ethically appropriate to ensure that the cluster members I approached were aware of the documents that I would be accessing in this way, so that they could make a fully informed decision about whether or not to take part in the 
research. At the time that cluster members wrote their milestone reports, it was unlikely that they envisaged these documents being used for research purposes. To this end, the information sheet that was provided to all invited participants explained what data would be collected and how. Participants accepted or declined involvement of their cluster based on that information.

The anonymity of the research participants has been maintained, from the individual level to the school and cluster level. Data collected during the research process was kept in secure drawers at the Ministry of Education in Wellington or in locked cabinets in my home.

Chapter 4: Results, provides the results of my analysis of the data and guides the reader through my use of the Grounded Theory process as outlined in this chapter. 


\section{Chapter 4}

\section{Results}

This chapter reports the experiences and perceptions of EHSAS participants and clusters as they unfold without the imposition of external evidence or judgements about the quality of the practices. These are based on excerpts from data that described EHSAS leaders' practices, the analysis of the interview transcripts and other cluster documents, and the identification and analysis of practices and their relationships, patterns and consequences.

This chapter is organised into two main parts. The first part, entitled Categories that Emerged from the Data outlines the results of the analysis processes termed Open and Selective Coding (as described on page 56 in Chapter 3). The second part, entitled Raising the Data to Grounded Theory outlines the themes or ideas that were most representative in all of the data that emerged through the Theoretical Sampling analysis process (as described on page 56 in Chapter 3). This is where the analysis is raised to a more conceptual level and connections between categories are considered in order to find the core constructs of the categories. The connected components and the underlying patterns of EHSAS leaders' beliefs and practices are described as well as the purposes of those practices and their intended consequences. The emerging patterns begin to build the Grounded Theory.

\section{Categories that Emerged from the Data}

An overview of the results of a combination of Open and Selective Coding of the data is provided in this section. This comprises the initial process of analysis. It is then followed by a deeper analysis to establish and understand the themes that were most represented in all of the data. The nine interview transcripts, and three sets of cluster documents that comprised the sources of the data were stored in NVivo, enabling me to examine the data and select individual statements that were made by participants about the practices they used. The individual statements that emerged from this process were compared with each other, and then sorted according to their similarities and differences. 
The statements that emerged from Cluster A fell into a total of 18 categories (see Appendix D) which provided brief descriptions of the behaviours that they represented. This was a first attempt at conceptualising the data in order to understand the main concerns and experiences of the participants. The category names were short sentences or single words summarising the properties within them.

Following Open and Selective Coding and Constant Comparison processes the data from Cluster B produced new and revised categories. Appendix E lists these, and identifies the 11 categories that emerged as completely new, as opposed to those categories that were added due to Constant Comparison with data from Cluster A. As concepts about participants' experiences became clearer when considered alongside new data from other clusters I created new categories.

Following the same analytical process again and using the data from Cluster C, I identified four new categories. These are outlined in the table in Appendix F which illustrates each of these new categories as representing only one or two participants. The table also outlines the existing categories that were revised through further Constant Comparison with the new data, and category names were changed or split in two.

These results indicated that saturation point had not yet been reached. However, given the few new categories emerging from the third cluster's data, and the few participants that those categories represented (see Appendix F) I was satisfied that I was near enough to saturation point to move to the next stage of analysis. Furthermore, time constraints did not allow me to return to the field to gather data from a further cluster. This was an unavoidable limitation of the study.

Memos were written after the dataset for each cluster was analysed. The contents of these inform parts of this chapter. For example, when I conducted the Open Coding of the data from Cluster A, particular ideas seemed to be rising above the other data. I noted in a memo that many codes appeared to be fitting into particular categories, such as Trust and Hierarchy. My thinking about these and other categories discussed in memos is included throughout the remainder of this chapter and the next. 
Participants' discussion about impacts on students were largely in response to the oral interview questions about student achievement (see Appendix A). The other categories emerged from a range of data sources or interview questions. Apart from writing brief memos discussing categories, I did not undertake any further analysis at this stage as the Selective Coding process itself was sufficient to conceptualise how individual statements related to each other. At this early stage of analysis, category names reflected the thinking that occurred as data was sorted.

\section{Raising the Data to Grounded Theory}

Once I had undertaken analysis of data from each cluster, I then conducted one further iteration of Selective Coding and Constant Comparison across data from all three clusters. This required me again to contrast and compare incidents in the data to develop new or existing categories. This process resulted in a final list of 70 categories as copied from NVivo8 (see Figure 2 on the following pages).

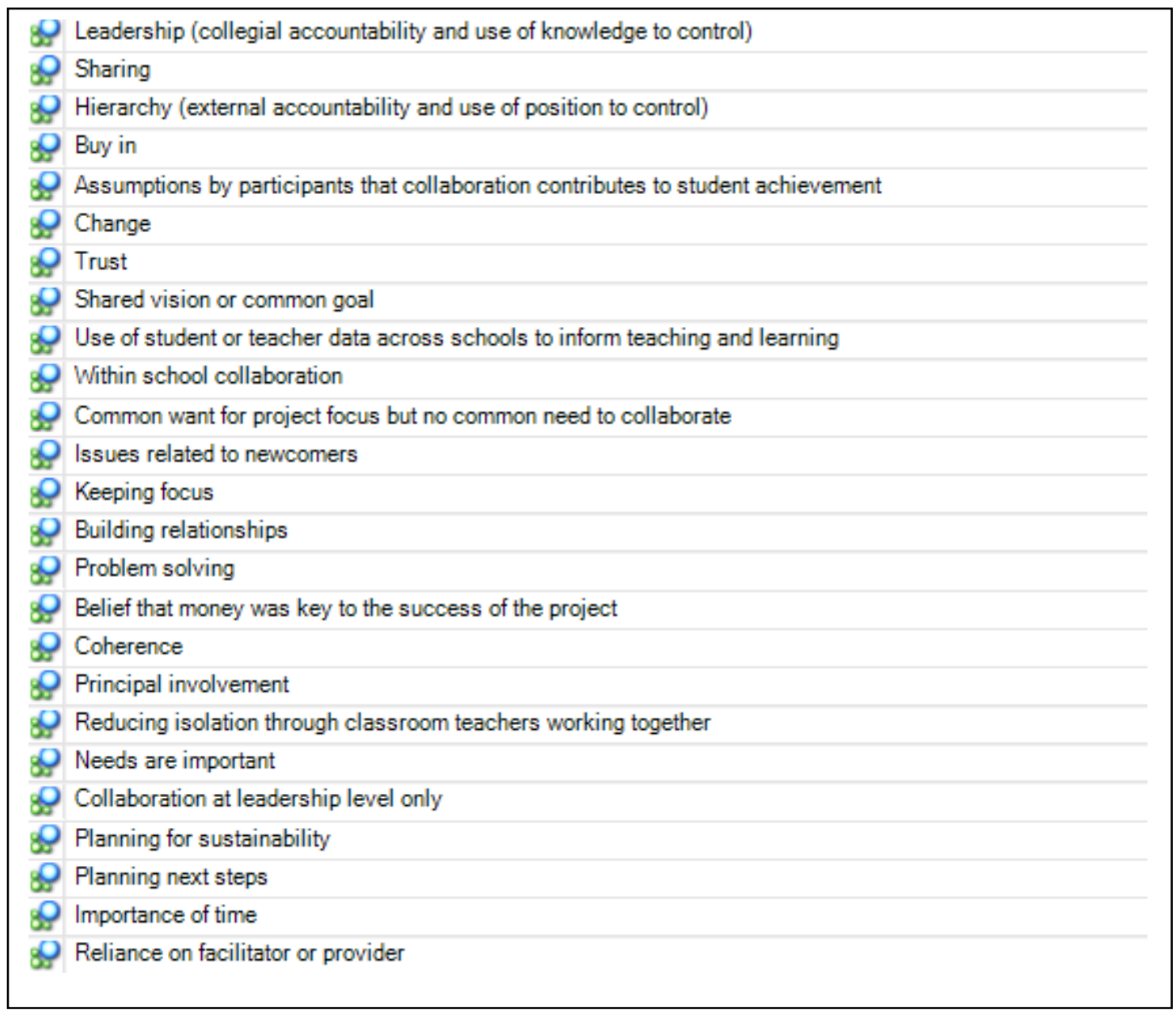




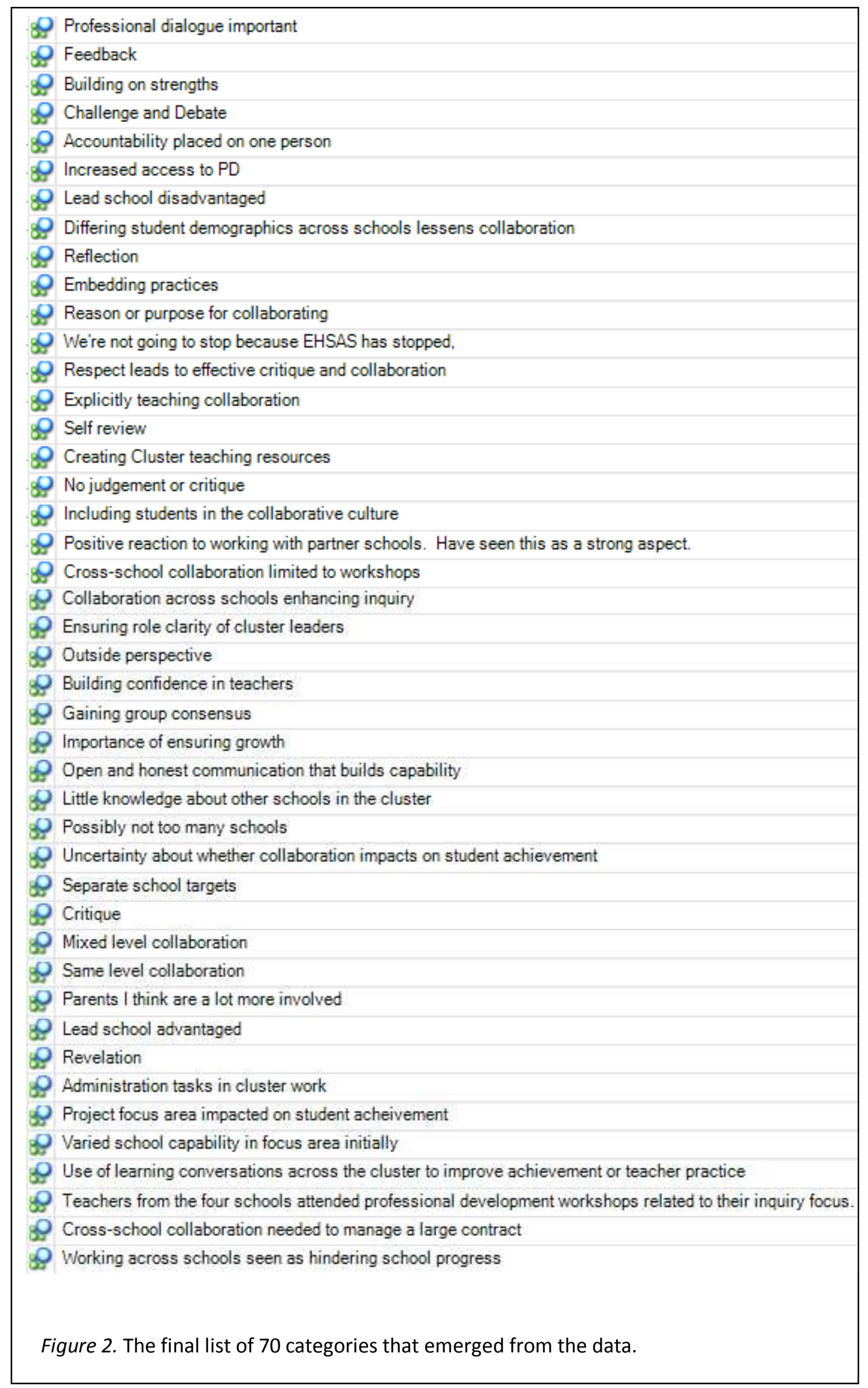


The next step was to identify the categories that were most represented in all of the data. To find these I used NVivo8 to search for categories where 11 or 12 data sources were represented; and categories with more than 21 individual statements representing all nine participant interviews. ${ }^{8}$ This allowed me to locate the categories that were most representative of all three clusters and all nine participants that were part of the study. I could then spend more time analysing those categories and less time on categories that only represented one or two clusters, or very few participants. Seven categories emerged from this sorting process. Table 6 shows two of the seven categories that contained data from all nine participant interviews and had at least 21 individual statements.

Table 6

Categories with a High Number of Statements where all Nine Participants were Represented

\begin{tabular}{|l|l|l|}
\hline Category & Number of sources & $\begin{array}{l}\text { Number of individual } \\
\text { statements }\end{array}$ \\
\hline Hierarchy & 10 & 57 \\
\hline Commitment of Teachers & 10 & 48 \\
\hline
\end{tabular}

Table 7 shows the remaining five categories that contained data from 11 or 12 sources.

Table 7

Categories Representing 11 or 12 Data Sources

\begin{tabular}{|l|l|l|}
\hline Category & $\begin{array}{l}\text { Number } \\
\text { of sources }\end{array}$ & Number of individual statements \\
\hline Leadership & 12 (all) & 125 \\
\hline Sharing & 12 (all) & 75 \\
\hline Changing Teacher Practice & 12 (all) & 38 \\
\hline $\begin{array}{l}\text { Assumptions by participants that } \\
\text { collaboration contributes to } \\
\text { student achievement }\end{array}$ & 11 & 38 \\
\hline $\begin{array}{l}\text { Fostering a Common Vision or } \\
\text { Goal }\end{array}$ & 11 & $\begin{array}{l}21 \\
33 \text { (two categories merged into one) }\end{array}$ \\
\hline
\end{tabular}

\footnotetext{
${ }^{8}$ By "data sources" I mean all nine participant interviews and all documents that were used in the coding process. That is, nine interviews (three for each cluster) and three sets of documents (one set for each cluster) containing annual milestone reports, Ministry monitoring notes, and cluster applications and plans.
} 
The fourth category in Table 7 (Assumptions by participants that collaboration contributes to student achievement) represented participants' perceptions about the effect of collaborative practices on student achievement. It was removed from the list of categories that were most represented in all of the data because it contained only data that participants provided in answer to the interview question: "Did you perceive collaborative practice as making a difference to student achievement?" It could not therefore be considered as information that emerged naturally through the discussion about collaborative practice. I then decided that as this data was a direct result of my questioning, it could be used instead to describe the intended consequences of participants' practices, and to inform the final Grounded Theory. The other six categories contained information that appeared to have emerged more naturally through discussions about collaborative practice. I was not able to link those individual statements back to one particular interview question. Therefore, there were a total of six categories that were most represented in all of the data.

During Open Coding, it was sometimes appropriate for me to place individual statements in more than one category. For example, a statement that was suited to the Changing Teacher Practice category could also be suited to the Problem Solving category. These incidents in the data are where connections can be seen between categories. In order to locate such connections between the six main categories and all other data, I returned my focus to all 70 categories to see what was going on in a larger sense. This process is the initial stage of Theoretical Sampling, as described in Chapter 3: Methodology (p. 56) and would allow me to find themes that are most represented in all of the data, thereby identifying links and integrating them into the final theory.

The first step in this process was to compare data across the six main categories (see Tables 6 and 7) with all 70 categories that emerged from the Open and Selective Coding process, in order to find connections. Table 8 on the following page shows the results of this comparison. The 27 categories that emerged contained data from at least one of the six main categories (labelled A to F in the table). All other categories that did not contain data from the six main categories were dismissed from any further analysis. 
Table 8

Results of the Process to Determine the Constructs that were most Represented in all Data.

\begin{tabular}{|c|c|c|c|c|c|c|c|}
\hline & A & B & C & D & $\mathbf{E}$ & $\mathbf{F}$ & $\begin{array}{c}\text { Intercon- } \\
\text { nectedness } \\
\text { across core } \\
\text { categories }\end{array}$ \\
\hline SHARING (A) & & & 1 & & & & 1 \\
\hline LEADERSHIP (B) & 1 & & 1 & 1 & 1 & & 4 \\
\hline CHANGING TEACHER PRACTICE (C) & 1 & 1 & & 1 & & 1 & 4 \\
\hline HIERARCHY (D) & 1 & & & & 1 & & 2 \\
\hline $\begin{array}{l}\text { FOSTERING A COMMON VISION OR GOAL } \\
\text { (E) }\end{array}$ & & 1 & 1 & 1 & & 1 & 4 \\
\hline COMMITMENT OF TEACHERS (F) & 1 & 1 & 1 & & 1 & & 4 \\
\hline PLANNING FOR SUSTAINABILITY & & & & & & 1 & 1 \\
\hline $\begin{array}{l}\text { POSITIVE REACTION TO WORKING WITH } \\
\text { PARTNER SCHOOLS }\end{array}$ & & & & & & 1 & 1 \\
\hline PROBLEM SOLVING & 1 & 1 & & & & 1 & 3 \\
\hline ISSUES RELATED TO NEWCOMERS & & & & & 1 & 1 & 2 \\
\hline $\begin{array}{l}\text { USE OF STUDENT AND TEACHER DATA } \\
\text { ACROSS SCHOOLS TO INFORM } \\
\text { TEACHING AND LEARNING }\end{array}$ & & & 1 & & 1 & & 2 \\
\hline $\begin{array}{l}\text { RESPECT LEADS TO EFFECTIVE } \\
\text { CRITIQUE... }\end{array}$ & & & & & 1 & & 1 \\
\hline TRUST & 1 & 1 & & & 1 & & 3 \\
\hline REFLECTION & & & 1 & & & & 1 \\
\hline PROFESSIONAL DIALOGUE IMPORTANT & 1 & 1 & 1 & & & & 3 \\
\hline FEEDBACK & 1 & & 1 & & & & 2 \\
\hline NEEDS ARE IMPORTANT & & & 1 & & & & 1 \\
\hline WITHIN SCHOOL COLLABORATION & 1 & & 1 & & & & 2 \\
\hline CASCADE OF INFORMATION & 1 & 1 & 1 & & & & 3 \\
\hline $\begin{array}{l}\text { ASSUMPTIONS THAT COLLABORATION } \\
\text { CONTRIBUTES TO STUDENT } \\
\text { ACHIEVEMENT }\end{array}$ & 1 & 1 & 1 & & & & 3 \\
\hline PRINCIPAL INVOLVEMENT & & 1 & & & & & 1 \\
\hline BUILDING RELATIONSHIPS & & 1 & & & & & 1 \\
\hline $\begin{array}{l}\text { WE'RE NOT GOING TO STOP BECAUSE } \\
\text { EHSAS HAS STOPPED }\end{array}$ & 1 & 1 & & & & & 2 \\
\hline $\begin{array}{l}\text { COLLABORATION AT LEADERSHIP } \\
\text { LEVEL ONLY }\end{array}$ & & 1 & & & & & 1 \\
\hline $\begin{array}{l}\text { ENSURING ROLE CLARITY OF CLUSTER } \\
\text { LEADERS }\end{array}$ & & 1 & & & & & 1 \\
\hline $\begin{array}{l}\text { REDUCING ISOLATION THROUGH } \\
\text { TEACHERS WORKING TOGETHER }\end{array}$ & 1 & & & & & & 1 \\
\hline BUILDING ON STRENGTHS & 1 & & & & & & 1 \\
\hline PLANNING NEXT STEPS & & 1 & & & & & 1 \\
\hline Connections (total/27) & 14 & 14 & 12 & 3 & 7 & 6 & \\
\hline
\end{tabular}

From this point forward, the six main categories labelled A to F in Table 8 and identified earlier as most represented in the data will be referred to as "themes". Table 
8 shows that Sharing was frequently connected with the other categories, appearing in 14 out of 27 of them, but it only appeared in one of the five other themes. Leadership was also frequently connected with the other categories, appearing in 14 out of 27 of them and was represented in four of the five other themes. Changing Teacher Practice appeared in 12 of the 27 categories and, like Leadership, it was represented in four of the five other themes. This means that Leadership and Changing Teacher Practice were more significant themes than Sharing. The other three themes were represented far less across the 27 categories, but two of them were represented in four of the five other themes.

NVivo8 was able assist me in identifying connections between categories, but it could not describe those connections. To explore exactly how and why connections were formed, I read through the data for each category noting key ideas. I found, for example leadership ideas in other categories, and then returned to the raw data sources stored in NVivo8 to analyse why this should be so.

I drew the following conclusions. First, leaders perceive that leadership is essential for enabling change in teacher practice and second, leaders' experiences of collaborating reveal the connections between the Leadership and Sharing themes. I address these points in the following section and then propose that the EHSAS leaders' focus on change in teacher practice is at the core of their collaboration with links to Sharing, Hierarchy, Commitment of Teachers and Fostering a Common Vision or Goal themes. Finally, I outline the EHSAS leaders' perceptions about the consequences of their practices.

\section{Leadership is essential for EHSAS cluster work.}

In the Introduction to this thesis, I explained that I had specifically asked for participants in my research who had been fully involved in EHSAS cluster work. As a result, each cluster volunteered participants that were either Lead Teachers or Principals. This research cannot be representative of classroom teachers' or student experiences. Rather, it is ultimately about cluster leaders' perspective. Each leader perceived some type of leadership as being essential in the cluster work. According to the leaders, essential elements of the leadership role included their collegial 
accountability and their monitoring of the progress of each other and the project as a whole, and their use of knowledge to lead and mentor others.

All participants made explicit statements about the need for leadership within EHSAS clusters. For example, in response to being asked what types of structures should be in place for effective cluster work, Participant A2 claimed: "You've gotta have some sort or direction and leadership". Similarly, when asked about her role in the cluster, Participant A1 explained that leadership must drive the project:

The principals? Well, because of my own study and my own belief that unless a principal is driving something and is part of something, don't bother putting your school into it.

Participant B1 emphasised the role of leadership in having and driving a vision for the project: "You've really got to have somebody at the top that has a clear vision". A milestone report for Cluster $\mathrm{C}$ showed a similar belief: "the key to this success was completing this as a leadership team so we were able to drive this together" and Participant C1 (Cluster C) explained: "It all comes from the leadership again because if that leadership doesn't bring it back then it doesn't happen". These excerpts and others from participants involved in this study provide evidence that without exception, all EHSAS cluster leaders believed that their leadership was essential to their projects.

Moreover, it was apparent through some participants' discussion of an equal sharing of authority over the project and its outcomes, that collegial accountability among leaders was important. It allowed leaders to monitor each other and teachers in the cluster. Participant B1 (Cluster B) noted that at the beginning of each year "principals worked together to plan out the year's work" and Participant B3 (Cluster B) confirmed this by saying that "as a group of principals, we met together, we decided where the next steps were to be for us". A milestone report for Cluster C made the following statement in relation to equality in leadership across the cluster: "I think the key to this success was completing this as a leadership team so we were able to drive this together".

However, Leadership was not always shared equally in project implementation. Cluster A placed a heavy reliance on a hired facilitator who seemed to be a key leader in this 
area who controlled the entire cluster, from running staff meetings to working with individual teachers to change their practices. Participant A1 described that facilitator's role clearly:

Participant A1: The facilitator was doing the work. Remember it wasn't us and the facilitator touched base all the time with the principals, and all the time with the um programme managers $[\ldots]$ and she took staff meetings each term in each of the schools and perfected what was happening, and could also say "oh you need to go and look at such-and-such school”, so having that one common link. You know what, some of the EHSAS things, it just happened in each school. This, by having one common person, pulled all the strands together. We didn't do any of the data crunching, that was her job. She pulled all the data in but we could all look at each other's data.

This participant's comments about how the facilitator "touched base" with leaders indicates a belief that leadership presence was still essential, even though a facilitator was leading the work. It appears that the leaders each monitoring roles that made them accountable to each other and that allowed them to look at each other's data. This seems to have been the leadership presence that they believed was essential in the cluster.

When Principals led the planning and coordination of cluster work, kept the focus on the cluster's desired outcomes, and worked with lead teachers to ensure that their own and classroom teachers' capability was improved, monitoring roles were also evident. As noted in a milestone report for Cluster A: "Lead teachers were also expected to undertake observations of colleagues and improve teacher capability by giving feedback". Cluster A's project plan (written by self-nominated cluster members as part of the Proposal stage of the application process) noted the following: "Lead teachers will participate in a programme to create a sustainable system for maintaining and developing effective teacher practice through building the skills of lead teachers to give quality feedback to colleagues".

Two of the nine interviewees also discussed how they undertook observations of colleagues after receiving professional development. As Participant B2 states: "As the 
team leaders we then went back to our schools with observation type sheets and really clear guidelines of what we were going to be looking for when we went into classrooms".

The use of knowledge to lead was evident when participants discussed how leaders (principals and lead teachers) used their pedagogical knowledge to design and demonstrate project outcomes. They were seen by interviewees (all of whom were also principals or lead teachers) as experts leading professional development in the cluster by actively taking part in it and then passing the knowledge and expertise to classroom teachers. They were conduits between the desired knowledge and the classroom teachers. As Participant C2 (Cluster C) noted:

We go and do a session with [provider] and then what we'd do then as a leadership team is we'd come back and take that same session with our staff so, you know we were leading the learning within our schools.

According to the data, lead teachers in all three clusters had key roles in working together to decide how knowledge would be shared with classroom teachers and how the latter would need to change. In each cluster, lead teachers were accountable to each other to ensure the project reached classroom teachers while principals worked together to plan the next steps in the project based on feedback from lead teachers and each other. Collegial accountability was a key idea that emerged from the data in the Leadership category. This occurred between principals and lead teachers in each cluster when each had certain knowledge that allowed them to control information and professional development delivered to the "next level down". Participant A1 noted that "Lead teachers and our project leaders had a lot more training than perhaps the teachers down on the ground level". It is obvious, therefore, that EHSAS leaders saw their leadership in all cluster activities as very important. They received more training, or were trained first and engaged in controlled handover of knowledge to those who were not leaders.

According to my analysis of the data, principals and lead teachers in each cluster worked together in separate groups whilst classroom teachers were receivers of knowledge and recipients of a change agenda. Participant B2 (a lead teacher) explained 
how she shared knowledge with classroom teachers by saying that her role "was to do the learning alongside the principals and guide the practice that was happening back at schools and support the practice back at schools".

The leadership that participants particularly valued often involved guiding others using knowledge, rather than position. This occurred through mentoring (helping others to learn in the focus area) during which lead teachers worked with classroom teachers and each other in all three clusters. In Cluster B, the lead principal mentored lead teachers in how to facilitate meetings. The lead school in that cluster was recognised as a mentor to the other schools because it was further along in the implementation process in the focus area. As the lead school in Cluster B mentored other schools, these schools became equal in capability and no longer thought that they needed to learn from the lead school or each other. It appeared from my analysis of the interview and milestone report data that leadership in Cluster B shifted over time from the lead school overseeing the project, to schools then separating and leading their own in-school projects with a focus on their own needs as they developed the knowledge that they needed. Participant B3 from that cluster described the tension between working as a collaborative group, and meeting the needs of individual schools as knowledge grew across the cluster:

I think at the end of it, what we have now is each school has developed their own model of [project focus] and as I'm going to say in my report, to a certain extent that was really great but it also brought with it some frustration because you're trying to deal with...everybody wants something different out of the contract so it was trying to...we had to keep saying well what is it that you want to be developing? And so I guess where we started with a reasonable amount of commonality, that really branched out as the project went on. But I think in a way it has a downside in that it is hard to organise PD and keeping it like a tight, altogether project. But when I actually went back and revisited the goals of the project, it was actually for each school to have developed their own way of doing things at the end and not becoming a clone of our school. 


\section{EHSAS leaders' collaborative practices.}

This section provides insights into EHSAS leaders' perceptions about collaborative practice, that involved what I have termed Sharing. As previously discussed, Sharing was one of the most predominant themes in the data and this indicates EHSAS leaders' preference for using practices at this level over practices that might be more effective. I defined Sharing as involving the exchange of information, resources, ideas, strengths or expertise between cluster members. Most data in this category actually contained the words "share" or "sharing". I considered that sharing was a term used for practices that involved simple "give and take" arrangements. I created separate categories for collaborative practices that seemed to be more than sharing. I named them "challenge and debate", "building on strengths" and "critique". While Sharing emerged as a large category, those categories that represented more than sharing remained small. An example of sharing was provided by Participant B1 as "the opportunity of being in each school and just you know, soaking up the flavour of that school”, whereas an example of more than sharing was given by Participant C2: "Getting to know people, getting to know what their strengths are and then having that culture of being a learner".

The combined use of systems and resources such as funding and professional development was a large component of the "sharing" category. Milestone reports for all clusters show that schools used some of the funding from EHSAS to pay for the delivery of professional development. This sharing of resources was seen by participants as positive for schools because it made it easier to access expensive professional development. Participants noted that professional development was more cost effective when accessed by groups of schools. For example, Participant B3 stated "We will carry on out of necessity because to get really good professional development costs money."

Where clusters had a particular focus area for professional development, useful systems in implementing it were shared across the schools. Clusters created opportunities to meet in each other's schools to see how they were organised. Resources were created alongside the project activities to improve teacher practice. Cluster A created a video resource for effective teacher practice in its focus area. General teaching resources were pooled and this appeared to be new for some participants. Participant A2 noted the 
following:

I can remember one day somebody wanted a PAT listening comprehension test or something like that, you know and because now we have that relationship we can do that, whereas up until then I didn't know anybody from the neighbouring schools.

The combining of ideas for effective teacher practice and for school organisation also frequently occurred in this category. Teachers exchanged knowledge and ideas, and observed each other. They valued getting outside their own classroom, visiting other schools, and "soaking up the flavour" (Participant B1) of other schools - just seeing what they were doing and getting ideas were considered beneficial practices. According to participants, these practices shifted over time with initial sharing occurring at the cluster-wide professional development sessions. Later however, it occurred in smaller groups (for example, cluster lead teacher to classroom teacher in another school). In discussing this type of sharing, a milestone report from Cluster B noted that the cluster members were "becoming more aligned in their thinking. Teachers [were] using a common language and there [was] a shared understanding of the process".

Within the Sharing category there was an emphasis on the perceptions that school visits also enabled clusters to showcase developments and achievements. This involved seeing examples of good practice and teachers discussing their own school's work. This type of sharing occurred across schools at cluster-organised events or between clusters as a result of meeting at EHSAS conferences organised by the Ministry of Education.

Sharing expertise and strengths was mentioned by several participants. However, they did not mention building on those strengths as a cluster. Participants described more "give and take" scenarios. A milestone report from Cluster A stated that "the staff meetings provided valuable opportunities for teachers across the cluster to meet in year group clusters and share expertise, challenges and useful systems related to Assessment for Learning". 
While the projects appeared to be focussed on growth in teacher knowledge and capability, many cluster participants preferred to affirm current practices, rather than take part in or enable real change. Participant B1 commented that at the end of the project, rather than change occurring, the schools had "actually taken just the good points of that [professional development] and gone back to more about how [they] were before". In stating that they took "good points" from the professional development, Participant B1 indicated that they would then increase their knowledge alone, outside the cluster model. She also noted that there were differing levels of implementation in individual schools and that this appeared to be a reason for the lack of continued collaboration or change in teacher practice.

In addition, there were some comments in Cluster B milestone reports indicating that, rather than affirming change the project had value in terms of affirming what the teachers were already doing. Typical comments were that:

EHSAS allows schools to do what they were already doing, but makes it better, easier, faster. (Milestone report, Cluster B)

[EHSAS] reinforced what we already have in place. (Milestone report. Cluster B)

[Schools were] willing to take on board a variety of [teaching] approaches that [were] in line with our school needs. (Milestone report, Cluster B)

A milestone report from Cluster B pointed out how the schools combined strong teaching strategies that were effective for Maori students. The report explained that the schools "have also shared different strategies or ideas that work well with Maori students as part of lead teacher days".

Overall, through my analysis of the connections between the themes of Sharing and Changing Teacher Practice I identified participants' beliefs that collaborating at the sharing level combined with a focus on change in teacher practice had led mainly to positive outcomes in the schools involved. The next section presents participants' experiences and perceptions related to the focus that leaders had on change. 


\section{EHSAS leadership style to achieve change in teacher practices.}

Theoretical Sampling revealed that the Changing Teacher Practice theme appeared more frequently across all data than most other themes. Not only did it extend across the other five themes, it also appeared in a large number of all 27 categories. At first, the connections appeared complex, but upon analysing the related data, I found that participants (leaders) perceived that change occurred through a hierarchical cluster structure that could transmit knowledge and goals to teachers.

\section{Hierarchical Cluster structure.}

The key role of EHSAS leaders was not only to take part in the learning, but also to ensure that all other teachers in the clusters were committed to the project focus and were making changes in their practice so as to meet desired outcomes. The need for accountability was highlighted earlier in this chapter where EHSAS leaders' monitoring roles were discussed. To enable such monitoring for accountability, the hierarchical models of leadership that were used ensured change through a top down approach to disseminating knowledge to classroom teachers. Figures 3, 4 and 5 on the following pages provide a diagrammatic depiction of each cluster's hierarchical structure.

Figure 3 (overleaf) provides a diagrammatic interpretation of the Cluster A structure as it was described in documents and by interviewed participants. The arrows within this diagram indicate a two way relationship between groups involving dialogue such as feedback about the project's implementation. Two-way dialogue about the project was not evident in the data between the Project Facilitator and Programme Managers, or between teachers and students. Therefore, one-way dialogue arrows have been placed in those areas. 


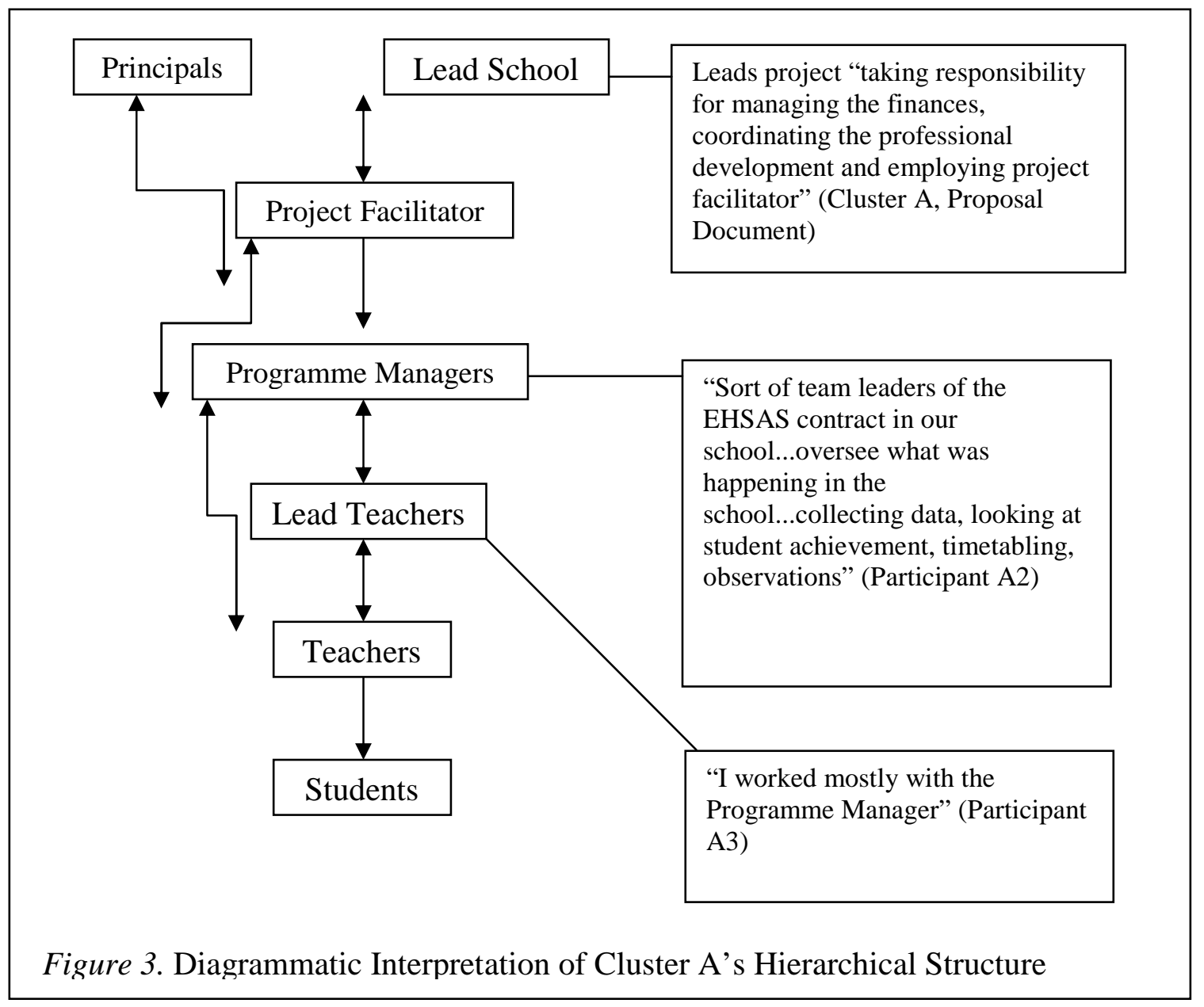

Participant A1 from this cluster gave the following reason for the selection of programme managers:

You had the programme managers who were some of our older staff, and so for them to get buy in [...] they had to agree to be high integrity and moral leaders within their group and then the lead teachers and then the teachers so it was this cross-group collaboration.

This comment highlights the fact that the structure for Cluster A included the recruitment of programme managers and lead teachers who could successfully lead change in classroom teachers. 


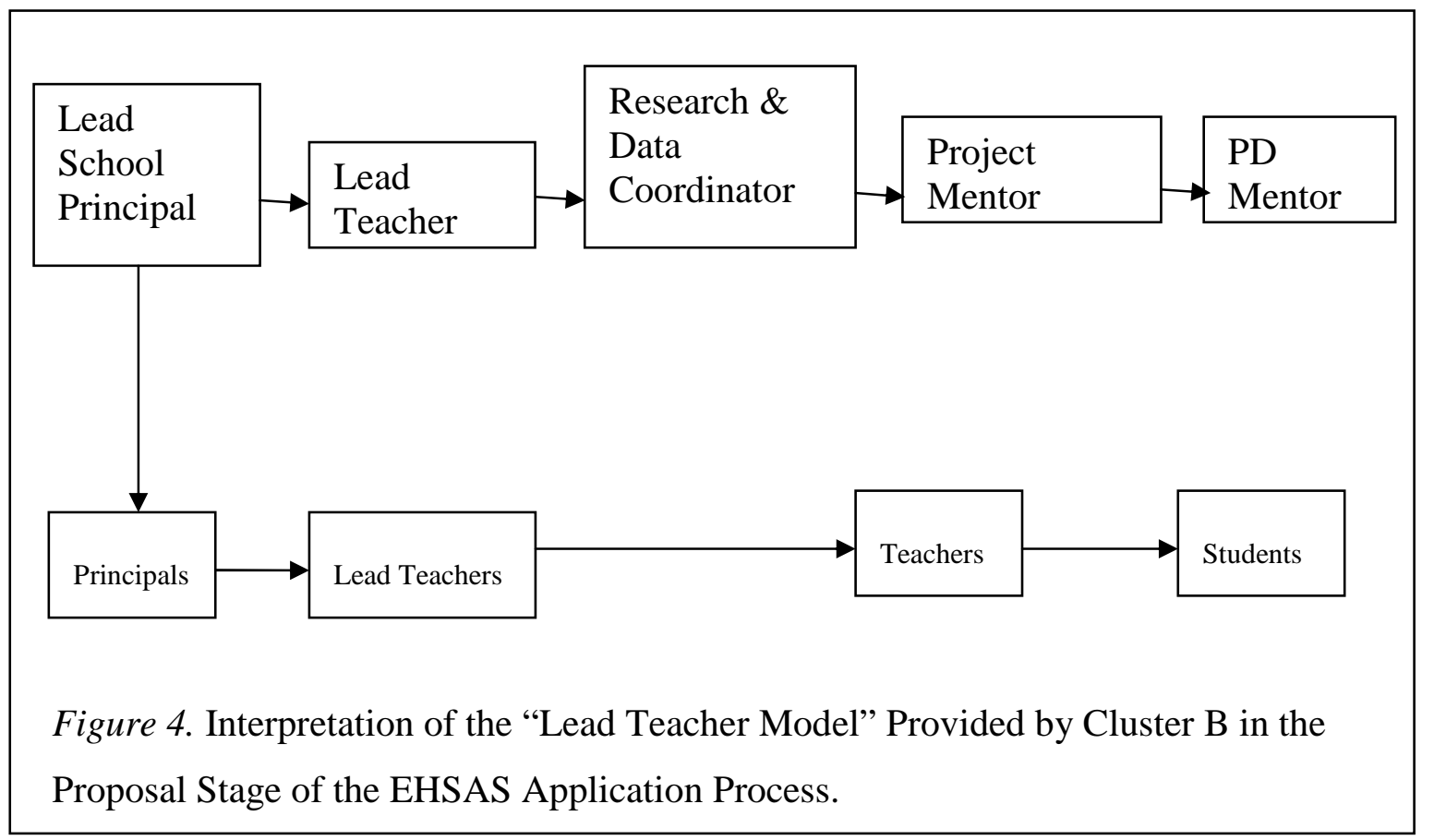

Cluster B submitted a diagram to the Ministry of Education showing their cluster structure (Figure 4). This structure places the lead school principal in the top left corner of the diagram with arrows leading out to all other groups indicating that all information and knowledge came from that principal. The lead teacher in the lead school appears at the top of the structure alongside outside experts, while all other principals and teachers appear in the bottom of the diagram as recipients of new knowledge. This suggests that the lead school in Cluster B saw itself as more knowledgeable than other schools in the cluster as it had been working in the cluster's chosen focus area for longer.

In Cluster B the lead school principal was seen by interview participants as having the most input into the project design and goals. She planned the project and used her own knowledge to adapt a cluster structure she'd seen work in a literacy programme in which her school had been involved and initiated the cluster. The application process for funding was also led by her. Other participants saw her as the person who was doing more to keep the project running due to her prior knowledge in the focus area. When discussing the ideal number of schools in a cluster, the lead principal herself (Participant B3) stated that "more than four you would be...I think you'd be running yourself ragged trying to try and please all people and do all things for everyone". 
Participant B1 stated that this lead school principal "was basically leading the project and because she was my principal, you know, a lot of probably my work was done by her". The same participant noted how the lead school seemed to end up in this position as it was more advanced in the project focus area: "Sometimes, you know, it would be us accommodating them, but we sort of felt comfortable with it but I know that some of the other schools felt as though [the lead school principal] was too much in charge".

The lead principal (Participant B3) discussed the pressures of being in a formal contract. Comments were made about feeling pressured and indeed obligated to stay in the contract, stick to the original plan and do the work. She referred to the cluster's obligations through the contract with the Ministry of Education which she saw as positioned at the top of the hierarchy:

They had licence to go their own ways so they still had autonomy that way but then overall um, we still had this project that we had to do and gather evidence for. So what I had to do with people was basically to get the other principals on board I had to take them right back through the whole contract and say "these are what my obligations are" and then I had to be a little bit, um, not mean I suppose but it was saying like "you either want to take this on board or you get off now, but if you're here, this is what is expected of you".

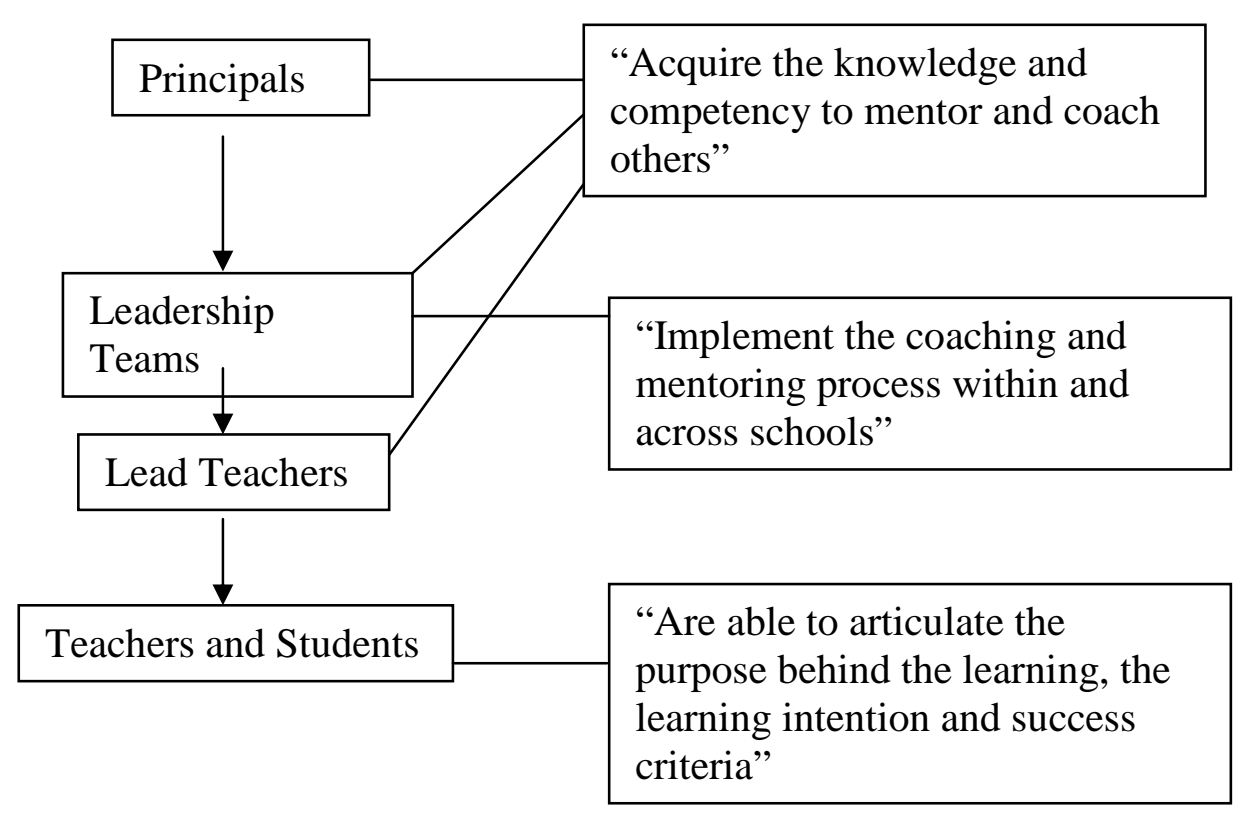

Figure 5. Diagrammatic Interpretation of Cluster C Hierarchical Structure. 
The interpretation of the structure of Cluster C (see Figure 5 above) was derived from information provided in milestone reports. As was the case for Clusters A and B, the structure reflected a hierarchical approach to knowledge acquisition. A hierarchy was seen by some participants as a positive structure for leading change. Participant A1 stated that "by having a hierarchy, if someone really felt strongly about something they've got three people above their team leader that they can go to". However, that same participant also felt that having a hierarchy hindered collaboration, and provided an explanation of their project: "Part of it was not collaborative. In the end it became authoritarianism and the teachers didn't feel good about it".

When discussing hierarchical practices, Participant C3 expressed a similarly conflicting opinion:

Whoever that person is, needs to have enough positional power within the school to be able to lead change but it doesn't necessarily have to be the principal. No matter how level they'd like the playing field, they [principals] are still at the top of the pyramid.

\section{Leading change in teachers.}

Leaders had a role in mentoring teachers, and leading and checking for change in teacher practice and its impact on students. Participants discussed the need for change, and also the importance of getting the level and pace of it right and for ensuring that teachers had good attitudes towards the project goals. It appears from the data that not all participants saw a need for a change in their own leadership practices in order to reach their cluster goals or outcomes. When discussing the need for leaders to take part in learning, EHSAS leaders suggested they should lead by example, rather than change their leadership practices.

Principals in every cluster took part in learning and emphasised the importance of the project. They focused on increasing the capacity and knowledge of lead teachers who then acted as mentors for classroom teachers. While principals encouraged learning by taking part in professional development alongside their staff, they did not change or analyse any of their own leadership practices in their schools or in the cluster. As one 
principal commented, the principals "met twice a term and we always had a morning meeting and our job was to say 'how's it going? What effect are we having on our teachers? Are we seeing any impact on data?"' (Participant A1).

The fostering of positive change in teacher practice was also valued by participants. In Cluster B, lead teachers had the role of managing change in their schools and were mentored to do this. A milestone report from this cluster explains that the "lead teacher and lead principal meet with schools to discuss effecting change and change management among staff". Such an explicit focus on enabling change indicates the value placed on it.

According to some, the level of change required of teachers had an impact on the degree of collaboration. One participant felt that sharing any teaching practices across schools (in the hope of enabling positive change) had to come later on in the project. Participant A1 stated that "change happening in the school makes it really hard to collaborate across schools as well". These leaders felt that changing teacher practice was a difficult task that had to occur within a single school before it could occur between schools working together.

\section{Fostering a common vision or goal.}

The theme of Fostering a Common Vision or Goal was connected to the themes of Leadership, Change and Hierarchy. Further analysis of these connections revealed participants' beliefs that if leaders fostered a common vision, change in teacher practice would be further enabled.

Participant B1 was clear that leaders enabled change in teacher practices by transmitting a common vision. She thought that a cluster needed "one person with the real vision" for effective collaboration to happen. However, other participants emphasised the importance of a common vision within a school and across all involved. Overall Common Vision/Goal category showed that participants valued the presence of a leader who kept the focus on the cluster's vision or goal. Participant B3 illustrated this by saying: "As the cluster got stronger it became the principals who really held and kept the vision going". 
The involvement of many others to keep that vision or goal alive throughout the duration of the project was also valued by participants. Participant B1 noted that "if everybody doesn't have the same vision, just too many people on their own agenda, I think that would have a detrimental effect". Participant C2 emphasised a similar point:

A shared vision, it wasn't just a vision that the principals had thought up and said this is what we're going to do - it was something that we all knew about and that the staff knew about as well so the big picture was shared by everybody.

Participants discussed what happens if the focus was lost and ways to keep it by gaining agreement from all involved, having leadership drive it, and taking responsibility for embedding it and keeping it alive.

\section{Intended consequences of EHSAS leaders' practices.}

The leadership practices noted so far in this chapter were aimed at changing teacher practices in order to improve student achievement. The intended consequences of all leadership practices were to get commitment from teachers, to change teacher practice and ultimately to improve student achievement.

\section{Commitment of teachers.}

Data was associated with the Commitment of Teachers if it represented the need for participants in the cluster work to be committed to the project, or to be willing to engage in the collaboration or project work. In order for the cluster to succeed in reaching its goals participants emphasised that people in the cluster needed to have a commitment to the project outcomes or vision. In defining collaboration, Participant A1 discussed the need for commitment:

When we brought in the cross-school collaboration, that was when the teachers had to have some commitment to the project as well and agree about how we're going to move it forward I suppose. 
The role of leaders was a key idea in the Commitment of Teachers category. Five of the nine interview participants emphasised the need for cluster leaders to be committed to the project. In particular, principals needed to buy into the project in order for it to be successful. When I asked one principal (Participant A1) about what her role was, she discussed this in light of previous experiences of collaboration with other schools, stating the following:

Principals...that's our role, it's the leadership role....and it was really interesting, we had a new principal come into one of the schools who didn't totally buy in, and you knew it immediately. Now I had run two other cluster groups, one was an ICT one - a big one, and um, the other one was the gifted and talented one. So I understood implicitly that if the principal is not on board, then nobody's on board.

Another key idea that emerged in the Commitment of Teachers category was the concern about staff turnover, which participants believed affected an entire school's commitment to the project. Participant B1 noted that "there was a high turnover of teachers and that was really really hard on the project because it was like starting all over again, having to bring everybody up to speed again". As well as high teacher turnover, Cluster B also lost two principals during the course of the project. Participant $\mathrm{B}$ noted that when the new principals joined the cluster it was decided that the project should be put "on hold for a little while until they got used to their schools and then they could start focusing on that".

Cluster A also experienced staff turnover which affected the levels of capability across staff members. Participant A3 described this situation: "[We] did have staff turnover which is inevitable isn't it? And so, to be honest there would be some teachers who'd be in it for the whole time who probably had experienced more collaborative practice than some of them who come in towards the end".

Like Cluster A, Cluster C experienced staff turnover and concerns about staff capability. However, Participant C2 pointed out that they had systems in place to cater for new staff: "If we did have staff turnover, what we did is we set up sessions so that any new 
staff to the schools could learn about peer coaching - let's say we had peer coaching sessions with the whole staff".

Participant B3 recalled that when a principal was replaced, the new leader would state something like "Well I've got all this other thing to focus on and your contract's a tack on on the side". According to the participant, "that actually took quite a lot of work and talk to get people on board to get everybody moving again”. Other participants found that sometimes new staff did not commit to the project. There was a need for teachers to have ownership of the work in order to be on board with the rest of the cluster.

In order to gain that critical commitment from all participants in a cluster, cluster leaders suggested strategies such as involving people in planning and target setting, ensuring that the project addressed teachers' needs, involving everyone equally, and discussing the project, thus ensuring a continual focus on it.

\section{Change in teacher practice.}

Change in teacher practice was an intended consequence of the leadership practices in EHSAS clusters. Some clusters checked for evidence of change by measuring teacher practice. In Cluster A, teachers completed self assessments, as noted by Participant A1: "Teachers were given the matrix and this is how we also monitored the data and they had to decide where they were on this matrix at the beginning of the year, at the end of the year". In Cluster C, rather than refer to evidence, Participant $\mathrm{C} 1$ made assumptions that change had occurred in all classrooms: "I think if it made a difference in two rooms, it's probably made a subtle difference in most rooms". Cluster B measured changes in teacher practice through a particular technique where teachers and students were interviewed and their answers compared. Cluster $\mathrm{C}$ used a "classroom walkthrough" technique which was a process for providing evidence-based feedback to classroom teachers about their instructional practices and their students' learning. The classroom walkthrough allowed the observer (usually a lead teacher or principal) to gain a snapshot of a particular aspect of practice in order to check for change and improvement and provide feedback to the teacher. Cluster A used a facilitator to observe change in teacher practice over time and milestone reports recorded statements about teacher progress. For example, Cluster A's 2010 milestone report stated that 
"teachers became more reflective practitioners...the use of assessment tools for feedback and self and peer assessment...increased".

Leaders believed that their collaboration and associated practices would gain the commitment of teachers to change and improve. They believed that these consequences would lead to improved outcomes for students. They saw that requiring and checking for change in teacher practice was the main way that they as leaders could contribute to improving student achievement.

\section{Improved student achievement.}

All participants were asked if they perceived their practices as making a difference to student achievement during the interview process. Cluster A provided evidence of improvement in student achievement in Reading and Writing through milestone reports. Participant A1 discussed this improvement, stating that it was a direct consequence of teachers inquiring into and improving their practice through talking to each other and to leaders about what they were doing: "What are you doing? - that was the single question: What are you doing?". However, Participants A2 and A3 were not as confident in answering the question due to the fact that I was asking if it was collaborative practice that had made the difference, rather than practices in general. Participant A3 expressed her reservations about the question in the following way:

We had the assessment data from the tools that we used so that was easy to measure but... whether the collaboration made an impact, I don't know and I don't know how you...because maybe in the end actually we were still satellite schools making a difference for the students here but maybe what we did at [our school] had nothing to do with the great things that happened at [another cluster school].

Cluster B provided student achievement data in Reading in their first year of implementation of EHSAS, which showed that achievement shifts in some schools were minimal, with some students doing worse than they had before the project. In other schools student achievement had gradually improved in years prior to the project and in the first year of the project. The cluster then changed to a measurement tool that 
focused on student engagement rather than achievement, with the underlying assumption that improved engagement would equal improved achievement. No further evidence of improved achievement was provided. All three participants from Cluster B explained how harmonious collaborative practice could impact positively on student achievement but did not state that student achievement had actually improved in their cluster. As Participant B3 commented:

I think the more you grow the teacher, the more likely you are to improve student achievement in your school. And I think for us, the eye was always on how do we...if we can engage these kids in learning and we can make learning meaningful and authentic and um, like basically get the parental involvement. All of those things are going to impact on student achievement.

Cluster $\mathrm{C}$ had gathered student achievement data in relation to Numeracy throughout the term of their EHSAS project. They stated in their analysis that "student achievement over the last 3 years has shown continual improvement because of the use of analytical, challenging and critical questioning by teachers" (final Cluster C Milestone Report). Each of the three interviewed participants confirmed that changed teacher practices had an impact on student achievement. Participant C3 believed that this was due to collaboration across teachers. Participant C2 stated that changed teacher practices around inquiry and collaboration "made the data real for us to know actually we can change student achievement and we can improve it and we can work on it together. So we sort of did it you know as a group". Participant C1 had similar perceptions:

Whether it was making a difference - we never collected data before and after so we've got, you know I can't say categorically yes it raised student achievement but I think if you look at, you know, I know of a couple of teachers whose classroom practice changed - not radically - but definitely changed in that all of a sudden they were setting learning intentions, they were using um rubrics with success criteria, they were giving very specific feedback to students...it made a difference in those rooms - I happened to be working with a couple of them. 
It is clear that the aim of the EHSAS clusters' projects was to raise student achievement. However, it is not clear as to whether or not achievement was raised, or if it was, whether it could be attributed to the EHSAS project and changed teacher practices.

\section{Summary of the Results}

The participants in this research described the collaborative practices used in their clusters and their beliefs and perceptions about the impact of those practices on teachers and students. The analysis of the data presented in this chapter allowed me to locate underlying patterns, such as the reasons for using certain collaborative practices and the intended consequences of cluster activities.

EHSAS leaders claimed their roles in the cluster work to be very important, with the largest area of discussion being about the significance of leadership practices in achieving change and improvement in teachers and students. They exchanged information, resources, ideas, strengths and expertise, and used hierarchical structures to gain teachers' commitment to changing their practices with the ultimate aim of improving student outcomes.

These emerging patterns are examined in Chapter 5, where they are considered in relation to relevant literature and the final theory is formed and discussed so that the research questions can be answered. 


\section{Chapter 5}

\section{Discussion and Conclusions}

In this chapter I aim through discussion and critique to integrate relevant research literature into the emergent theory in order to present the final theory based on the beliefs of the EHSAS cluster leaders involved in this study. The validity of their claims is assessed by "the degree to which the [participants'] theoretical claims are consistent with well-established knowledge in the field" (Dey, 2007, p. 168). Each section of this chapter addresses the original research questions, further examining EHSAS leaders' beliefs about effective collaborative practice.

\section{EHSAS Leaders' Beliefs}

At the end of Chapter 4, I considered patterns underpinning the collaborative practices used by EHSAS leaders. The following statements summarise the beliefs of EHSAS leaders in relation to their cluster work:

1. By sharing resources, ideas, strengths and expertise with one another EHSAS leaders believed they would then have knowledge that would enable teachers to change and improve their practices, and raise student achievement.

2. EHSAS leaders believed that a hierarchical cluster structure was the best way to transmit their newly acquired knowledge and goals to teachers.

3. EHSAS leaders believed that principals in the clusters must monitor student achievement data to check on school progress and hold each other to account. They believed this was essential for changing teacher practices and improving student outcomes.

These statements take into consideration the EHSAS leaders' beliefs about the consequences of using practices which I termed "sharing". Each leader's beliefs took account of the importance he or she placed on certain collaborative practices, cluster structures and processes, and leadership styles. Throughout the rest of this chapter, 
each belief is considered in relation to the original research questions. Research question (b) on participants' perceptions about the benefits and limitations of their practices is considered alongside the first two research questions. Throughout both of those sections, comparisons are made between participants' perceptions and the literature on collaboration in educational settings in order to answer the fourth research question (c): How consistent are participants' perceptions with research findings in the field?

\section{Research Questions: What collaborative practices were used by the participants in the EHSAS clusters? What do the participants perceive as the benefits and limitations of collaborative practice?}

This study has found that while some EHSAS leaders reported the use of a few highly effective collaborative practices such as challenge and debate, building on strengths and critique between cluster members, these were not as effective as they could have been because they were used within rather than across schools. The practices that were used across schools and that were most commonly reported by EHSAS leaders included the sharing of resources, ideas, strengths and expertise between cluster members. Such practices are not sufficient for raising student achievement because, as noted in Chapter 2, they can create a climate that Hudson-Ross (2000) suggests may be too positive where members do not challenge each other and therefore further entrench ineffective practices that make them feel good. Cluster members preferred to share existing strengths and expertise through visiting each others' schools, "soaking up the flavour" (Participant B1). Schools showcased developments and achievements during their EHSAS projects and believed that alignment in thinking and language among staff members would lead to change and improvement.

In providing reasons for sharing resources, ideas, strengths and expertise, EHSAS leaders demonstrated a good understanding of the purposes of effective collaboration. They valued the aims of learning and improvement for their teachers. But the collaborative practices they used showed a lack of understanding about what would best achieve those aims. 
It may be that change and improvement did occur in teachers as part of the EHSAS project, but when considering the current research (Annan, 2007; De Lima, 2001; Fullan \& Hargreaves, 1992; Katz et al., 2009; and Timperley, 2007) it is unlikely that the "sharing" across schools by cluster members was effective in enabling change and improvement. The "sharing" level of collaboration does not involve challenge, a key practice required by cluster members if they are to build relationships, skills and knowledge to achieve change and improvement. As discussed in Chapter 2, Fullan and Hargreaves suggested that if cluster members move away from advice-giving and material-sharing and towards more challenging practices such as asking difficult and necessary questions about their work and how to improve, they will successfully build relationships, skills and knowledge. Indeed, De Lima emphasises the use of conflict as a catalyst for school change and improvement whilst Timperley et al., (2007) and Katz et al. (2009) claim that the role of external expertise to assist in creating more challenging dialogue across a group. Annan's "learning talk" (p. 187) is one way to introduce the necessary challenge and critique that was largely missing from EHSAS leaders' cluster practices. As noted in Chapter 2, such talk assists groups of schools working together to solve student achievement problems.

In emphasising practices that remained at an unchallenging level, EHSAS leaders neglected to mention other more effective approaches such as those involving contexts enabling "capacity building" through inquiry-based practices that challenge understandings, as discussed by Fullan and Hargreaves (1992). EHSAS leaders explained how using collaborative practices at this unchallenging level enabled alignment in thinking and a common language across their clusters. This might have been the case, but as Katz et al. (2010) and Timperley et al. (2009) comment, such alignment and commonality is only effective in raising student achievement if the schools have established commonality of need. It is effective to stay focussed on change and improvement (as EHSAS leaders say they did), but as Little (2002) notes, school leaders cannot "simply equate change with improvement" (p. 935) without inquiring into evidence of need and checking the impact of their professional practices on student outcomes. Timperley et al. (2009) also link such needs-based alignment across schools with inquiry approaches. 
The ongoing evaluation of teaching and learning activities is now widely known in New Zealand as being embedded in the "inquiry and knowledge-building cycle" (Timperley et al., 2007) and is supported by several researchers as the most effective way for schools to improve student outcomes (Annan, 2007; Katz et al., 2010; and Timperley et al., 2010). This cycle is appropriate in facilitating change as it allows teachers and school leaders to focus on existing teaching-learning links and then determine what they need to learn and do to promote students' learning. The emphasis is on needs and problems that allow teachers to see themselves as "agents of change - for their students and their own learning" (Timperley et al., 2007, p. xliv). Through their collaborative practices, EHSAS leaders facilitated a model which focused more on sharing strengths than addressing needs. While using such a model can help school practitioners and leaders to identify what is working in order to further innovate and build good practice, it may not be as effective as the inquiry and knowledge-building cycle in promoting change and improvement.

Evidence of the more effective collaborative practices noted by several researchers including challenge and critique, and problem solving and inquiry-based practices (Annan, 2007; Hudson-Ross, 2001; Katz et al., 2009; Robinson \& Lai, 2006; Timperley et al., 2007) was displayed by clusters whose focus area required staff to learn these skills at the classroom level. However, there was no evidence that these same practices were utilised at the clusters' leadership level. This means that while teachers were building their capability to select and use effective practices in their classrooms, leaders were not in fact supporting them through building and modelling their own capability. As noted in Chapter 2, Timperley and Parr (2010) provided evidence that school leaders must work alongside teachers to locate their level of competence when engaging in inquiry, therefore engaging in their own cycle of inquiry to improve. The "continuum of development" (Timperley et al., 2010, p. 38) is a tool that can assist leaders to measure their capability and locate next steps in their learning in order to improve.

When EHSAS leaders were asked to identify the limitations of collaborative practice, they believed that as schools changed during the cluster projects, a lack of commonality emerged that reduced collaboration. It is likely that the lack of commonality across each cluster's schools came about because EHSAS leaders focused too much on implementing change programmes for teachers, and not enough on inquiring into 
teachers' practices and students' needs in order to identify common needs across the schools. Thus, as schools were not seeing the benefits that effective collaboration based on common need can provide, they preferred to work alone. Such inquiry would have allowed the leaders to ensure that they were regularly adjusting their project focus to accommodate the needs of all schools involved.

It appears therefore, that while EHSAS leaders focussed on change in teacher practice, they failed to use a cluster approach that would have enabled change. Schools essentially worked independently in a particular focus area (such as developing formative assessment skills) and concentrated on implementing new learning, rather than inquiring into how teachers and leaders were changing ineffective practices. It is possible that EHSAS leaders preferred to keep collaboration at this less challenging and less effective level because it allowed them to maintain what Fullan and Hargreaves have described as "cosy relationships" (p. 76) with their colleagues in the cluster.

Another factor that may have resulted in leaders collaborating at a less effective level is that they were accountable to the Ministry of Education in reporting on the use of funding and the effectiveness of their activities. Consequently, clusters may have felt pressure to provide visible results quickly. As mentioned in Chapter 4: Results, the sharing of funding and professional development made up a large component of the Sharing category. Rather than taking part in or enabling change to current practice, many cluster participants preferred to affirm current practices, taking the "good points" of the cluster professional development and further progressing them within their own schools. It is also possible that trust existed between participants, but had not developed sufficiently either within each school or between the schools in a cluster to allow a new, more challenging version of it to develop.

\section{Research Question: Do the research participants perceive the collaborative practices that they used as making a difference to student achievement and what did they perceive were the benefits and limitations of those practices?}

In summary, EHSAS leaders believed that their choice of cluster structures, processes and leadership styles were necessary for improved student outcomes. They believed that leadership should be shared equally among cluster principals and defined the 
principal's role as a monitoring one that involved checking on their own school's progress and reporting back to the other principals. Thus they held each other accountable for the outcomes of the cluster project. In keeping with a leadership style that enabled monitoring, principals worked together creating processes to decide next steps in the project, and to develop ways to keep the focus on project activities. Each cluster hired outside expertise to lead aspects of the implementation of their projects. Lead teachers in each cluster were involved first through receiving new knowledge and second through delivering this to classroom teachers. By observing the classroom teachers and providing feedback to them, the lead teachers added another layer of monitoring at the implementation level. Classroom teachers were the recipients of new knowledge and a change agenda to raise student achievement.

The research questions above are considered in the following subsections which are the main themes that emerged from data analysis.

\section{Leadership style makes a difference to student achievement.}

According to research, the key purposes for collaboration should be for school leaders, teachers and students to learn and improve (as noted by Annan, 2007; Katz, Earl and Jaafar, 2009; Timperley and Parr, 2010; and Timperley, Wilson, Barrar and Fung, 2007). EHSAS leaders understood what the purpose of a leader in a group of collaborating schools should be. They believed that their leadership was important to enable teacher change and improved student outcomes. However, while EHSAS leaders had this clear understanding, they may actually have hindered learning and improvement in their teachers and students since they did not evaluate the effectiveness of their school and cluster activities. Timperley et al. refer to "evaluative capability" (2010, p. 31). Without this, school leaders are less likely to be able to develop teachers' instructional competence by ensuring that their schools are "organised to maximise instructional time" (Timperley et al., 2010, p. 30). In order to build their own evaluative capability, leaders in schools would need to have systems that allow teachers and leaders to engage in inquiry. It may be that EHSAS leaders did operate in schools with such systems in place, but they did not inquire into their own leadership practices. Ultimately, this would have hindered the classroom teacher's ability to develop 
knowledge and skills required to "select and use effective instructional practices for particular groups of students" (Timperley et al., 2010, p. 28).

\section{Hierarchical cluster structures make a difference to student achievement.}

In addition to their overall emphasis on leadership, EHSAS leaders led change by adopting hierarchical cluster structures to transmit knowledge and goals to teachers. They believed that this would assist them in transmitting knowledge and goals to classroom teachers. The principals in the clusters led planning and monitoring related to the broad outcomes by checking student achievement data and deciding on next steps. According to Katz, et al. (2009), this was an appropriate use of principals' skills and knowledge in a collaborative group.

Each cluster included lead teachers who encouraged the building of skills and knowledge in the classroom teachers in their own schools. EHSAS leaders selected older staff or staff with integrity in their schools to be the lead teachers and they were seen as "moral leaders" (Participant A1) for classroom teachers. This second tier of leaders under principals was provided with the new learning first so that the knowledge could then be transmitted to classroom teachers in the cluster.

When EHSAS leaders were asked what the disadvantages of their collaborative experiences were (see Appendix A), participants from two of the clusters noted how the hierarchical structure of their clusters created a feeling of negative obligation in people lower down in the structure. They felt that those above them were "too much in charge" (participant B1). Both lead school principals and the Ministry of Education were seen as those groups at the top of the hierarchy. This negativity towards the cluster structure could be teachers' reactions to principals' expectations of them to change and improve, whilst not being fully aware of why they had to change and improve because little or no evidence had been gathered about teacher practice.

That participants expressed such mixed views about their experiences of clusters' structures seems to be consistent with this research which claims that both hierarchical and non-hierarchical approaches can support effective collaboration (Annan, 2007; Fullan and Hargreaves, 1991; Head, 2003; Katz, et al., 2009; Robinson, et al., 2009). 
Although the lead teachers demonstrated what Annan has described as "non-hierarchical learning connections" by working alongside classroom teachers to develop knowledge, the principals' lack of emphasis on the use of evidence to check for change and improvement in teacher practice indicates the likelihood that the cluster members were not using their hierarchical structures in an optimal way. As Fullan and Hargreaves (1992) have pointed out, using evidence to check for change and improvement allows a leader to learn as well as to lead. However, within the EHSAS projects weak evidence of change in teacher practice was collected (such as self-assessments), or change and improvement was assumed in all teachers by checking the practices of a sample few (as noted by a participant from Cluster C).

It is also possible to argue that the Ministry of Education contributed to the less than optimal use of the hierarchical structures by EHSAS leaders on two counts. First, the Ministry required clusters to adopt a "lead school". Second, the Ministry asked clusters to develop four year plans then conducted only light monitoring and support to the clusters during the implementation of their projects. The Ministry's limited involvement fitted a light-touch accountability policy for self-managing schools. But a negative consequence of that policy was that the Ministry failed to check that the hierarchical transfer of knowledge to teachers and students was successful and that teachers understood and used the knowledge. For the Ministry, checking capability and then providing appropriate support for schools to change and improve was second to holding schools accountable for outcomes.

\section{The commitment of all cluster members makes a difference to student achievement.}

EHSAS leaders believed that they and their staff had to be committed to the cluster goals throughout the term of their projects if their clusters were to succeed in making a difference to student achievement. To gain commitment, all teachers had to have ownership of the work and agree to change. Leaders ensured this buy-in through involving teachers in planning, target setting and the overall change process and by ensuring that there was a continual focus on the project and that it addressed teacher needs. 
The emphasis that EHSAS leaders placed on gaining the commitment of teachers to improving their practice and student outcomes is supported by research (Hudson-Ross, 2001; and Head, 2003). However, the leaders did not show an understanding of the practices required to gain commitment. To be genuinely committed, Head has claimed that teachers needed to know and understand their roles in the cluster work so that the benefits for them were clear and according to Bryk (2003) they also needed to build "relational trust" (p. 42), a type of trust made up of actions that reduce the sense of vulnerability between cluster members who are dependent on one another to achieve desired outcomes. Such actions, as discussed by Bryk, include "respectful exchanges" p. 42) between group members even when there is disagreement.

EHSAS leaders attempted to gain teachers' commitment through involving them in planning and target setting. However, the need to foster underlying practices that enable such involvement were not emphasised. Leaders needed to encourage "relational trust" and establish "personal regard" between group members which would show the "willingness...to extend themselves beyond the formal requirements of a job definition" (Bryk, 2003, p. 42).

EHSAS cluster leaders were concerned that staff turnover affected commitment in that it created more work for the existing cluster members who had to acquaint new members with the learning that others had been through. The leaders did not recognise that commitment could be influenced by the practices outlined by Head (2003) and Bryk (2003) above, and other practices such as De Lima's (2001) "cognitive conflict" (p. 116) which must occur if teachers are to commit to school change. While EHSAS leaders did not link such practices to gaining commitment from teachers, some data indicated that role clarity, challenge and debate did occur when determining and agreeing on next steps. However, this was a relatively small part of the data and did not emerge as a theme. Similarly, the fostering of high trust alongside high challenge was seen by some participants as important, but the reasons offered for this view had little to do with commitment, change or improvement. Trusting and challenging behaviours were seen by those who discussed it as fostering the sharing of good practice and ideas, and the de-privatisation of classrooms. 


\section{Keeping the focus on a common vision or goal makes a difference to student achievement.}

The EHSAS leaders' emphasis on the need for cluster leaders to keep the focus on the cluster's common vision or goal is consistent with research literature that claims all members of a learning community or cluster should have this (Katz, et al., 2009; Timperley, et al., 2009; \& Wenger, 1998). While the literature does not emphasise the leader's role in maintaining the cluster goals, it makes sense that in having a responsibility for monitoring cluster activities towards outcomes, these leaders saw the significance of their roles in ensuring that the common vision or goal was maintained throughout.

By involving teachers in cluster planning and target setting, leaders believed that they maintained the common vision or goal and that this would gain the commitment of teachers. This is in line with Wenger's notion of “joint enterprise” (1998, p. 77) which requires community members to define and agree on a shared goal. As noted in Chapter 2, EHSAS cluster leaders were exposed to Wenger's theories about communities of practice through regional seminars. Thus EHSAS leaders' practices in this instance may have been influenced by exposure to Wenger's theories and research. There was no clear evidence that EHSAS cluster goals were based on needs, as emphasised by Annan (2007), Katz et al. (2009) and Timperley et al. (2009). Through the same regional seminars, they were shown aspects of Annan's research that emphasised a deeper analysis of need when determining goals. Annan's (2007) research favours schools that come together in the first place for a needs-based reason. It is likely that EHSAS leaders favoured Wenger's position because they were exposed to both perspectives only after they had already formed their clusters. It was perhaps too much work to return to the drawing board to renegotiate their cluster goals based on the identified needs of students in each school.

Some effective collaborative practices were used by EHSAS leaders including challenge and debate, and critique between cluster members. These have been acknowledged by many researchers as having an impact on student achievement (Annan, 2007; HudsonRoss, 2001; Katz et al., 2009; Robinson \& Lai, 2006; and Timperley et al., 2007, 2009). However, EHSAS leaders did not fully realise the potential impact of those practices 
and instead emphasised less effective collaborative practices across their schools such as sharing ideas and resources, and associated those with improved student achievement. This highlights their strong focus on learning and change without a corresponding focus on evidence of change and was perhaps a result of the way the EHSAS project was implemented by the Ministry of Education. The pressure that cluster leaders felt to comply with the requirements to provide results combined with a lack of monitoring and support from the Ministry of Education may have left cluster leaders feeling confused about how to combine compliance tasks with the effective practices in order to get the improvement that all parties desired. It also appears from the report by Martin Jenkins and Associates Limited, that the practices the lead school planned to extend across the clusters were not in fact "proven or tested within the lead school" (2008, p. 9). Moreover, the Ministry of Education did not appear to have used selection criteria that required schools to have already inquired into and established the effectiveness of the practices to be shared.

\section{Conclusion}

Through interviews and milestone reports EHSAS leaders discussed how their collaborative practices allowed the following to occur:

- $\quad$ The monitoring of student achievement data between principals to ensure the accountability of each of them for project outcomes.

- $\quad$ The monitoring of teacher change by checking their own teachers' progress and sharing of that with each other through discussions.

- $\quad$ The commitment from teachers in order to change their practices.

- $\quad$ The achievement of a common language and shared understanding of cluster processes.

- $\quad$ The transmission of knowledge and goals to teachers.

EHSAS leaders believed that the above outcomes equated to the purposes and benefits of collaboration. These beliefs align with the literature on collaboration which emphasises the necessity of similar beliefs in order to reach a common goal. However, following my analysis of the practices used by EHSAS clusters to achieve these purposes and benefits, I found that they did not use the most effective collaborative practices and that leaders did not look for learning and improvement in their own or in 
teachers' practices. Instead, EHSAS Leaders were more focussed on monitoring the implementation of project activities.

EHSAS leaders focussed on the delivery of professional development to change teachers but the clustering approach was not used in an optimal way to make a difference. Ultimately, there was a sharp focus on learning and change but this could have happened just as effectively in the individual schools without the cluster structure. The only collaborative practices that occurred across schools were at the basic "sharing" level, as described in Chapter 2 of this study.

The following three statements make up the final Grounded Theory of the collaborative practices of EHSAS cluster leaders.

1. EHSAS leaders understood the purposes of effective collaboration and their roles as leaders in enabling learning and improvement. However, they made assumptions about the consequences and impact of the practices they used and did not inquire into their needs, their capability as leaders, or the impact of their collaborative practices at teacher, school and cluster level. Collaborative practices that would achieve those aims most effectively were not therefore used. Thus leaders did not fully enable the learning and improvement that they espoused to be leading.

2. EHSAS leaders believed that it was effective to adopt a hierarchical cluster structure and principals were appropriately the leaders of planning and monitoring cluster goals, while lead teachers monitored the progress of classroom teachers. However the principals did not require lead teachers to use evidence to check for progress in classroom teachers and did not evaluate their own leadership practices in enabling improvement in teachers and students.

3. EHSAS leaders understood the need for cluster members to focus on and commit to a common vision or goal. They ensured this through involving teachers in cluster planning and target setting. However, cluster goals were not needs-based, so any success they may have had in achieving student achievement targets was unlikely to be due to their focus on cluster goals. By 
involving teachers in planning and target setting to gain their commitment, they showed a lack of understanding about the practices that gain commitment from teachers.

\section{Issues and Implications}

EHSAS leaders knew why they were working together and had clear aims but they were not using appropriate collaborative practices to achieve those aims. They were either lacking the knowledge, or the will to recognise this fact and to improve their practices through inquiry. The selection of appropriate outside expertise has important implications for how knowledge is built. Cluster leaders should have identified a common problem or need in advance in order to inquire into it and to find solutions. Identifying solutions requires the input of an outside expert, such as a professional development provider who can assist in making their explicit and in identifying the necessary knowledge and skills that need to be built (Timperley and Parr, 2010; Robinson and Lai, 2006).

The monitoring role of the Ministry of Education also has important implications for how knowledge is built and for how school leaders are held to account for making their practices more effective. In choosing to conduct light monitoring and support for EHSAS clusters, the Ministry of Education was not necessarily able to become an effective partner to the schools and their chosen outside experts. By being involved in closer monitoring of the implementation of cluster plans, the Ministry of Education could have provided an extra layer of expertise, observing where effective practices, processes and systems were or were not operating and challenging or supporting cluster members and outside experts to address issues or learn new knowledge and skills. The Ministry of Education is also in a unique position of power in such situations because it is monitoring for accountability purposes. Where an outside expert contracted by schools may feel uncomfortable when he or she creates discord, the Ministry of Education is able to support both schools and outside experts to welcome discord that enables change, without being at risk of losing a contract. 


\section{Limitations of this study}

This section outlines the various limitations of this study in relation to meeting the requirements of the Grounded Theory Method and my position as a civil-servant involved in monitoring the EHSAS clusters.

Due to time constraints, it was not always possible to adhere to all of the requirements of the Grounded Theory Method. In particular, the sample size had to be predetermined so that the study was manageable within the timeframe for producing a Master's thesis. The decision was made to select three clusters for research, and nine participants across the clusters for interviewing. Essentially, this means that "saturation point" was being predetermined, which is not in line with Grounded Theory Method. The result was that saturation point had not been reached after the third set of cluster data had been through the theoretical sampling process. Normally the researcher would have returned to earlier conceptualising phases, sampling new settings (or clusters) until saturation point is reached, as noted on page 56, Chapter 3: Methodology. However, as noted in Chapter 4: Results, given the few new categories emerging from the third cluster's data, I was satisfied that I was near enough to saturation point to move to the next stage in analysis.

The validity of the data that was collected and analysed is also a limitation of this study. Information gathered from milestone reports and interview participants was subjective in that it provided cluster members' perceptions about the effectiveness of the practices that they used. Those perceptions were unsupported by concrete evidence such as teacher observation data or analyses of teacher and leader practices during the projects. The perspectives of outside expertise contracted by clusters to deliver professional development or to be a critical friend were found in some milestone reports, but again there was a lack of evidence to support their perspectives. Student achievement data was provided in milestone reports, however it was not possible to determine from this reporting how well the data was analysed and used to inform each cluster's processes and practices. As the Ministry of Education did not become involved in the cluster work as a genuine partner, no internal monitoring notes provided any insight into data analysis and use for each cluster. As noted in Chapter 4: Results, due to this lack of 
information it is not clear as to whether or not achievement was raised, or if it was, whether it could be attributed to the EHSAS project and changed teacher practices.

Finally, EHSAS cluster members may have felt pressured into providing certain information or to answering questions that ensured that their projects were not compromised by what could be seen as "extra monitoring" by myself as a civil-servant. I can never be entirely certain that those issues and my continued employment by the Ministry of Education did not have an influence over the information provided by the cluster members through both interview and documents.

\section{Recommendations and Further Research}

This section makes recommendations for improving the way schools and the Ministry of Education implement collaborative projects. I also pose questions for further research about school leadership and Ministry of Education practices.

The findings of this thesis may inform the thinking about how schools collaborate in New Zealand in the future. It is clear that collaboration is not just about using the right practices if it is to be effective. It is also about ensuring the right structures and processes are in place to enable the right practices to be used. The effectiveness of those practices should be checked along the way. The need for such precursors has implications for the reasons that schools choose to collaborate and for how school leaders plan and establish systems that will enable clustering that is effective. If in the future, the Ministry of Education establishes another fund to encourage collaboration across schools, these findings should inform the design and implementation of the policy so that the schools accessing such funding can develop plans and implement systems and processes that facilitate collaboration that benefits student achievement.

It is clear from the findings in this thesis that school leaders required support to do the following:

- Expose their beliefs about the effectiveness of their practices.

- Inquire into their practices to check their effectiveness, exploring the needs of students, teachers and leaders.

- Build their knowledge and capability to select and use effective practices. 
- Collaborate effectively.

The knowledge that these school leaders need to improve already exists. As noted in Chapter 2, there are tools and professional development providers that can support schools to analyse their data, to identify needs and to inquire into their effectiveness. These school leaders now need to engage with the relevant experts to build their knowledge and capability to select and use effective practices.

The tools provided by Timperley et al. (2010) to assist school leaders and teachers to locate their levels of competence when engaging in inquiry are useful indicators to guide next steps in improvement. However, I have found through working with school leaders that the indicators can easily be misinterpreted by those learning to implement the inquiry cycle if they do not have a clear understanding of what the brief summary statements look like in practice. In order to develop their understanding, school leaders and teachers need to engage with outside expertise who can help them to locate their current capability to inquire and then understand what it is that they need to learn next.

Through my experiences working with these clusters and with other schools in my role as a civil-servant, it is not always clear to school leaders who should provide this support: The leaders themselves? The Ministry of Education? Professional development providers? Or other experts? I propose that it is a combination of these in partnership with one another. Such partnerships are already proven to be successful in clusters of schools and the involvement of outside expertise has already been discussed as an effective partnership for improving schools (see page 101). Partnerships between the Ministry of Education and schools were explored through Timperley's and Robinson's (2003) research. They found that the work schools involved in reform did together focussed on the development of strategies "to achieve project ownership and increased confidence, rather than the more demanding task of school improvement" (p. 271). Timperley and Robinson argue that when schools identify solutions to their needs without the input of outside experts, "institutional norms that maintain the dysfunctional status quo" (p. 250) may not be challenged. They found that schools were more effective in making changes for improvement if they pursued tasks to reach their goals in partnership with the Ministry of Education. Their definition of partnership is summarised in the following excerpt: 
Two or more entities are in partnership when they accept some responsibility for a problem or task, and establish processes for working together that imply mutual accountability and shared power over task-relevant decisions. (Timperley and Robinson, 2003, p. 250)

In focussing on the task, Timperley and Robinson (2003) claim that the partnership between the Ministry of Education and schools will be motivated and relationships will be regulated. By this they mean that the "different perspectives of each partner would need to be negotiated and resolved according to their likely impact on task success" (p. 271) and therefore relationships will not be hindered by misunderstandings or suspicions about why the Ministry of Education is closely involved in the work. Both schools and the Ministry of Education need to consider how their decisions impact on task success, what their responsibility is in the task, and how the task is to be pursued in partnership. Through such actions Timperley and Robinson found that the Ministry of Education was accepted as a partner and could ask schools to "justify how their projects impacted on [outcomes, which] brought a more direct focus on educational goals" (p. 272).

An issue that the Ministry of Education could face in developing partnerships with schools that contribute to educational goals is one of capability. It may be that the Ministry of Education staff who work with schools or clusters will not initially have the appropriate level of expertise that allows them to carry out their role in addressing school needs through tasks. Timperley and Robinson (2002) suggest that in this case, "once the task of the partnership is clarified, it is important for the partners to discuss openly how they will recognise and develop the differing levels of expertise that each partner can contribute to the task" (p. 43).

Schools that choose to collaborate also need a way to measure the levels of collaboration in which they engage. The summary of effective and ineffective collaborative practices provided in Table 4 in Chapter 2: Literature Review could be the basis of a set of indicators similar to those provided by Timperley et al. (2010) for measuring the capability of schools to engage in inquiry cycles. However, the same risk applies in that indicators can be misinterpreted or misunderstood if schools do not have 
the support of outside expertise to assist them in identifying what they need to learn and do to improve in this area. The partnership approach discussed above could be used in combination with the summary in Table 4, and if schools wanted to improve their cluster structures, all partners would need to question their effectiveness as collaborative partners.

The findings of this study pose further questions about school leadership practices in New Zealand and the implementation practices of the Ministry of Education: Why do New Zealand educators try strategies and assume the impact of those strategies without formulating measures of effectiveness and inquiring into their own needs and capabilities? Why weren't policy recommendations that a research and evaluation plan be scoped prior to the launch of the EHSAS project carried out? What is the capability of the Ministry of Education to implement projects and monitor contracts? What is the capability of the Ministry of Education to work in partnership with groups of schools to support the use of effective collaborative practices, processes and systems that will raise student achievement? Timperley and Robinson (2002) emphasise their concerns about the capacity of state agencies in such work, noting that "when a state agency assumes such a role without adding sufficient educational value to the partnership, its contribution is too readily seen as a set of bureaucratic intrusions" (p. 148). However, if the Ministry of Education deepens its educational knowledge in order to engage as an effective partner with schools, professional development providers and other experts, the potential to improve system capability will not be lost. 


\section{References}

Annan, B. (2007). A Theory for Schooling Improvement; Consistency and Connectivity to Improve Instructional Practice. Unpublished $\mathrm{PhD}$ thesis, The University of Auckland Faculty of Education, Auckland, New Zealand.

Annan, B., Kuin Lai, M., and Robinson, V. (2003). Teacher talk to improve teaching practices. Set Research Information for Teachers, 1, 31-35.

Borko, H. (2004). Professional Development and Teacher Learning: Mapping the Terrain. Educational Researcher,33,3, 3-14.

Bryant, A. and Charmaz, K. (Eds.) (2007). The SAGE Handbook of Grounded Theory. London: SAGE Publications.

Charmaz, K. (2005). Grounded Theory in the $21^{\text {st }}$ Century: Applications for Advancing Social Justice Studies. In N. K. Denzin and Y. S. Lincoln (Eds.), The Sage Handbook of Qualitative Research 3, 507-535). California: SAGE Pulications.

Charmaz, K. (2006). Constructing Grounded Theory: A Practical Guide Through Qualitative Analysis. London: SAGE Publications.

Coburn, C. E. (2001). Collective sensemaking about reading : how teachers mediate reading policy in their professional communities. Educational Evaluation and Policy Analysis, 23, 2, 145-170.

Cohen, L., Manion, L., and Morrison, K. (2007). Research Methods in Education $\left(6^{\text {th }}\right.$ ed.). Oxon: Routledge.

Corbin, J., \& Holt, N. L., (2005). Grounded Theory. In Somekh, B., and Lewin, C. (Eds.) (2005). Research Methods in the Social Sciences. (pp. 49-55). London: SAGE Publications Ltd.

De Lima, J. A. (2001). Forgetting about friendship: using conflict in teacher communities as a catalyst for school change. Journal of Educational Change, 2, 97-122.

Dey, I. (1999). Grounding Grounded Theory: Guidelines for Qualitative Inquiry. San Diego: Academic Press.

Dey, I. (2007). Grounding Categories. In Bryant, A. and Charmaz, K. (Eds.) (2007). The SAGE Handbook of Grounded Theory. (pp. 167-190). London: SAGE Publications.

Du Four, R. (2007). Professional Learning Communities: A Bandwagon, an Idea Worth Considering, or Our Best Hope for High Levels of Learning? Middle School Journal, 39, 1, 4-8. 
Earl, L., Katz, S., Elgie, S., Jaafar, S. B., and Foster, L. (2006). How Networked Learning Communities Work: Volume 1 - The Report. Toronto: Aporia Consulting Limited.

Firestone, W. A., and Pennell, J. R. (1997). Designing State-Sponsored Teacher Networks: A Comparison of Two Cases. American Educational Research Journal, $34,2,237-266$.

Fullan, M. G., and Hargreaves, A. (1991). What's Worth Fighting For? Working Together For Your School. Ontario: Ontario Public School Teachers' Federation.

Gillham, B. (2000). The Research Interview. London: Continuum International Publishing Group.

Glaser, B. G., \& Strauss, A. L., (1967). The Discovery of Grounded Theory: Strategies for Qualitative Research. Chicago: Aldine Publishing Company.

Hall, V., and Wallace, M. (1993). Collaboration as a Subversive Activity: A Professional Response to Externally Imposed Competition between Schools? School Organisation, 11, 3, 101-117.

Hammersley, M., \& Atkinson, P. (1995). Ethnography: Principles in practice (2 ${ }^{\text {nd }}$ ed.). London: Routledge.

Hargreaves, D. H. (1995). School Culture, School Effectiveness and School Improvement. School Effectiveness and School Improvement, 6, 1, 23-46.

Head, G. (2003). Effective Collaboration: deep collaboration as an essential element of the learning process. Journal of Educational Inquiry, 4, 2, 47-61.

Hattie, J. (2003, October). Teachers Make a Difference: What is the Research Evidence? Paper presented at the Australian Council for Educational Research Annual Conference on Building Teacher Quality, Australia. Retrieved from http://www.visionschools.co.nz/assets/documents/john_hattie.PDF

Holton, J. A., (2007). The Coding Process and its Challenges. In Bryant, A. and Charmaz, K. (Eds.) (2007). The SAGE Handbook of Grounded Theory. (pp. 265-289). London: SAGE Publications.

Hudson-Ross, S. (2001). Intertwining opportunities: participants' perceptions of professional growth within a multiple-site teacher education network at the secondary level. Teaching and Teacher Education, 17, 433-454.

Hynds, A. (2007). Navigating Uncharted Waters: Teachers collaborating across difference. Unpublished doctoral thesis, Victoria University of Wellington Faculty of Education, Wellington: New Zealand.

Katz, S., Earl, L., and Jaafar, S. B. (2009). Building and Connecting Learning Communities: The Power of Networks for School Improvement. Ontario: Corwin Press. 
Lempert, L. B. (2007). Asking questions of the data: Memo writing in the grounded theory tradition. In Bryant, A. and Charmaz, K. (Eds.) (2007). The SAGE Handbook of Grounded Theory. (pp. 245-264). London: SAGE Publications.

Little, J. W. (2002). Locating learning in teachers' communities of practice: opening up problems of analysis in records of everyday practice. Teaching and Teacher Education, 18, 917-946.

Ministry of Education. (2004). Submission (POL Min (04) 24/8): Cabinet Policy Committee: Minute of Decision: Extending High Standards in Schools. Wellington: Ministry of Education.

Ministry of Education. (2005a). Submission (RP10/31/00/1): Extending High Standards in Schools: Policy Framework. Wellington: Ministry of Education.

Ministry of Education. (2005b). Submission (RP10/31/00/1): Revised Submission: Extending High Standards in Schools Operational Policy. Wellington: Ministry of Education.

Ministry of Education (2007). The New Zealand Curriculum. Wellington: Learning Media Limited.

Ministry of Education. (December, 2008). Resourcing Handbook Chapter 1: Operational Funding. In Ministry of Education. Retrieved from http://www.minedu.govt.nz/NZEducation/EducationPolicies/Schools/SchoolOpera tions/Resourcing/OperationalFunding/ResourcingHandbookChapter1OperationalF unding.aspx.

Multi Serve Education Trust (2005). Extending High Standards in Schools Business Plan. Multi Serve Education Trust: Auckland.

Northcutt, N and McCoy, D. (2004). Interactive Qualitative Analysis: A Systems Method for Qualitative Research. Thousand Oaks, CA: SAGE Publications.

Ogier, S. and Sankar, M. (2008). Extending High Standards Across Schools: Evaluability Assessment. Martin Jenkins: Wellington.

Patton, M. Q. (2002). Qualitative Research and Evaluation Methods ( ${ }^{\text {rd }}$ ed.). California: Sage Publications.

Robinson, V., Hohepa, M., and Lloyd, C. (2009). School Leadership and Student Outcomes: Identifying What Works and Why: Best Evidence Synthesis Iteration $(B E S)$. Wellington: Ministry of Education.

Ross, J. (1999, April 10). Ways of Approaching Research: Qualitative Designs. Retrieved from http://www.fortunecity.com/greenfield/grizzly/432/rra3.htm 
Stern, P.N. (2007). Properties for Growing Grounded Theory. In Bryant, A. and Charmaz, K. (Eds.) (2007). The SAGE Handbook of Grounded Theory. London: SAGE Publications.

Suddaby, R. (2006). From the Editors: What Grounded Theory is Not. Academy of Management Journal, 49, 4, 633-642.

Timperley, H., McNaughton, S., Lai, M., Hohepa, M., Parr, J., and Dingle, R. (2009). Towards an Optimal Model for Schooling Improvement. (Position Paper 1). University of Auckland: New Zealand Council for Educational Research.

Timperley, H., McNaughton, S., Lai, M., Hohepa, M., Parr, J., and Dingle, R. (2010). Towards an Optimal Model for Building Better Schools. In Timperley, H., and Parr, J. (Eds.) (2010). Weaving Evidence, Inquiry and Standards to Build Better Schools. Wellington: NZCER Press.

Timperley, H., and Parr, J. (Eds.) (2010). Weaving Evidence, Inquiry and Standards to Build Better Schools. Wellington: NZCER Press.

Timperley, H., Phillips, G., Wiseman, J., and Fung, I. (2003). Shifting the Focus: Achievement Information for Professional Learning: A Summary of the Sustainability of Professional Development in Literacy. Wellington: Ministry of Education.

Timperley, H., and Robinson, V. (2002). Partnership: Focusing the Relationship on the Task of School Improvement. Wellington: NZCER Press.

Timperley, H., and Robinson, V. (2002). Partnerships: Accomplishing Important Work Together. Set: Research Information for Teachers, 3, 41-43.

Timperley, H. S., and Robinson, V. M. J. (2003). Partnership as an Intervention Strategy in Self-Managing Schools. School Effectiveness and School Improvement, 14, 3, 249-274.

Timperley, H., Wilson, A., Barrar, H., and Fung, I. (2007). Teacher Professional Learning and Development: Best Evidence Synthesis Iteration (BES). Wellington: Ministry of Education.

Toole, J. C. and Seashore Louis, K. (2002). The Role of Professional Learning Communities in International Education. In Leithwood, K., and Hallinger, P. (Eds.), Second International Handbook of Educational Leadership and Administration: Part One. The Netherlands: Kluwer Academic Publishers.

Wenger, E. (1998). Communities of Practice: Learning, Meaning and Identity. New York: Cambridge University Press.

West-Burnham, J., and Otero, G. (2004). Educational leadership and social capital. Incorporated Association of Registered Teachers of Victoria Seminar Series, August, no. 136. 
Wohlstetter, P., Malloy, C., Chau, D., and Polhemus, J., (2003). Improving Schools through Networks: A New Approach to Urban School Reform. Educational Policy, 17 399-430. 


\section{APPENDIX A}

\section{Interview Questions:}

\section{Establishing context}

Tell me how your project went in its final year.

Where is your cluster at now? Do you still work together?

Did you keep the same focus in your project throughout? (talk over original proposal and focus on student achievement)

What was your role in your cluster?

Prompts: - what did this involve?

- who did you work with and how?

\section{How do selected research participants define collaborative practice?}

How would you define collaborative practice?

Prompts: - does your answer come from experience, research, both or other?

- Are there different levels of collaboration across principals, teachers in different schools, lead teachers, within schools, across schools? What different things do each of these involve?

- From your definition, is there an order of importance in terms of the characteristics you gave? Are some things more necessary than others?

\section{What were the collaborative practices experienced by EHSAS cluster research}

\section{participants?}

What collaborative practices did you experience during your involvement with EHSAS?

Prompts: - who was involved in the collaborative practices across the schools in your cluster and how?

- were schools involved equally or did they have different roles/different numbers of staff involved?

- what were important factors in learning to collaborate in your EHSAS project? 
- what were the benefits and disadvantages of your collaborative experiences?

- have you found that there has been more collaboration within your school, or across the schools? why/why not?

- was that a result of being in EHSAS or was this happening prior to that? Were there other factors that could have been an influence?

\section{Across School Collaboration vs Within School Collaboration}

Thinking about both types of collaboration: across schools and also within your own school, do you think there is a need for particular structures to enable that to happen effectively?

Prompts: $\quad$ - by structures we might mean: roles, timeframes, settings, number of schools or people involved...

- explain the process for how decisions were made about your cluster work (who was there, how did it feel)

- did you manage to achieve these ideals?

- why would there be a need for particular structures? How would the structures contribute to collaboration that was actually effective?

Do you think there is a need for particular cultures to enable effective collaboration across and within schools?

Prompts: - by cultures we might mean: agreed norms, relationships between people, behavioural norms, interpersonal relationships)

- what did it look/feel like when you had a problem to solve in the cluster?

- How did newcomers learn about the cultures?

What were your cluster's key strengths in enabling effective collaboration? - who did these impact on? How?

What were your cluster's weaknesses in collaboration across schools? Within schools?

Prompts: - how were these weaknesses?

- how/why did these weaknesses develop? What enabled their development? 
- who did these impact on? How?

Would you change anything if you could start your EHSAS project again?

Prompts: - if so, what and why?

- would you change, add or delete specific roles, structures, types of people involved, hierarchy, support, use of specific practices or research, levels of collaboration, project focus and goals, communication, project planning (this list could be given to participants as a prompt)

Why did the clusters rule in certain collaborative practices and rule out others?

Research shows that there are certain collaborative practices that are effective. You've discussed ..... as being effective. Why do you think they were effective?

Did your cluster choose certain collaborative practices over others?

Prompts: - if so, which ones and why?

- who made these decisions/choices?

Did your cluster rule out certain collaborative practices?

Prompt: $\quad$ - if so, which ones and why?

- who made these decisions/choices?

Did anything hinder collaboration across your cluster?

Prompts: - if so, what and why?

- how do you know this was what hindered collaboration?

- was anything done about this? If so, what was done and who was involved?

Did anything help collaboration in your cluster?

Prompts: - if so, what and why?

- how do you know this was what helped collaboration?

Did the research participants perceive collaborative practices as making a difference to student achievement? What evidence do they have to support their 


\section{answers? How does the evidence compare with existing research on collaborative}

practices?

Tell me about the effect of your cluster's collaborative practices on student achievement.

- think about direct and indirect effects

- on what basis have you formed that opinion?

- do you have any concrete evidence or data that supports this opinion?

- can you cite any examples of improved student achievement (over

time) that are linked to collaborative practices in your cluster?

- what are your reasons for labelling those practices effective?

- what specific things enable effective collaboration (that raise student achievement)?

- Think about structures, roles, types of people involved, hierarchy, support, use of specific practices or research, levels of collaboration, project focus and goals, communication, project planning (this list could be given to participants as a prompt)

Close: Review of what's been covered. Any questions? 


\section{APPENDIX B}

\section{E-mail 1:}

From: [withheld to protect identity]

Date: Mon, Dec 20, 2010 at 2:34 PM

Subject: RE: EHSAS Research Results

To: Rebbecca Sweeney

Rebecca read your findings and I have nothing to add. I think you have captured the essence of our project. It is complex data that you have synthesised well. Thanks [withheld to protect identity]

[withheld to protect identity]

From: Rebbecca Sweeney

Sent: Sunday, 19 December 2010 6:11 p.m.

To: [withheld to protect identity]

Subject: EHSAS Research Results

Kia ora [withheld to protect identity]

How are you both?

I'm writing to provide you with a very draft copy of my analysis chapter from my thesis. Part of my final analysis will include your feedback on the attached, if you wish to provide any comments or thoughts or further information. This lines up with the Grounded Theory method that I'm using in my research and allows co-construction of meaning so that the findings are truly representative of your experiences/perceptions.

I've purposely provided this chapter to you in a draft state so that I didn't solidify the results in my head without first getting your input. 
If you have the time and the inclination, I'd very much appreciate your feedback on the results before I move on to complete the Discussion/Implications chapter. Please also remember that these results represent data from your cluster, plus two other EHSAS clusters, so they should represent the views of nine different people and provide an overall picture rather than a specific picture of collaborative practices experienced. I'm interested in any reaction you have to the findings, any thoughts you may have and any concerns or further information you might wish to provide. Please also pass this on to [withheld] as I don't have her e-mail address.

If you are able to get back to me by the beginning of February, that would be ideal - but I do understand that you are about to go on your break from work and may not wish to engage with this process, so please just let me know if that's the case.

thanks and regards

Rebbecca

\section{E-mail 2:}

From: [withheld to protect privacy]

Date: Wed, Jan 19, 2011 at 12:54 PM

Subject: EHSaS

To: rebbecca.sweeney

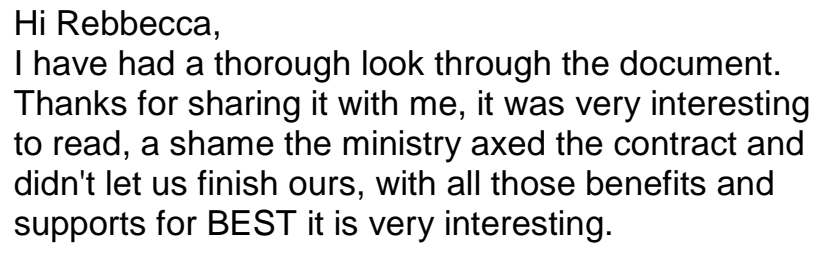

Thanks I have nothing to add.

Regards

[withheld to protect privacy] 
APPENDIX C

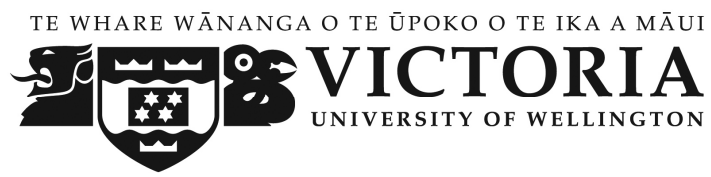

\title{
Participant Information Sheet for EHSAS Cluster Participants
}

\author{
Researcher: Rebbecca Sweeney: School of Education, Victoria University of Wellington.
}

I am a Master of Education student at Victoria University of Wellington. As part of this degree I am undertaking a research project leading to a thesis. The project I am undertaking is an exploration of the adult collaboration within Extending High Standards Across Schools (EHSAS) clusters. I work full time at the Ministry of Education as a senior adviser. From 2006-2008 I worked as an adviser with EHSAS clusters. I haven't been connected to EHSAS clusters through my work at the Ministry since March 2008. I will be accessing information from the Ministry of Education (such as your cluster's annual EHSAS reports, the Ministry's monitoring notes and proposal applications) through the Official Information Act, which is the normal process for accessing information for any external researcher. I will store all of the accessed data at the Ministry of Education national office in Wellington in locked electronic files or locked paper file drawers. No one, apart from my supervisor, Vivien van Rij and myself will have access to these files.

The University requires that ethics approval be obtained for research involving human participants.

I am inviting adult members of selected EHSAS clusters to participate in this study as interviewees. You are being asked to take part in a one hour interview about your experiences as a member of a group of collaborating schools. You will have the opportunity to provide feedback on my summary of your interview, and on preliminary findings on the cluster.

Your feedback (where provided) will be acknowledged and addressed in the final analysis, while keeping your identity and your cluster's identity confidential. At no point will you be identified in any written acknowledgements.

Should you feel the need to withdraw from the project, you may do so without question at any time before the data is analysed, by advising me.

Responses and answers to interview questions collected will be important components of my research project and will be included in a written report on an anonymous basis. Only grouped responses (per cluster) will be presented in this report and EHSAS clusters will not be identified by school or cluster name. All material collected will be kept confidential. No other person besides Vivien van Rij and myself will see the original information that you submit either in writing or through the interview process. The thesis will be submitted for marking to the Faculty of Education and deposited in the Faculty's Scott Library on the Karori campus. All original comments submitted by you will be destroyed two years after the end of the project.

If you have any questions or would like to receive further information about the project, please contact me through the details at the bottom of this page. Alternatively you can contact my supervisor, Vivien van Rij, at the Faculty of Education, at Victoria University of Wellington, Karori, PO Box 600, Wellington, phone 463 9706, vivien.vanrij@vuw.ac.nz

Rebbecca Sweeney

e-mail: rebbecca.sweeney@minedu.govt.nz

This research has been assessed and approved by Victoria University Faculty of Education Ethics Committee. 


\section{Consent Form}

Title of Project: An exploration of the collaboration within groups of New Zealand schools who are working towards improving student achievement

I have been given and have understood an explanation of this research project. I have had an opportunity to ask questions and have them answered to my satisfaction.

$\square \quad$ I understand that I may withdraw myself (or any information I have provided) from this project (before data collection and analysis are complete) without having to give reasons or without penalty of any sort.

I understand that any information I provide will be kept confidential to the researcher and the supervisor. The published results will not use my name, and no opinions will be attributed to me in any way that will identify me.

I understand that I will have an opportunity to check the analysis and provide feedback before publication, and that my feedback will be acknowledged by the researcher whilst maintaining my anonymity. I will not be identified in any acknowledgements.

I understand that the data I provide will not be used for any other purpose or released to others

I understand that the published results relating to the data I provide may be presented at a conference or published in a journal, and will not use my name, or identify me in any way

I would like to receive a summary of the results of this research when it is completed

Signed:

Name of verifier/participant:

(please print clearly)

Date: 


\section{APPENDIX D}

Categories that Emerged from Cluster A

\begin{tabular}{|c|c|}
\hline Category & Properties \\
\hline Awareness of impact on students & $\begin{array}{l}\text { - assumed impact of shared problem } \\
\text { solving } \\
\text { - principals ensuring clear understanding }\end{array}$ \\
\hline Blocks to Collaboration & $\begin{array}{l}\text { - fragmentation within schools } \\
\text { - high turnover of teachers } \\
\text { - time } \\
\text { - losing two principals }\end{array}$ \\
\hline Building Trust & $\begin{array}{l}\text { - honest discussion of own practice } \\
\text { - lack of trust in newcomers } \\
\text { - no judgement } \\
\text { - no other hidden agendas } \\
\text { - really comfortable with each other } \\
\text { - there to help each other } \\
\text { - newcomers discomfort } \\
\text { - went to Australia together as a group }\end{array}$ \\
\hline $\begin{array}{l}\text { Compliance as a reason to remain in the } \\
\text { collaboration after its usefulness }\end{array}$ & \\
\hline Definitions of collaboration & \\
\hline $\begin{array}{l}\text { Difficulty managing differences in opinion } \\
\text { or personality }\end{array}$ & - understanding the personalities \\
\hline $\begin{array}{l}\text { Effects of within school practice on across } \\
\text { school collaboration }\end{array}$ & $\begin{array}{l}\text { - non-fragmentation } \\
\text { - fragmentation }\end{array}$ \\
\hline Ensuring shared vision & $\begin{array}{l}\text { - lead teacher role in ensuring shared } \\
\text { vision } \\
\text { - one person with the real vision } \\
\text { - somebody at the top that has a clear } \\
\text { vision }\end{array}$ \\
\hline Hierarchy & $\begin{array}{l}\text { - compliance as a reason to remain in } \\
\text { charge } \\
\text { - connection between principals and lead } \\
\text { teachers } \\
\text { - lead school open to other approaches } \\
\text { - ensuring equality in role of lead teachers }\end{array}$ \\
\hline Mentoring & $\begin{array}{l}\text { - Mentoring between teachers } \\
\text { - lead schools as mentor } \\
\text { - building knowledge through mentoring } \\
\text { - other schools didn't know what they } \\
\text { didn't know } \\
\text { - pick our brains } \\
\text { - we showed them } \\
\text { - we were there as mentors to help } \\
\text { - mentoring between teachers }\end{array}$ \\
\hline \multicolumn{2}{|l|}{ Planning next steps } \\
\hline Positive group relationships & - cooperative group rules \\
\hline
\end{tabular}




\begin{tabular}{|l|l|}
\hline & $\begin{array}{l}\text { - effectiveness of agree focus } \\
\text { - human dynamics of each layer important }\end{array}$ \\
\hline Principal involvement & $\begin{array}{l}\text { - minimal connection between principals } \\
\text { and lead teachers }\end{array}$ \\
\hline Problem solving & $\begin{array}{l}\text { - awareness of differences in schools } \\
\text { - changes came through with emails } \\
\text { - lead teachers problem solving together }\end{array}$ \\
\hline Retrospective learnings & \\
\hline School change as a result of the project & $\begin{array}{l}\text { - bring it back to the cluster and work it all } \\
\text { out } \\
\text { - cascading knowledge sharing } \\
\text { - valuing cross cluster sharing } \\
\text { - observing other schools } \\
\text { - soaking up the flavour of other schools } \\
\text { - overall reaction to collaboration } \\
\text { - meetings } \\
\text { - jump at the chance }\end{array}$ \\
\hline $\begin{array}{l}\text { Seeing the benefits of sharing knowledge } \\
\text { more widely }\end{array}$ & \\
\hline $\begin{array}{l}\text { Social interaction and professional } \\
\text { interaction together }\end{array}$ & \\
\hline
\end{tabular}




\section{APPENDIX E}

Categories that Emerged from Cluster B

\begin{tabular}{|c|c|}
\hline Category & Type \\
\hline $\begin{array}{l}\text { Use of student or teacher data across } \\
\text { schools to inform teaching and learning }\end{array}$ & New category \\
\hline Administration task in cluster work & New category \\
\hline Issues related to newcomers & New category \\
\hline $\begin{array}{l}\text { Varied school capability in focus area } \\
\text { initially }\end{array}$ & New category \\
\hline $\begin{array}{l}\text { Cross-school collaboration limited to } \\
\text { workshops }\end{array}$ & $\begin{array}{l}\text { New category which includes data from } \\
\text { Cluster A categories }\end{array}$ \\
\hline $\begin{array}{l}\text { Belief that money was key to the success of } \\
\text { the project }\end{array}$ & New category \\
\hline $\begin{array}{l}\text { Little knowledge about other schools in the } \\
\text { cluster }\end{array}$ & New category \\
\hline $\begin{array}{l}\text { Collaboration across schools enhancing } \\
\text { inquiry }\end{array}$ & New category \\
\hline Possibly not too many schools & $\begin{array}{l}\text { New category which includes data from } \\
\text { Cluster A categories }\end{array}$ \\
\hline $\begin{array}{l}\text { Use of learning conversations across cluster } \\
\text { to improve achievement or teacher practice }\end{array}$ & New category \\
\hline Ensuring role clarity of cluster leaders & $\begin{array}{l}\text { New category which includes data from } \\
\text { Cluster A categories }\end{array}$ \\
\hline Reflection & $\begin{array}{l}\text { New category which includes data from } \\
\text { Cluster A categories }\end{array}$ \\
\hline $\begin{array}{l}\text { Social Interaction has been changed to } \\
\text { "Building Relationships" }\end{array}$ & New category \\
\hline Creating cluster teaching resources & New category \\
\hline $\begin{array}{l}\text { Uncertainty about whether collaboration } \\
\text { impacts on student achievement }\end{array}$ & New category \\
\hline
\end{tabular}




\section{APPENDIX F}

Categories that Emerged or Changed after Analysis of Cluster C Data

\begin{tabular}{|c|c|}
\hline Category & Type \\
\hline $\begin{array}{l}\text { Cross-school collaboration needed to } \\
\text { manage a large contract }\end{array}$ & $\begin{array}{l}\text { New category. One participant } \\
\text { represented. }\end{array}$ \\
\hline Critique & $\begin{array}{l}\text { New category. One participant } \\
\text { represented, plus the milestone report from } \\
\text { the same cluster. }\end{array}$ \\
\hline $\begin{array}{l}\text { Working across schools seen as hindering } \\
\text { school progress }\end{array}$ & $\begin{array}{l}\text { New category. One participant } \\
\text { represented. }\end{array}$ \\
\hline Mixed Level Collaboration & $\begin{array}{l}\text { New category. Two participants } \\
\text { represented. }\end{array}$ \\
\hline $\begin{array}{l}\text { Respect leads to effective critique and } \\
\text { collaboration }\end{array}$ & $\begin{array}{l}\text { This category was part of "trust" but I } \\
\text { separated it out when adding a new code. } \\
\text { Almost all codes in this category (apart } \\
\text { from one from the first cluster) are from } \\
\text { the third and final cluster. }\end{array}$ \\
\hline Accountability placed on one person & $\begin{array}{l}\text { Data from two clusters were merged to } \\
\text { create this category. }\end{array}$ \\
\hline Professional Dialogue Important & $\begin{array}{l}\text { Data from two clusters were merged to } \\
\text { create this category. }\end{array}$ \\
\hline No Judgement or Critique & $\begin{array}{l}\text { Data from two clusters were merged to } \\
\text { create this category. }\end{array}$ \\
\hline Differing student demographics & $\begin{array}{l}\text { Data from two clusters were merged to } \\
\text { create this category. }\end{array}$ \\
\hline Embedding practice & $\begin{array}{l}\text { Data from two clusters were merged to } \\
\text { create this category. }\end{array}$ \\
\hline Keeping Focus & $\begin{array}{l}\text { This was initially part of "shared vision or } \\
\text { common goal" but I decided to separate it } \\
\text { out. Participants from all three clusters } \\
\text { discuss the importance of keeping the } \\
\text { focus going during the project. They } \\
\text { discuss ways to keep that focus and they } \\
\text { discuss what happens if you lose the focus. } \\
\text { Ways to keep focus include gaining } \\
\text { agreement and having leadership drive it } \\
\text { and take responsibility for embedding } \\
\text { focus and keeping it alive. Focus is linked } \\
\text { to having goals and getting buy-in, and } \\
\text { even to common needs. It's a category of } \\
\text { nodes that seem to be represented in other } \\
\text { categories and this could be a real hub } \\
\text { category that represents a possible bigger } \\
\text { theme later on when I attempt to lift } \\
\text { concepts to theory. Keeping focus is all } \\
\text { about sticking to the agreed }\end{array}$ \\
\hline
\end{tabular}




\begin{tabular}{|l|l|}
\hline Needs are important & focus/vision/purpose. \\
\hline Feedback & $\begin{array}{l}\text { Data from three clusters were merged to } \\
\text { create this category. }\end{array}$ \\
\hline Reason or purpose for collaboration & $\begin{array}{l}\text { Data from three clusters were merged to } \\
\text { create this category. }\end{array}$ \\
\hline & $\begin{array}{l}\text { Data from two clusters were merged to } \\
\text { create this category. }\end{array}$ \\
\hline
\end{tabular}

